\title{
VOCABULARY LEARNING STRATEGIES IN \\ MASSIVELY MULTIPLAYER ONLINE ROLE-PLAYING GAMES
}

BY

\section{JULIE ANN BYTHEWAY}

\begin{abstract}
A thesis
submitted to Victoria University of Wellington in partial fulfilment of the requirements for the degree of Master of Arts in TESOL
\end{abstract}

Victoria University of Wellington

Te Whare Wānanga o te Ūpoko o te Ika a Māui 



\begin{abstract}
This small-scale case-study used research processes inherent in Grounded Theory to identify and explain vocabulary learning strategies used by players in MMORPGs (massively multiplayer online role-playing games), an informal second language learning context. This investigation was in response to informal reports of second language vocabulary gains from gamers at Victoria University of Wellington (New Zealand) and the University of Twente (The Netherlands). Data was collected from observations of, interviews with, and elicited texts from six participants, and three types of extant texts from World of Warcraft. Constant comparative analysis was used to allow patterns and processes to emerge from the data to explain social phenomena. Participants identified fifteen vocabulary learning strategies and aspects of MMORPGs that affect these strategies. Vocabulary learning strategies in MMORPGs are affected by play, which affects learning processes and motivation; MMORPG culture, which affects participants' interaction, curiosity, and independent learning; and the range and use of language in MMORPGs, which affects participants' language use, attitudes, and vocabulary learning strategies. Findings were compared to Gu's (2005) model of vocabulary learning strategies in contexts, and Gu's model was adapted to suit this MMORPG second language learning context. Aspects of MMORPGs affect second language vocabulary learning strategies gamers develop, select and use. This study highlights the need to value MMORPGs as contexts for learners' vocabulary learning strategies and argues for further study into MMORPGs as contexts of vocabulary learning strategies.
\end{abstract}

\title{
Key words
}

vocabulary learning strategies, learning strategy context, second language learning, MMORPGs, massively multiplayer online role-playing games, World of Warcraft 


\section{Intellectual property rights}

This thesis may be used for research or study purposes when it is appropriately acknowledged. I agree that the Victoria University of Wellington may copy this thesis for other libraries' collections and individuals.

\section{Attestation of authorship}

This thesis is my own work and any material originally from or published by someone else has been acknowledged and formally cited. No part of this thesis has been submitted as any part of any other qualification at any other educational institute.

Julie Bytheway

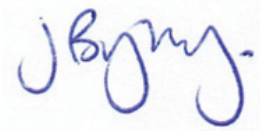

22 February 2011 


\section{Acknowledgements}

Thank you to all the research participants for sharing their experiences and ideas. It was wonderful to work with such experienced and expert gamers.

Thank you Averil Coxhead, my supervisor at Victoria University of Wellington, for giving excellent academic guidance and feedback, for chillin' me out and motivating me, and reminding me how relephant Frodo is!

Thank you Bernadette/Linda Forward at Victoria University of Wellington for interrating and Audrey Rhodes in Borne for proof reading, and thank you both for discussing language and learning issues with such passion.

Finally, a huge thanks to those that have inspired me and supported my tertiary learning from the start: my sister, Patrea Andersen in Wollongong; my sons, Jared Kelly/Sevareinveis in Azeroth, Paul Kelly in Rotorua, and Tom Kelly in Dunedin; my husband, Rob Sloot at home beside me; and my bestmate, Sharon Whillis from her garden in New Brighton! 


\section{Contents}

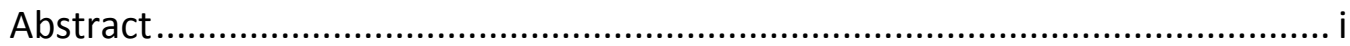

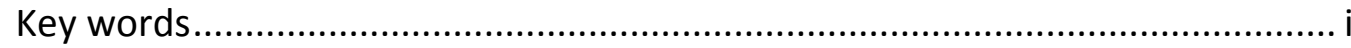

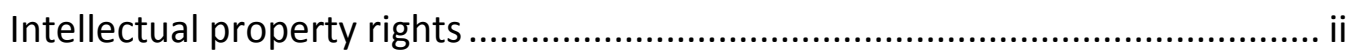

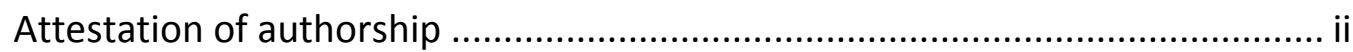

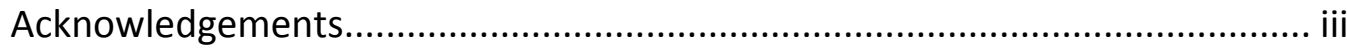

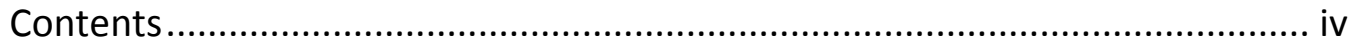

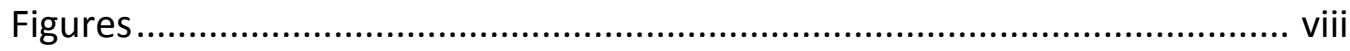

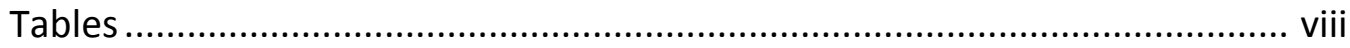

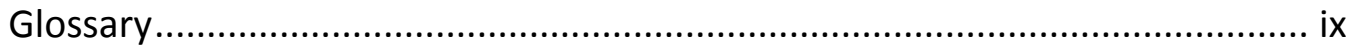

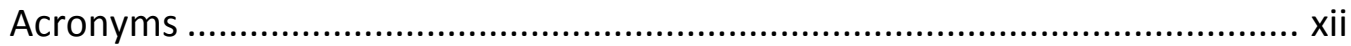

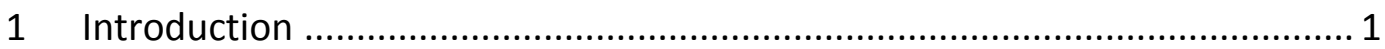

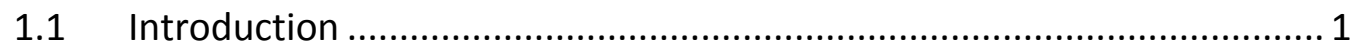

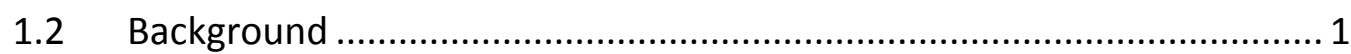

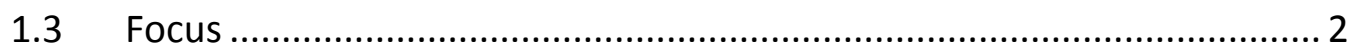

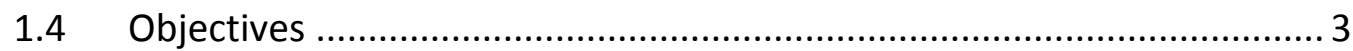

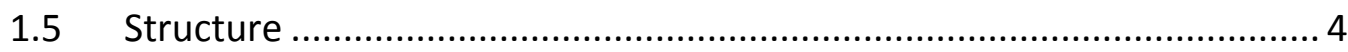

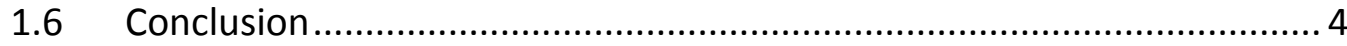

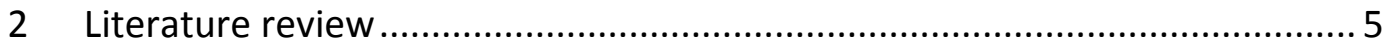

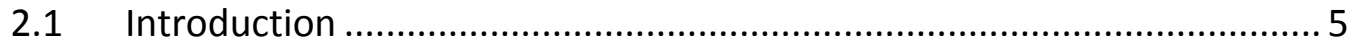

2.2 MMORPGs as context of vocabulary learning strategies .......................5

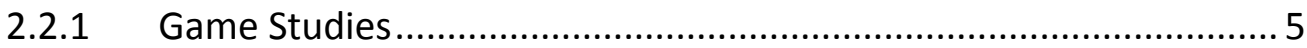

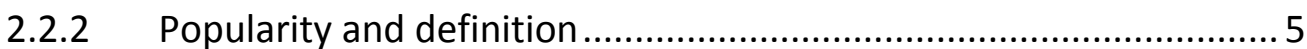

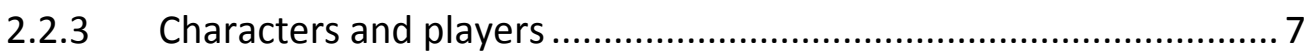

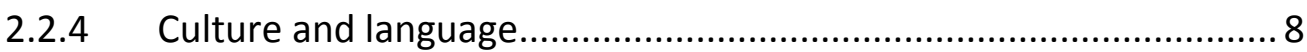

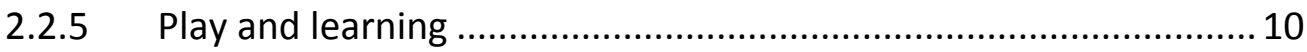

2.2.6 Language and vocabulary Learning .......................................... 11 


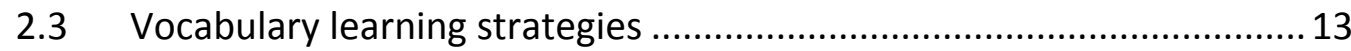

2.3.1 Learning vocabulary ................................................................ 13

2.3.2 Language learning strategies................................................ 14

2.3.3 Definition of vocabulary learning strategies ...............................15

2.3.4 Taxonomies of vocabulary learning strategies.............................16

2.3.5 Context of vocabulary learning strategies................................... 17

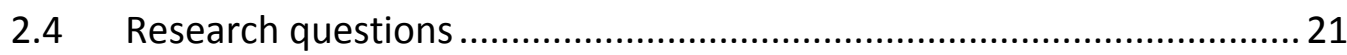

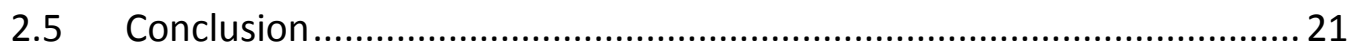

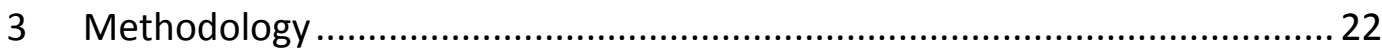

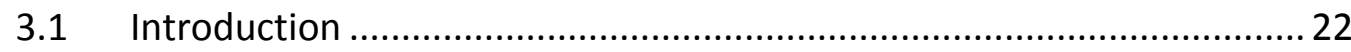

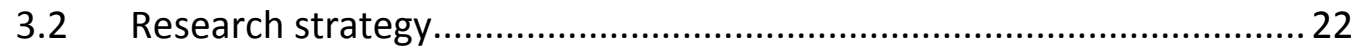

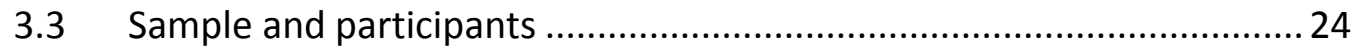

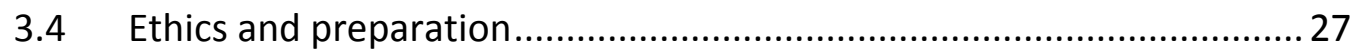

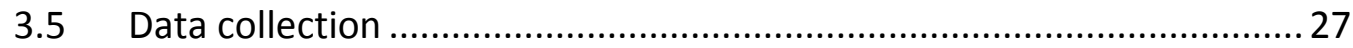

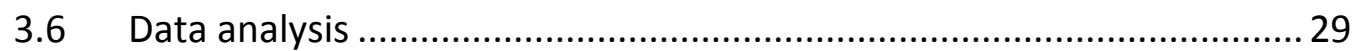

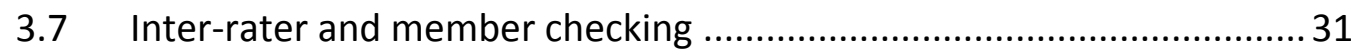

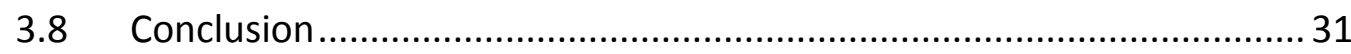

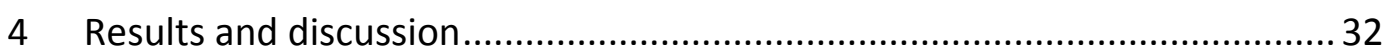

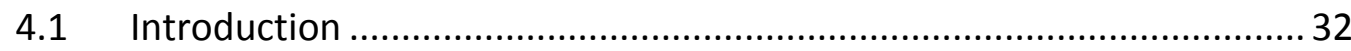

4.2 Reported vocabulary learning strategies............................................32

4.2.1 Playing/chatting in English ........................................................ 33

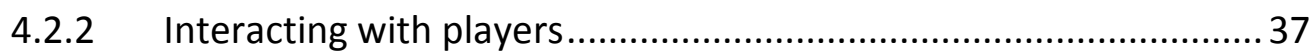

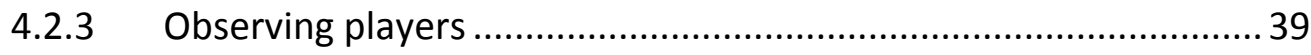

4.2.4 Reading in-game information/pop-ups .....................................40

4.2.5 Looking up words in dictionaries/Google.................................. 41

4.2.6 Noticing frequency/repetition of words ................................... 42

4.2.7 Recognizing knowledge gap and selecting words for attention .....43 
4.2.8 Noticing in other contexts and adding to existing knowledge ........44

4.2.9 Requesting/giving explanations .............................................. 45

4.2.10 Receiving/giving feedback .................................................... 46

4.2.11 Equating image/action to word ................................................ 46

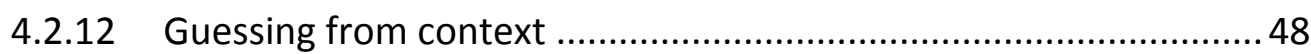

4.2.13 Using word to learn word use .................................................... 49

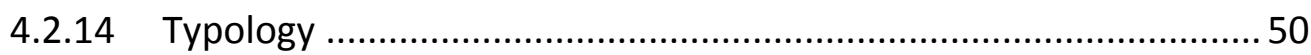

4.3 How MMORPG context affects vocabulary learning strategies .............51

4.3.1 How MMORPG language affects vocabulary learning strategies ...51

4.3.2 How MMORPG culture affects vocabulary learning strategies.......58

4.3.3 How play affects vocabulary learning strategies...........................61

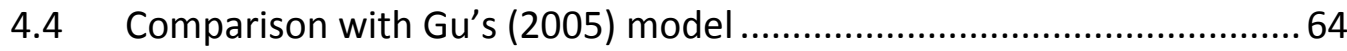

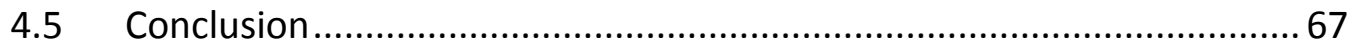

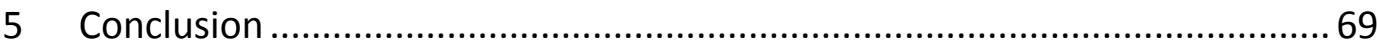

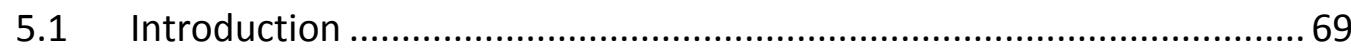

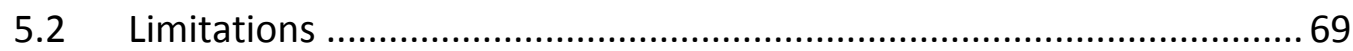

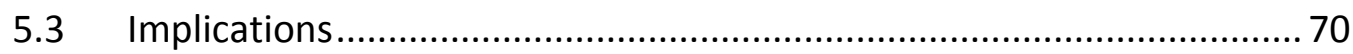

5.4 Suggestions for further research .................................................. 71

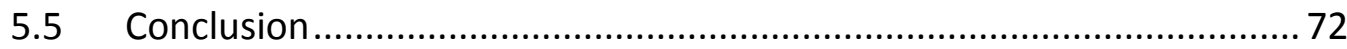

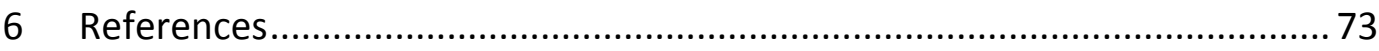

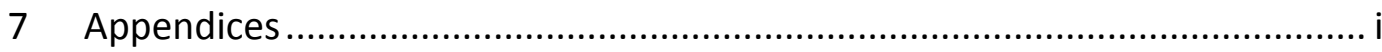

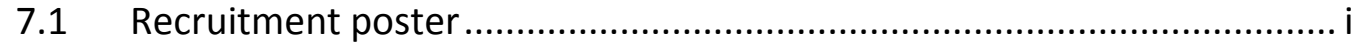

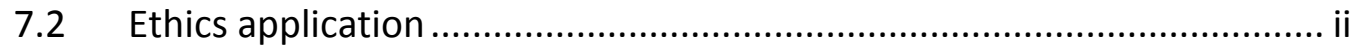

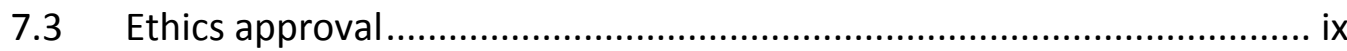

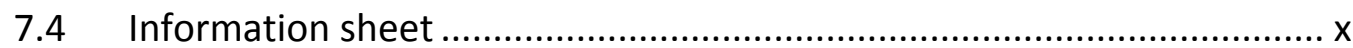

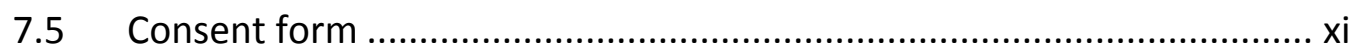

7.6 Interview questions ........................................................................ 


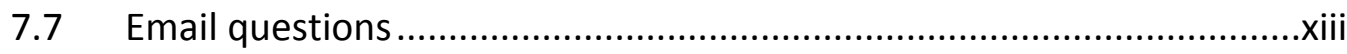

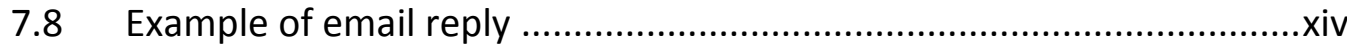

7.9 Example of quest instruction text..................................................... XV

7.10 Example of talents text ....................................................................

7.11 Example of chat log text ...................................................................

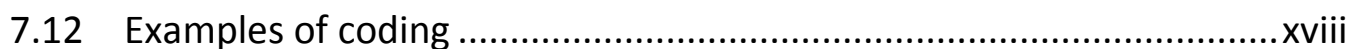

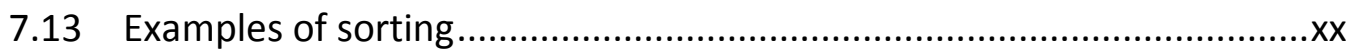

7.14 Example of mind map (1) ...................................................................

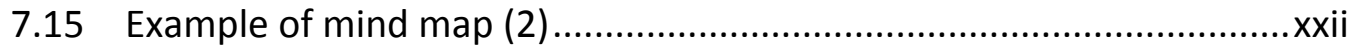




\section{Figures}

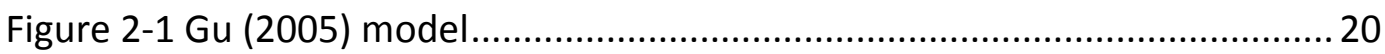

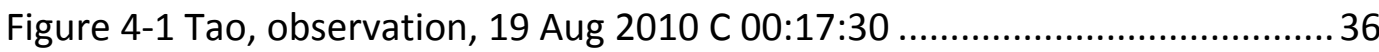

Figure 4-2 Alex, observation, 19 Aug 2010 00:05:13 ….................................... 41

Figure 4-3 Alex observation, 19 Aug 2010 A 00:21:37 ......................................... 48

Figure 4-4 Li, observation, 19 Aug 2010 C 00:17:30......................................... 52

Figure 4-5 Alex, observation, 19 Aug 2010 A 00:33:02 ...................................... 54

Figure 4-6Li, observation, 19 Aug 2010 C 00:17:29............................................. 56

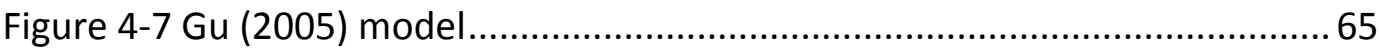

Figure 4-8 Adaptation of Gu's (2005) model for MMORPG context .....................66

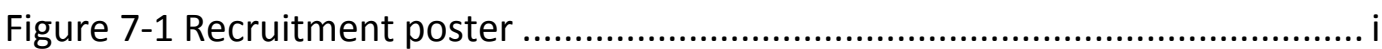

Figure 7-2 Quest instructions, Destroying the Altars, Icecrown, World of Warcraftxv Figure 7-3 Talent description, Cheat Death, Aldore Rise, World of Warcraft........xvi Figure 7-4 Chat log, Durotar, World of Warcraft. Li, observation, 19 Aug 2010 C

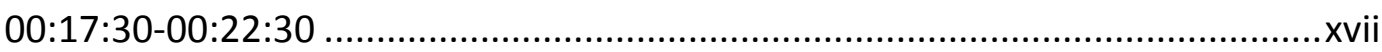

\section{Tables}

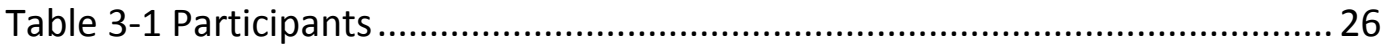

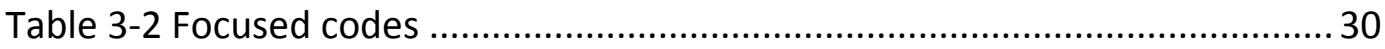

Table 4-1 Reported vocabulary learning strategies ............................................. 33

Table 4-2 Comparision with Gu's (2005) categories ......................................... 50

Table 4-3 Examples of chat language from chat log, Durotar, World of Warcraft56

Table 4-4 Examples of advanced terms from Rogue Talents, World of Warcraft 57 Table 7-1 Example of coding. Hung, interview, 17 Aug 2010 00:36-13-00:41:07xviii Table 7-2 Examples of sorting $\mathrm{xX}$ 


\section{Glossary}

ArenaNet

a subsidiary of NCSoft Corporation that develops, produces, and publishes digital games

Azeroth

World of Warcraft's virtual fantasy world

Blizzard Entertainment, Inc

a subsidiary of Activision that develops, produces and publishes digital games

buff and debuff

digital game terms that describe how the strength of in-game effects are increased or decreased

digital games

also known as video games, computer games, online games, electronic games, e-games, and e-sports-games where players use a computer or gaming console to interact with a game program which is displayed on a monitor or screen

First Language (L1)

also known as mother tongue or native language-the language (or languages)

a person learns as a child from their family or community

formal learning

learning that is deliberately directed by society or an educational institution

Game Based Learning (GBL)

learning from serious games or education orientated games that have predefined learning objectives

informal learning

learning that occurs outside educational institutes and does not conform to a predefined curriculum or syllabus

language learner strategies (LLS)

activities learners use to manage and facilitate their learning massively multiplayer online role-playing games (MMORPG) also known as MMOGs (massively multiplayer online games), MMOW (massively multiplayer online worlds), VW (virtual worlds), metaverses-digital 
games where thousands of people simultaneously play a real-time strategy role-play game within a persistent virtual-world

non-playing character (NPC)

a character in a digital game that is controlled by the computer program, not by a person playing the game

persistent world

a virtual-world that exists even when players are not logged into a game

Player versus Environment (PVE)

MMORPG gameplay where players play against characters or things which are controlled by the computer program, not controlled by a person playing the game

Player versus Player (PvP)

also known as player killing or PKing-MMORPG gameplay where players compete against other players in real-time-combat or dueling between players

Second Language (L2)

language (or languages) that are learned after and in addition to a person's first language

serious game

a game with an educational objective, rather than purposeless play Skype

a VolP program that allows people (including pairs and groups) to talk in realtime, and also offers typed chat, video streaming, file transfer, and sharescreen functions

steam client

an application developed by Valve Corporation that automatically applies software updates, including language translations to users' systems Ventrilo

also known as Vent-a VolP program that allows people (including pairs and groups of up to eight people) to talk in real-time

Voice over Internet Protocol (VoIP)

an internet technology that allows users to make and receive voice calls over the internet 
vocabulary learning strategies (VLS)

activities learners use to manage and facilitate their learning of vocabulary World of Warcraft ${ }^{\circledR}$ (WoW)

the most popular subscription-based MMORPG with more than 12 million subscribers 


\section{Acronyms}

Some gaming and computer terms are more commonly referred to by an acronym than a full length term. Therefore, in this thesis editing conventions are sometimes reversed, and well-known gaming and computer acronyms are written first and the full term is provided afterwards in brackets.

MMORPGs massively multiplayer online role-playing games

VolP $\quad$ voice over internet protocol

WoW World of Warcraft ${ }^{\circledR}$ 


\section{INTRODUCTION}

\subsection{Introduction}

This chapter provides brief background information on vocabulary learning and research into vocabulary learning strategies, particularly how the learning context affects learners' vocabulary learning strategies. It introduces and justifies MMORPGs (massively multiplayer online role-playing games) as a context where second language learners use vocabulary learning strategies. The focus of the study is discussed and the objectives are identified. Finally the structure of this thesis is outlined.

\subsection{Background}

Learning vocabulary is an essential part of second language acquisition (Nation, 2001; Schmitt, 2000; Schmitt \& Mcarthy, 1997). An increasing body of research in applied linguistics reflects how explicit and implicit vocabulary learning is now regarded as a critical part of second language learning (Ahmed, 1989; H. D. Brown, 2007; Coxhead, 2006; R. Ellis, 1994; Gu, 2003b, 2005; Harmer, 2007; Hirsh, 2010; Laufer \& Hulstijn, 2001; McCarthy, 1984; Meara, 1996; Nation, 1990, 2001, 2008; Nation \& Gu, 2007; Schmitt, 2000; Schmitt \& Mcarthy, 1997).

A large portion of second language vocabulary learning research focuses on which words learners have learned and should be learning (Gu, 2005); however, vocabulary learning processes and strategies are recognized as increasingly important. Nyikos and Fan (2007) and Schmitt (1997) stress that learners' use of vocabulary learning strategies affects vocabulary acquisition, but Ahmed (1989), Gu (2005) and Nation (2008) increase the stakes and assert that learners' vocabulary learning processes can to a considerable extent determine overall success or failure of second language acquisition.

How vocabulary learning processes and strategies affect second language learning are increasingly being examined and explored (R. Ellis, 1994; Meara, 1980). Many researchers have used artificial memory and recall tasks to examine psychological memory strategies, list learning, short term recall tasks, initial learning and basic recognition, and incidental learning. However, the ecological validity and pedagogical authenticity of many of these experiments is questionable (Gu, 2005, pp. 73-74). 
Qualitative research conducted in authentic L2 learning environments adds valuable insight from another perspective.

Research into vocabulary learning strategies has focused on identifying strategies that learners use to create comprehensive taxonomies (Ahmed, 1989; Gu, 2005; Gu \& Johnson, 1996; Hatch \& Brown, 1995; Kudo, 1999; Schmitt, 1997; Stoffer, 1997; Tao, 2006) and also evaluating strategies to identify those that increase learning (Fan, 2003; Graham, 1997; Gu, 2005; Gu \& Johnson, 1996; Jurković, 2006; Kojic-Sabo \& Lightbrown, 1999; Lawson \& Hogben, 1996; Sanaoui, 1995; Schmitt \& Mcarthy, 1997). However, researchers are also exploring how learning environments and cultures affect learners' selection and use of learning and vocabulary learning strategies (R. Ellis, 1994; Gu, 2003b, 2005; Locastro 1994; Nyikos \& Fan, 2007; Oxford, 1996). Formal and informal language learning environments are recognized as valuable (H. D. Brown, 2007; Gass, 1977; Gass \& Selinker, 1994; Mitchell \& Myles, 2004; Ortega, 2009).

\subsection{Focus}

This qualitative study focuses on vocabulary learning strategies in a specific learning context: MMORPGs (massively multiplayer online role-playing games). This study examines how learners select and use vocabulary learning strategies in MMORPGs. MMORPGs are worth examining as informal second language learning environments because they are renowned as rich, positive learning environments (Delwiche, 2006; Forman, 2003; Gee, 2007b, 2008; Gibson, Aldrich, \& Prensky, 2007; Prensky, 2006; Squire, 2005; Steinkuehler, 2007a, 2007b; Steinkuehler \& Squire, 2009; Yu, 2009) and are played by tens of millions of people all over the world every day (Chatfield, 2010b; Yee, 2006a; Yu, 2009). In addition, several researchers are now questioning how MMORPGs and other digital technologies may be changing how people learn (Bonk, 2009; Chatfield, 2010b; Collins \& Halverson, 2009; Joinson, McKenna, Postmes, \& Reips, 2007; Oxford, 2009).

I became interested in MMORPGs as a context where L2 learners use vocabulary learning strategies after gamers at Victoria University of Wellington and the University of Twente informally reported English second language vocabulary gains from playing MMORPGs (personal communication Coxhead, 2009, March 1; University of Twente students, 2010, January 7). Rather than which words gamers were learning, or how 
many words gamers were learning, I was interested in how gamers were learning words autonomously in these informal learning environments. An initial review of the literature revealed that research into second language vocabulary learning within MMORPGs was limited (Rankin, 2008).

However, researchers are studying how web technologies affect second language learning (Darhower, 2002; Delwiche, 2006; Godwin-Jones, 2005; Nardi \& Harris, 2006; Oxford, 2009; Purushotma, 2005; Steinkuehler, 2007a; Sykes, Oskoz, \& Thorne, 2008; Thorne, 2008). Researchers have identified that digital games and MMORPGs provide opportunities for meaningful communication which could facilitate second language vocabulary learning (Frank, Sanbou, \& Terashima, 2006; Piirainen-Marsha \& Tainiob, 2009; Rankin, 2008; Thorne, 2006, 2008; Turgut \& İrgin, 2009; Zheng, Young, Wagner, \& Brewer, 2009). However, the value of MMORPGs as second language learning environments is still being debated (deHaan, 2005). How gamers learn vocabulary in MMORPGs and how MMORPG environments affect learners' selection and use of vocabulary learning strategies requires further investigation.

\subsection{Objectives}

This qualitative case study explores the vocabulary learning strategies that second language learners use in MMORPGs, and examines aspects of MMORPGs that affect second language learners' selection and use of vocabulary learning strategies. It suggests implications for second language vocabulary learning strategy use and recommends areas requiring further research. Specifically, this study's objectives are:

1. Identify vocabulary learning strategies that second language learners use in MMORPGs.

2. Identify and classify aspects of MMORPGs that affect second language learners' vocabulary learning strategies.

3. Examine and explain how these aspects of MMORPGs affect second language learners' vocabulary learning strategies 


\subsection{Structure}

Chapter 2 Literature review defines MMORPGs and describes and evaluates inherent aspects of MMORPGs that may affect vocabulary learning strategies, including avatars, culture, language, play and learning principles. Then language learning strategies and vocabulary learning strategies are defined and significant research findings and taxonomies are described. Several studies which address how learning context affects vocabulary learning strategies are examined.

Chapter 3 Methodology provides an overview of the research strategy, describes the sample and participants, and explains ethical procedures that were completed. Data collection methods and analysis processes are described and discussed. Finally, results from inter-rater and member checking are presented.

Chapter 4 Results and discussion describes and discusses the results, including participants' vocabulary learning strategies, and aspects of MMORPG play, language, and culture that affected participants' vocabulary learning strategies. Gu's (2005) model of how learning contexts affect vocabulary learning strategies is used to discuss the results further.

Chapter 5 Conclusion describes the limitation of this study. It also presents implications for L2 learning and suggestions for further research

\subsection{Conclusion}

Second language acquisition is affected by learners' use of vocabulary learning strategies, and research shows that the learning context affects learners' vocabulary learning strategies. MMORPGs are used by tens of millions of people but have not yet been examined as a vocabulary learning strategy context.

This introduction gave a brief overview of the research context, focus and objectives, and the structure of this thesis. The next chapter is the literature review. Language learning strategies, vocabulary learning strategies and MMORPGs are defined and research and taxonomies are described, examined and discussed. 


\section{LITERATURE REVIEW}

\subsection{Introduction}

This chapter defines MMORPGs (massively multiplayer online role-playing games) and describes and discusses inherent aspects of MMORPGs that may affect vocabulary learning strategies, including avatars, culture, language, play and learning principles. Then language learning strategies and vocabulary learning strategies are defined and significant findings and taxonomies are described. Several studies which addressed how learning context affects vocabulary learning strategies are examined.

\subsection{MMORPGs as context of vocabulary learning strategies}

\subsubsection{Game Studies}

Second language researchers, teachers and learners value the vocabulary learning opportunities available in passive media such as television, radio, and newspapers. However, people are reducing their use of passive media and increasing their use of interactive media and digital games (Williams, 2006a; Williams, Yee, \& Caplan, 2008). Researchers and teachers need to acknowledge second language learners' increasing use of interactive media and examine how these technologies are affecting language learning processes and strategies to insure learning remains effective and relevant.

A variety of research is revealing insights into interactive media and digital games, and Game Studies is quickly evolving into a multidisciplinary and interdisciplinary field (including computer sciences, medicine, economy, art and design, psychology, sociology, anthropology, history, literature, media studies, communication, education and applied linguistics). However, research results appear to be not easily dispersed between academic disciplines, and myths about digital games remain common.

\subsubsection{Popularity and definition}

Digital gaming is dominating the entertainment industry (Steinkuehler, 2004) and is one of the most popular online activities (Shen \& Williams, 2010a). Over the last 50 years, digital games have rapidly moved from university laboratories, to arcades, to homes, to pockets (Mäyrä, 2008, p. 57), and Chatfield (2010b), game theorist, forecasts that within the next 50 years digital games will be a part of everyone's everyday experiences (p. 210). 
As of July 2010, digital games are a 50 billion (US) dollar industry (Chatfield, 2010a). High-speed internet connections and powerful computer processors combined with decreasing costs have made MMORPGs (massively multiplayer online role-playing games) accessible, playable and popular (Yee, 2006a). Conservative estimates propose that approximately 500 million people play digital games (Chatfield, 2010b, p. 169; McGonigal, 2011). Indeed, just one game-World of Warcraft (Blizzard Entertainment, 2009)-has over 12 million subscribers (Blizzard Entertainment, 2010). Popularity is wide-spread across genders, all age groups, ethnicities and economic classes (Steinkuehler, 2004; Yee, 2003-2006, 2006a). The idea that only teenage boys play digital games is a myth.

The time people spend playing MMORPGs could affect second language learners' selection and use of vocabulary learning strategies. Studies show that gamers are replacing television watching with gameplay (Seay \& Kraut, 2007; Williams, et al., 2008). Gamers play 22 to 25 hours per week, but more than 30 hours gameplay per week is not uncommon (Seay \& Kraut, 2007; Williams, et al., 2008). Approximately $10 \%$ of gamers play for more than 40 hours per week (Thorsen, 2009; Yee, 2003-2006, 2006a).

MMORPGs (massively multiplayer online role-playing games) are digital games played online by thousands of players simultaneously in real-time. MMORPGs enable synchronous interaction between users, and between users and a navigateable and persistent virtual-world (Klastrup, 2003, p. 101; Mäyrä, 2008; Yee, 2003-2006). Note, persistent-virtual worlds exist independently of players (Yee, 2006a).

MMORPGs are real-time strategy games where players complete collaborative tasks (e.g. quests and battles), trade virtual and real items, explore virtual worlds, and interact for social and in-game-business purposes (Blizzard Entertainment, 2004-2010; Chatfield, 2010b; Klastrup, 2003; Mäyrä, 2008; Williams, et al., 2008; Yee, 2003-2006, 2006c). Players earn points and increase levels, gain access to new skills, abilities and areas, and also earn currency and items (Blizzard Entertainment, 2004-2010; Kasavin, 2004). Players follow rules set by games' developers (Blizzard Entertainment, 20042010; Kasavin, 2004), but also 'unwritten' cultural rules known to the game community (Corneliussen \& Rettberg, 2008, p. 9). MMORPGs are huge games. World of Warcraft is 
endless (J. W. Rettberg, 2009, p. 170). It would take a player months just to see all of Azeroth (World of Warcraft's virtual world) (1UP, 2004).

This study examines commercial, off-the-shelf MMORPGs (e.g. World of Warcraft (Blizzard Entertainment, 2009)). These games are not education orientated nor serious games (e.g. Croquelandia (Sykes, Reinhardt, \& Sauro, 2010)) that are created specifically for educational purposes, neither are they open social spaces (e.g. Second Life (Linden Lab, 1999-2009)) that allow social interaction but include no gameplay.

\subsubsection{Characters and players}

The use of avatars in MMORPGs could affect second language learners' selection and use of vocabulary learning strategies. In MMORPGs, players create and are represented by 3D animated personal avatars (also known as characters, chars or toons) which they control with a computer keyboard and mouse or gaming console.

Some researchers (North, 2007; Steinkuehler \& Williams, 2006; Williams, Caplan, \& Xiong, 2007) propose that using avatars allows players to mask their identities, which could lessen learning anxiety. By remaining anonymous, players have an increased sense of safety (Steinkuehler \& Williams, 2006), are "less hampered by restrictive social norms based purely on their demographics" (Williams, et al., 2007, p. 428), are more likely to share personal issues and secrets (Yee, 1999-2004), and develop new identities (Squire, 2006).

However, "the assumption that a virtual identity promotes anonymity and therefore, to a certain measure, freedom, may be a profound misunderstanding of the concept of 'anonymity', while the person's real-life identity remains anonymous, their in-world identity, because it is persistent, cannot remain that way for long" (Pearce \& Artemesia, 2009, pp. 139-140). Using an avatar does not allow the player to hide anonymously and invisibly behind a digital puppet. Players express their real-self through their virtual-self (Chatfield, 2010b; Pearce \& Artemesia, 2009; Yee, 2003-2006) and in addition their real-selves and virtual-selves co-evolve and affect each other (Yee, Bailenson, \& Duchenaut, 2009).

Ultimately, even though the selves are virtual, reputations are real. Avatars' reputations are made public through in-game statistics (e.g. level, skills, class), but also 
spread through players' social interactions (Mortensen, 2009, p. 216). Avatars quickly become known, for example, for their generosity and conversation abilities (S. Rettberg, 2009, p. 23).

\subsubsection{Culture and language}

Culture in MMORPGs could affect second language learners' selection and use of vocabulary learning strategies. The internet and MMORPGs are changing and creating communities, societies, and cultures (Beetham \& Sharpe, 2007, p. 6; Bennerstedt \& Linderoth, 2009; Chatfield, 2010b; Corneliussen \& Rettberg, 2008, p. 1; Mason \& Rennie, 2008, p. 13; Thorsen, 2009; Yee, 2003-2006, 2006a).

Collaboration is essential in MMORPGs (Delwiche, 2006; Godwin-Jones, 2005; Nardi \& Harris, 2006): Players must belong to teams, guilds and communities to succeed (Williams, et al., 2008; Yee, 2006c). In World of Warcraft, complex tasks require strategic teams of 10-60 people (Mortensen, 2009, p. 213; Williams, et al., 2007, p. 429). The idea that digital games isolate people from social interaction is a myth.

MMORPGs are social environments where players interact and create networks and meaningful relationships (Chatfield, 2010b; Cole \& Griffiths, 2007; Shen \& Williams, 2010b; Steinkuehler \& Williams, 2006; Thorsen, 2009; Yee, 2003-2006, 2006a). Social interaction in virtual-worlds and the real-world adhere to the same social norms (Yee, Bailenson, Urbanek, Chang, \& Merget, 2006); however, players already have a lot in common: they are not a random sample of the general population, but instead all enjoy role-playing as dwarves and the undead in a fantasy world (Yee, 2003-2006). Also, players are more likely to rapidly form deep bonds of trust because they rely on each other to survive repeated spontaneous and stressful crises (Yee, 2003-2006). Finally, MMORPG cultures are inclusive: all players belong in the game culture and are not considered foreigners (Gee, 2007a, p. 74).

Interestingly, MMORPGs appear to instigate and facilitate interaction and cooperation in virtual-worlds which is later transferred to the real-world (Delwiche, 2006). Some researchers forecast that MMORPG communities will become one of the most important forums for human interaction (Yu, 2009, p. 37) and will affect how we communicate and learn (Seay \& Kraut, 2007, p. 837). 
Language use in MMORPGs could affect second language learners' selection and use of vocabulary learning strategies. MMORPG interfaces provide a wealth of language, e.g. World of Warcraft includes written instructions and storyline, optional pop-up tips, accessible manual, animated film clips with spoken audio and same-language subtitles, synchronous and asynchronous (typed) chat messaging, real-time phone-like conversations with VolP software (voice over internet protocol), and interactive wikis (Blizzard Entertainment, 2004-2010). Players can simultaneously discuss multiple topics with different players or groups of players using different communication tools, including individual, team, parties, raids, guilds, or all players chat options (MacCallumStewart \& Parsler, 2009, p. 233; Thorne \& Payne, 2005).

The use of different languages and translation tools in MMORPGs could affect second language learners' selection and use of vocabulary learning strategies. Although Crystal (2006) states that English is frequently used as a lingua franca online, players logon to different online servers or realms with different languages. In Europe alone, Blizzard has seven languages available: English, French, German, Italian, Polish, Russian and Spanish (Gamespot, 2010). Players can use add-ons and steam clients to translate the games' interfaces.

The speed of communication in MMORPGs could affect second language learners' selection and use of vocabulary learning strategies. Players convey ideas quickly, which forces players to simplify speech (Yee, 2006b). Short forms become more useful than whole sentences (MacCallum-Stewart \& Parsler, 2009, p. 232) and vocabulary becomes more significant (MacCallum-Stewart \& Parsler, 2009, p. 232). These economical expressions use nonstandard orthography and grammar; players appear to enjoy freedom from prescriptive norms and purposefully use creative and playful language (Anis, 2007, pp. 110-111; North, 2007, p. 538).

Specialized terms in MMORPGs could affect second language learners' selection and use of vocabulary learning strategies. Players of MMORPGs, like other games and sports, use and adopt specialized terms to facilitate effective communication and also express belonging, identity and experience (Klastrup, 2003, pp. 105-106; Mäyrä, 2008, pp. 25-27), e.g. respawn, paladin. Some words take on new meanings in the game, e.g. grinding, camping (1UP, 2004; McNamara, 2004). MMORPGs also use acronyms, 
abbreviations and neologisms, e.g. lol (laugh out loud), loc (location), n00b (inexperienced user), pwned (to own, to conquer).

\subsubsection{Play and learning}

Games and play affect how people learn and could affect second language learners' selection and use of vocabulary learning strategies. In Western cultures play is considered a trivial activity (S. Brown, 2010; Pearce, 2006, p. 125; Pearce \& Artemesia, 2009 , p. 7). However, games are renowned for being fun, engaging, and immersive, and requiring deep thinking and complex problem solving (Gee, 2007b), and play is renowned as a powerful learning medium through which people test ideas, develop skills, experiment, integrate knowledge, and interact in social roles, (S. Brown, 2010; Bruce, 1994; Duncan \& Lockwood, 2008; Montessori, 2003; Opie \& Opie, 1984; Piaget, 1962; Sutton-Smith, 1997; Vygotsky, 1978). Play is difficult to define (Sutton-Smith, 1997) but is voluntary, occurs outside of normal life, is restricted by time and space, is uncertain, is apparently purposeless, uses rules, is make-believe, is not serious, promotes social groups, is thoroughly absorbing, alters passage of time, diminishes consciousness of self, is inherently attractive, and provides a continuation desire ( $\mathrm{S}$. Brown, 2010; Caillois, 2001; Huizinga, 1950). Note that when play is transferred to a formal educational environment, many of its inherent qualities are lost, e.g. it is no longer voluntary or purposeless.

Players do not read a manual or attend classes before playing MMORPGs. The computer interfaces are smart and intuitive (Kasavin, 2004). Gameplay is easy to grasp but not easy to master or complete (1UP, 2004; Yee, 2006c). Constant interaction and feedback change the game's complexity (Chatfield, 2010b, p. 42). Players complete tasks at the outer edge of their current competency (Steinkuehler, 2004), which ensures learning remains within Vygotsky's, well-known, zone of proximal development (1978) and also increases Csikszentmihalyi's state of flow (1992).

States of flow are not usually achieved during passive activities, such as television watching (Csikszentmihalyi, 1997, pp. 34, 39), but are easily achieved during gameplay (Lemay, 2007). Flow is achieved when people perceive a task as challenging but yet also achievable. States of flow merge awareness and actions: People achieve intense concentration and then act almost effortlessly in spontaneous and automatic ways. 
Paradoxically, people feel a sense of control and also a loss of control, and also relaxed and energetic. They become less self-conscious and passing of time seems altered. Activities that induce flow usually have clear goals and immediate feedback (Csikszentmihalyi, 1992). Games are designed purposefully to induce a state of flow (Koster, 2005).

MMORPGs are rich, positive learning environments that incorporate valuable learning principles (Delwiche, 2006; Gee, 2007b, 2008; Gibson, et al., 2007; Prensky, 2006; Squire, 2005; Steinkuehler, 2007a, 2007b; Steinkuehler \& Squire, 2009; Yu, 2009), which could affect second language learners' vocabulary learning strategies. Games are fundamentally interactive and provide experimental (Koster, 2005) and experiential learning experiences (Kolb, 1984). Repetition, extended practice and overlearning are a core part of gameplay (McGonigal, 2010; J. W. Rettberg, 2009; Steinkuehler, 2004). MMORPGs foster persistence and are highly motivating (Gee, 2008; Oxford, 2009; Sykes, et al., 2008). Players move only upwards: there is no downward mobility or failure (Gee, 2008; McGonigal, 2010).

However, MMORPGs are also complex social systems where players learn know-how and know-how-to-be (Corneliussen \& Rettberg, 2008, p. 7), which could affect second language learners' vocabulary learning strategies. Players learn from being observers and participants during gameplay (J. S. Brown, 2005, pp. 3-4). Through this process of legitimate peripheral participation players become enculturated into the MMORPG community and culture (J. S. Brown, 2005, p. 7). In line with Lave's (Lave \& Wenger, 1991) situated learning theory, players learn the logical, spatial, kinesthetic, interpersonal, intrapersonal, moral, creative, leadership and linguistic skills $(\mathrm{H}$. Gardner, 2000) required to participate in and belong to the gaming community of practice (Wenger, 1998)

\subsubsection{Language and vocabulary Learning}

Although vocabulary learning strategies were not specifically addressed, several studies show that MMORPGs could be used as L2 vocabulary learning contexts. DeHaan (2005), Thorne (2006, 2008) and Piirainen-Marsh and Tainio (2009) revealed that MMORPG environments provide a wide range of opportunities for meaning- 
focused communication for L2 learners, which could affect the vocabulary learning strategies learners' select and use.

Turgut and İrgin (2009) researched L2 vocabulary learning in digital games. They observed and interviewed students in Turkey while they played a range of digital games in English. They noted that motivation to play games and repetition of words in games helped L2 vocabulary learning. Participants reported using several vocabulary learning strategies: guessing from context, looking-up words in online dictionaries, and asking adjacent friends for meanings. Although, this study focuses on L2 vocabulary learning, it only revealed three vocabulary learning strategies and did not include massively multiplayer games so interactional opportunities were not included or examined.

Several successive studies led by Rankin (Rankin, 2008; Rankin, Gold, \& Gooch, 2006; Rankin, McNeal, Shute, \& Gooch, 2008; Rankin, Morrison, McNeal, Gooch, \& Shute, 2009) investigated second language vocabulary learning in MMORPGs from a computer science perspective. From between-subject experiments with vocabulary post-tests, and analysis of a digital tool (ClockWerk (C) that records interaction between native-speakers and non-native speakers, Rankin et al. (2006; 2008; 2009) claim that in-game social interaction between native speakers and non-native speakers of English increases learners' engagement, motivation and vocabulary learning; that virtual identities lower learning anxiety; and that in-game dictionaries providing word definitions and pronunciation will improve vocabulary learning. However, Rankin et al. (2006; 2008; 2009) arguments that MMORPGs are effective "unorthodox language learning tools" are not grounded with reference to L2 learning or education theories or research, and many learning variables appear to have been ignored and overlooked.

These studies show that MMORPGs provide opportunities for L2 vocabulary learning, but it remains unclear which vocabulary learning strategies learners are selecting and using and also how the MMORPG context affects learners' vocabulary learning strategies. 


\subsection{Vocabulary learning strategies}

\subsubsection{Learning vocabulary}

Learning vocabulary is a multifarious task and includes knowing many aspects of words or lexical units: spoken forms, pronunciation, phonological and suprasegmental features; written forms, orthography, length, morphology inflectional and derivational complexity; lexical forms, synforms, homonyms, grammatical patterns, collocations, parts of speech; sematic features, abstractness, specificity, register restriction, frequency, appropriateness, idiomaricity; multiple meanings, concepts, associations (Laufer, 1997; Nation, 1990, 2001). Although, McCarthy (1984) and Robinson (1989) state that learners need to know words before being able to use them automatically in a wide range of contexts, knowing words does not necessarily result in learners using words skilfully or appropriately (Nation, 2001).

Vocabulary learning is a complex process. Schmitt (2000, pp. 4-5; 2010, p. 20) presents vocabulary learning as an incremental process where words and aspects of words are learned gradually, at different times and rates; however, Takač (2008) explains vocabulary learning as a complex meandering process where learners acquire and lose partial knowledge and automatic use of words. Aitchison (1996) proposes that vocabulary learning develops from an incomplete knowledge of words in limited contexts and-through words' relationships to other words-learners gradually gain more extensive word knowledge and word skills in wider contexts. Gu (2005, p. 20) in part disagrees and reports that learners initially use words in skilled ways in limited contexts and-through repeated exposure to words and the use of words in diverse contexts-learners acquire more complete knowledge and use of words in wider contexts.

Gu (2005, p. 21) summarises the distinction between knowing words and using words: for word knowledge, learners use controlled processes which reveal declarative knowledge and the breadth of a static mental lexicon; whereas for word use, learners use automatic processes and performance skills which reveal procedural knowledge the depth of a dynamic mental lexicon. Nation and Gu (2007, p. 84) acknowledge that effective vocabulary learning needs to develop both word knowledge and word skills. Nation's (2007) Fours Strands of language learning provides guidelines which 
effectively balance development of learners' language knowledge and skills: one strand (25\%) focuses on language-focused learning that promotes learning knowledge about language; whereas, the remaining three strands (75\%)-meaning-focused learning (meaning-focused input, meaning-focused output and fluency)-develop word knowledge and word skills through experiential learning processes.

\subsubsection{Language learning strategies}

Vocabulary learning strategies are considered a subset of language learning strategies. Although research into language learning strategies started in the 1970s (Rubin, 1975; Stern, 1975), controversy still rages over how they are defined (Tseng, Dörnyei, \& Schmitt, 2006). However, Griffiths $(2008$, p. 87) defines language learning strategies as activities learners consciously choose to regulate their language learning. Interestingly, Cohen (2007) and Oxford (1990) include increasing enjoyment in their definition: learners use strategies to make language learning more successful and also more enjoyable. Enjoyment may affect gamers' vocabulary learning strategies in MMORPGs because play and games are renowned for being enjoyable (S. Brown, 2010; Gee, 2007b).

Several researchers (Bialystok, 1978; A. Cohen, 1998; O'Malley \& Chamot, 1990) agree that when learners use strategies automatically and unconsciously, they cease to be considered 'strategic' and are then regarded as learning processes. However, Gu (2005) argues that the most effective strategies become automatic after repeated use (p. 11). This study is limited to vocabulary learning strategies that participants were consciously selecting and using, and therefore able to describe.

Language learning strategy research has identified several main ideas. Learners are aware that vocabulary learning improves language learning and use vocabulary learning strategies more than learning strategies for other aspects of language learning (Schmitt, 1997). Successful learners use broad selections of strategies in flexible and versatile ways (Gu, 2005; Schmitt, 1997). Also, most learners prefer to use simple mechanical strategies (e.g. repetition) instead of deeper more complex strategies (e.g. contextual guessing). However, deep strategies appear to improve learning gains (Fan, 2003; Graham, 1997; Gu \& Johnson, 1996; Jurković, 2006; Lawson \& Hogben, 1996; Nation \& Gu, 2007; Schmitt, 1997; Tao, 2006) , which is in accordance with Craik and 
Lockhart's (1972) Depth of Processing hypothesis, which states that deeper analysis facilitates long-term memory gains. Interestingly, play and games are renowned for requiring deep thinking and complex problem solving (S. Brown, 2010; Gee, 2007b).

Metacognitive learning strategies include managing motivation. Dörnyei (2001a) asserts that "the learner's enthusiasm, commitment and persistence are key determinants of success or failure" of second language learning. Building on wellknown motivation theory (Deci, 1975; R. Gardner, 1985; Maslow, 1970; Weiner, 1986), Dörnyei (2001a) states that motivation initially needs to be generated, subsequently maintained, then evaluated. However, play and games are inherently highly motivating environments (Chatfield, 2010b; Gee, 2007a, 2007b, 2008; McGonigal, 2010, 2011; Oxford, 2009; Sykes, et al., 2008) and a play context could affect gamers' vocabulary learning strategies. In addition, later Dörnyei and Ushioda (2009) proposed the L2 Motivation Self System which argues that learners' motivation relates to their ideal L2 self, ought-to L2 self and the L2 learning experience. However in MMORPGs, players' avatars are players' projection or idealization of their own identity or a temporary experiment with a new identity (Yee, 2003-2006). How players use avatars as an idealized version of themselves in MMORPGs may also affect gamers' vocabulary learning strategies.

\subsubsection{Definition of vocabulary learning strategies}

Vocabulary learning strategies are defined as direct and indirect learning processes that learners deliberately use to obtain, store, retrieve, encode, rehearse and use words (Gu, 2005; Nation, 2008; Schmitt, 1997). When using vocabulary learning strategies, learners initially analyse vocabulary learning tasks, and then subsequently plan, monitor and evaluate their learning behaviours to learn second language vocabulary. Learners may focus, for example, on rehearsal, repetition, memory, form, meaning, content, frequency, salience, noticing, and/or interaction (Nation, 2008).

Note that vocabulary learning strategies facilitate explicit and implicit learning (Nation, 2001; Schmitt \& Mcarthy, 1997). Learners are aware of explicit learning and intentionally and actively aim to improve understanding and skills; whereas, learners are unaware of implicit learning which are unconscious processes that improve understanding and skills (N. Ellis, 1994). However, learners can select, use and manage 
vocabulary learning strategies that facilitate explicit learning (e.g. recalling words while using flashcards) and implicit learning (e.g. purposefully reading extensively).

Learning vocabulary is a multifarious task and includes knowing many aspects of words (Laufer, 1997; Nation, 1990, 2001). McCarthy (1984) and Robinson (1989) state that learners need to know words before using words; however, having knowledge about words does not mean learners will be able to use words skilfully, appropriately and automatically (Nation, 2001). Nation and Gu (2007) maintain that learners need to use vocabulary learning strategies that develop word knowledge and word skills (p. 84).

\subsubsection{Taxonomies of vocabulary learning strategies}

Researchers continue to classify language learning strategies in diverse and frequently overlapping ways (A. Cohen, 1998; N. Ellis, 1994; O'Malley \& Chamot, 1990; Oxford \& Lee, 2007; Rubin, 1981; Stern, 1986; Tarone, 1981). However, Oxford (1990) published the most comprehensive taxonomy of language strategies: Strategy Inventory for Language Learning (SILL). Oxford (1993) explains her categories simply: "metacognitive strategies can help students keep themselves on track; cognitive, memory and compensation strategies provide the necessary intellectual tools; and affective and social strategies offer continuous emotional and interpersonal support" (p. 22). Several researchers of vocabulary learning strategies (Gu, 2005; Gu \& Johnson, 1996; Kudo, 1999; Schmitt, 1997) based the development of their taxonomies of vocabulary learning strategies on Oxford's taxonomy.

Many researchers have created overlapping taxonomies of vocabulary learning strategies (Ahmed, 1989; Gu, 2005; Gu \& Johnson, 1996; Hatch \& Brown, 1995; Kudo, 1999; Nation, 2001; Schmitt, 1997; Stoffer, 1997; Tao, 2006).

Schmitt (1997) created a comprehensive taxonomy of vocabulary learning strategies. From his study of learners of English in Japan, he identified 58 vocabulary learning strategies which he organized into Oxford's (1990) language learning strategy categories-memory, cognitive, compensation, metacognitive, and affective and social strategies-plus determination of meaning strategies. Schmitt also identified how vocabulary learning strategies facilitated initial discovery and understanding of words and consolidation of word knowledge and skills. Kudo's (1999) research supports Schmitt's (1997) findings and taxonomy. 
Gu (2005) categorized vocabulary learning strategies into when they were used: during initial handling, consolidation, and activation of words. Nation (2001) classified vocabulary learning strategies into aspects of language learning: vocabulary planning (selecting focus, choosing words, strategies, planning, repetition), vocabulary sources (analysing words, using context, looking up, translating), and vocabulary learning processes (building knowledge, noticing, retrieving, generating). Although they do not use the term vocabulary learning strategies, Tseng, Dörnyei and Schmitt (2006) created a model of self-regulated vocabulary learning based on vocabulary learning processes which included commitment control, metacognitive control, satiation control, emotion control and environment control. However, as Nyikos and Fan (2007) summarize, "the resulting lack of uniformity in terminology among researchers has made it difficult to compare ... research findings". Currently vocabulary learning strategies are classified in various ways into overlapping categories with unclear boundaries.

\subsubsection{Context of vocabulary learning strategies}

Research into how learning contexts affect learners' vocabulary learning strategies has been based on studies that

- discover differences in learners' vocabulary learning strategies in different environments or

- compare vocabulary learning strategies in second language and foreign language environments or

- reviews of research that then compare vocabulary learning strategies in different environments.

LoCastro's (1994) study revealed that a taxonomy of vocabulary learning strategies developed in the United States of America was not considered appropriate by learners in Japan. LoCastro (1994) had Asian learners in Japan complete Oxford's (1990) Strategy Inventor for Language Learning and conducted unstructured group interviews to examine learners' use of language learning strategies. Participants reported that Oxford's taxonomy was inappropriate. They stressed that they selected and used language learning strategies according to the learning situation and their culture. LoCastro concluded that the culture of learning contexts affects learners' language learning strategies. Second language learning occurs in a huge variety of environments 
and cultures, so research is still needed to examine how environments and cultures affect vocabulary learning strategies including in informal learning contexts.

After reviewing the bewildering differences between Sanaoui's study (1995) of vocabulary learning strategies conducted in a foreign language context and LessardClouston's replication study (1996) conducted in a second language context, Kojic-Sabo and Lightbrown (1999) compared vocabulary learning strategies used in second language context in Canada and foreign language context in Yugoslavia. Kojic-Sabo and Lightbrown (1999) had 47 English as a second language learners and 43 English as a foreign language learners complete a questionnaire (adapted from Sanaoui's questionnaire (1995) that revealed structured and unstructured learners), and complete a vocabulary assessment and a general language proficiency test. Kojic-Sabo and Lightbrown concluded that the two groups showed similarities and differences. The most noticeable difference was creating opportunities to encounter and practice new words outside the classroom, which required less effort for participants in the second language environment.

Leeke and Shaw (2000) discovered that when learners change from a foreign language environment to a second language environment, some of their vocabulary learning strategies change. Through a study of learners use of vocabulary learning lists, where 121 students completed a questionnaire and 54 students participated in semistructured interviews, Leeke and Shaw found that learning styles, beliefs and motivation, level of proficiency and environment affected vocabulary learning strategies. Noticeably, when participants moved from a foreign language context to a second language context, approximately two thirds of their participants ceased using vocabulary lists.

Kojic-Sabo and Lightbrown's (1999) and Leeke and Shaw's (2000) studies show that learners' vocabulary learning strategies are affected by real-world second and foreign language contexts. However, the boundaries between second language and foreign language environments become blurred in virtual-worlds. Virtual-worlds are not located in any specific real-world culture or nation. People in virtual-worlds interact simultaneously with people all around the world using a variety of languages, including 
English as a convenient common language. Research still needs to examine how virtual environments affect learners' vocabulary learning strategies.

$\mathrm{Gu}(2003 \mathrm{~b})$ reviewed research about vocabulary learning strategies and asserts that "learning context has received only cursory attention" (p. 15). Gu states that most studies appear to ignore culture, authentic communication opportunities, and the learning environment (p. 15).

Gu's (2005) followed this review up with an in-depth study of vocabulary learning strategies of Chinese English foreign language students, which combined a case study of 4 learners and survey of 850 participants. Gu explored how learners in a specific context use strategies and how strategy use affects vocabulary learning. He categorized vocabulary learning strategies into when they were used: during initial handling, consolidation, and activation of words (Gu, 2005). He also discussed metacognitive, note-taking, encoding, memory, self-management strategies. Gu's (2005) results showed that learners who actively used a variety of strategies in several ways learned words more effectively than less active learners (pp. 36, 119). However, "the most effective predictor of overall proficiency was [use of the vocabulary learning strategy] selective attention" (pp. 189-193). Strategies that helped learners remember words did not appear to improve language skills because communication and further learning were not hindered by the number of words learners knew, rather learners were hindered by not being able to receptively and productively use the words they already knew (p. 190). Learning form and definition pairs appeared to create no significant learning gains, whereas purposeful use of new words both receptively and productively improved language learning (p. 3). Note, however, that rote learning and oral repetition were confirmed as beneficial (p. 191). Finally, effective strategies were different for beginner and advanced learners (p. 191).

Gu maintains that only after analysing the learning task and context, and available resources, do learners select, plan, use, monitor, and evaluate strategies to improve language learning. Gu asserts that vocabulary learning is affected by first the learning context and then the strategies that learners' use for specific tasks. See Gu's (2005) model on next page. 
Figure 2-1 Gu (2005) model

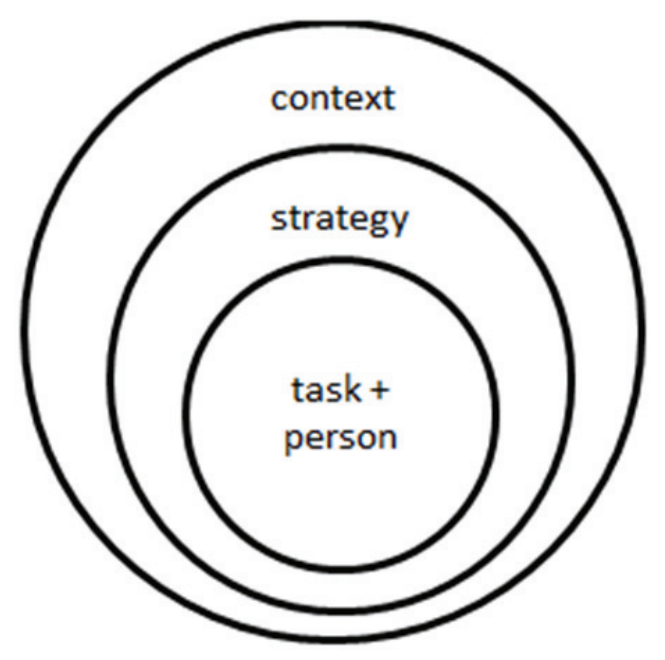

Gu defines context as the learning environment and culture, and opportunities for language input and output; and states that learners are affected by their attitudes, motivation, and prior knowledge; and that tasks vary in type, complexity and difficulty, and generalability. Gu (2005) warns that language learning strategies that work in some contexts might not work in others and stresses that research should examine how the task, learner and context affect the choice, use and effectiveness of vocabulary learning strategies, rather than the 'best' strategy for any context.

Nyikos and Fan (2007) also reviewed research about vocabulary learning strategies and identified factors that affect vocabulary learning strategy use: learners' proficiency level, learners' individual differences, learners' gender, learners' strategy development, and the learning environment. By comparing research by Fan (2003), Gu and Johnson (1996), and Gu (2003a, 2005), Nyikos and Fan identified that learning environments even affect the vocabulary learning strategies of people of the same cultural background. Fan's (2003) Chinese students learning English as a foreign language used word lists and memorization strategies most frequently; in comparison, Gu and Johnson's (1996) and Gu's (2003a, 2005) Chinese students learning English as a second language in Hong Kong reported using guessing strategies and practicing words in English speaking environments. Nyikos and Fan also call for research into vocabulary learning strategies in different cultures and environments.

In today's modern world, authentic learning environments also include virtual environments. Although, Cohen and Macaro (2007) fleetingly mention online language 
learning (pp. 109-110), terms such as digital, e-learning, internet, online, technology, virtual and web are noticeably absent from the content and index pages of the two landmark books (A. Cohen \& Macaro, 2007; Griffiths, 2008) that survey and celebrate over 30 years of language learning strategy research. Researchers heeding the calls by Gu (2005), and Nyikos and Fan (2007) for further research into how context affects vocabulary learning strategies need to ensure that digital and virtual environments are also examined.

\subsection{Research questions}

This study explores the following questions.

1. What vocabulary learning strategies do second language learners use in MMORPGs?

2. What aspects of MMORPGs affect second language learners' vocabulary learning strategies?

3. How do these aspects of MMORPGs affect second language learners' vocabulary learning strategies?

\subsection{Conclusion}

MMORPGs are informal second language learning contexts that could affect second language learners' vocabulary learning strategies. Although research has examined vocabulary learning opportunities in MMORPGs, vocabulary learning strategies in MMORPGs have not yet been specifically examined.

This chapter defined and discussed MMORPGs as a second language learning context and vocabulary learning strategies and taxonomies. Research questions were presented. The next chapter describes the research methodology, including the research strategy, data collection and analysis, and inter-rater and member checking. 


\section{METHODOLOGY}

\subsection{Introduction}

This chapter provides an overview of the research strategy, describes the sample and participants, and explains ethical procedures that were completed. Data collection methods are also described. Analysis processes and the focused-codes are discussed. Finally results from inter-rater and member checking are presented.

\subsection{Research strategy}

This case study of six experienced gamers who use English as a second language collected data from observations, semi-structured interviews, elicited email texts and extant MMORPG texts, which produced detailed, focused data. Patterns, process and themes emerged from the data by using constant comparative analysis (Glaser, 1978; Glaser \& Strauss, 1967) to compare data with data to determine similarities and differences.

An inductive approach was used to allow experiences, processes and patterns of a specific social group to emerge. This qualitative case study used research processes that are inherent in Grounded Theory (Glaser \& Strauss, 1967) to collect and analyse data from a variety of sources. Grounded Theory processes are an effective way to explore "unchartered territories" (Dörnyei, 2007, p. 155) where it is not known in advance what will be revealed or what will need further enquiry (L. Cohen, Manion, \& Morrison, 2007, p. 168).

A case study is a practical way to collect rich descriptions, and naturalistic and holistic representations (Mackey \& Gass, 2005, pp. 162-164) from a single research site (Denscombe, 2007, p. 35). The perspectives of a part of a group are explored in context (Biklen \& Casell, 2007) to gain insight into the general by focusing on the particular (Denscombe, 2007, pp. 35-36).

A criterion sample (Charmaz, 2006, p. 6), rather than a quantitative random sample, was used to facilitate theory development. Participants' on-going cooperation was essential, and a personal rapport was established with each participant to encourage them to become interested in the research and be available for further contact (Charmaz, 2006, p. 19). 
To minimize personal bias, interviewees participated in member-checking and a Victoria University of Wellington master's (in Applied Linguistics) student checked inter-rater reliability (Denscombe, 2010, pp. 155-157).

This case study used multiple methods and data sources to triangulate the data to decrease any systematic bias and increase validity (Dörnyei, 2007, p. 61). Data was collected from observations, semi-structured interviews, elicited email texts and extant MMORPG texts. These data collection methods produced detailed, rich, thick, and focused data (Charmaz, 2006, p. 14). The research processes were "cyclical and open ended processes" (Mackey \& Gass, 2005, pp. 162-164). Collecting, transcribing, coding and sorting data and reviewing literature and creating mind maps and writing memos continued throughout the research process. Constant comparative analysis (Glaser, 1978; Glaser \& Strauss, 1967) was used to compare data with data to determine similarities and differences in data and allow patterns, process and themes to emerge from the data.

Observations were used to "collect large amounts of data on the participants' behaviours and actions" (Mackey \& Gass, 2005, p. 176) and to check whether participants do what they report they do during interviews.

The semi-structured interviews were informal directed conversations (Charmaz, 2006, pp. 25-29) that enabled interviewees to explore and develop their ideas. Questions were not leading, highbrow, complex, irritating, or negative (McDonough \& McDonough, 1997, p. 177). In line with Charmaz's (2006) recommendations, participants were asked about their thoughts, feelings and actions; asked for further detail, deeper explanations, and examples of language or behaviour. I returned to previous comments and changed the topic; restated comments to check understanding; confirmed participants' humanity, perspectives or actions; used observational or social skills to further discussion; showed respect to participants; and expressed appreciation. Participants were regarded as experts; able to express views and tell stories; break silences; reflect on earlier events; choose what to tell and how to tell it; share significant experiences and teach the interviewer how to interpret the information provided (Charmaz, 2006, pp. 26-27). Previous interview responses were 
used to improve and create subsequent interview questions and discussion topics (L. Cohen, et al., 2007, p. 376).

Observations and directed discussions created rich, thick data (Charmaz, 2006, p. 45), which was analysed with codes derived from the data rather than preconceived codes from the literature (Charmaz, 2006, p. 5). Coding followed the principles outlined by Charmaz (2006). Initial open codes stayed close to the data; used short, simple and precise codes; preserved actions and processes (with gerunds) (pp. 45-46, 69). Subsequent rounds of coding compared data with data to determine similarities and differences and sort and group codes to search for emerging patterns and gaps in the data. Throughout the research process, I used techniques such as coding, recoding, clustering, sorting, mind mapping and memo writing (Charmaz, 2006, p. 48). I remained close to the data to avoid common sense theorizing and including any personal preconceptions into the coding and categorising (Charmaz, 2006, p. 67).

\subsection{Sample and participants}

A convenient criterion sample was used to explore gamers' perceptions of vocabulary learning strategies in MMORPGS. Participants were recruited from posters (see appendix 7.1) displayed at Victoria University of Wellington Kelburn, Pipitea, Karori, and Te Aro campuses, and during brief talks to Victoria University of Wellington Linguistics, English Proficiency Programme, and Foundation Studies classes.

Six male gamers, aged 20 to 30 , volunteered to be participants. All participants were identified with a pseudonym. Four participants were current Victoria University of Wellington students and two were partners of current Victoria University of Wellington students. All of the participants had completed secondary education and three of the participants had completed undergraduate tertiary qualifications. Participants' fields of studies and professions included foundation studies, aviation management, marketing, and electrical and mechanical engineering

The participants were from Germany, Malaysia, Ukraine and Vietnam, and two of the participants were from China. Their first languages were German, Hokkien, Russian and Ukrainian, Vietnamese, and Mandarin. All of the participants used English as a second language. Two of the participants also used three additional second languages: Cantonese, Malay and German; and French, Greek and Italian. All participants were 
proficient users of English as a second language and had a current IELTS overall band score of between 6.0 and 7.5.

All participants were experienced gamers and had played MMORPGs for at least five hours (sometimes exceeding 40 hours) every week for more than four years. Although the participants had experience playing a range of online games (Kong Kong Online, Maple Tree, Worm, Counter Strike, Heroes, Sushi, Dragonica, Warcraft 3, Dark Age of Camelot, Dawn of War), all participants were experienced players of the MMORPG World of Warcraft. Five of the participants were expert players of World of Warcraft and each played several high level characters (level 75 to 85 ).

(See Table 3-1 Participants on next page.) 


\begin{tabular}{|c|c|c|c|c|c|c|c|}
\hline & 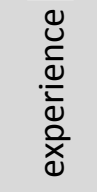 & $\begin{array}{l}\frac{n}{\sqrt{\pi}} \\
\stackrel{\lambda}{\lambda} \\
\end{array}$ & 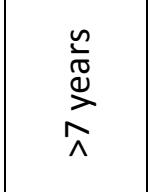 & 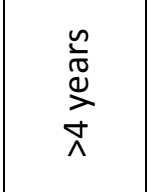 & 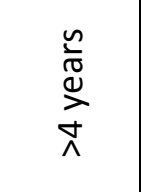 & $\begin{array}{l}\stackrel{n}{\pi} \\
\stackrel{0}{d} \\
\stackrel{2}{0} \\
\stackrel{-1}{\wedge}\end{array}$ & 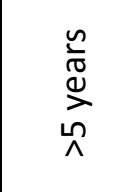 \\
\hline & 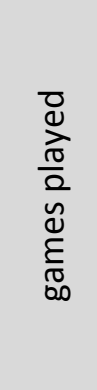 & 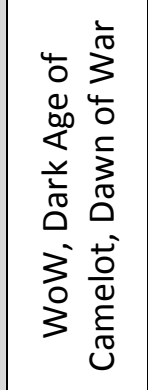 & $\begin{array}{l}m \\
4 \\
4 \\
\frac{\pi}{0} \\
\frac{0}{0} \\
\frac{\pi}{0} \\
3 \\
3 \\
3 \\
3\end{array}$ & ${ }_{3}^{3}$ & $\sum_{3}^{3}$ & 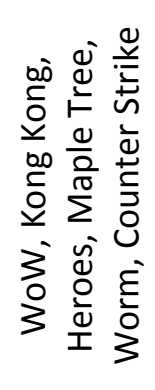 & 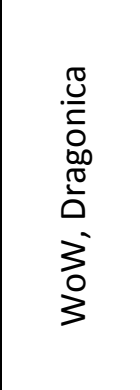 \\
\hline & IELTS & $\begin{array}{l}\circ \\
\dot{\varphi} \\
i\end{array}$ & $\stackrel{\llcorner}{\varphi}$ & $\stackrel{\circ}{\varphi}$ & $\stackrel{\circ}{\varphi}$ & $\stackrel{0}{\stackrel{0}{2}}$ & $\stackrel{\sim}{\sim}$ \\
\hline 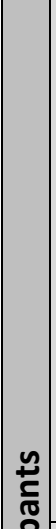 & 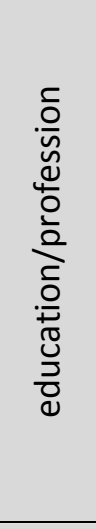 & 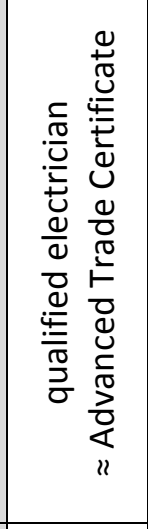 & 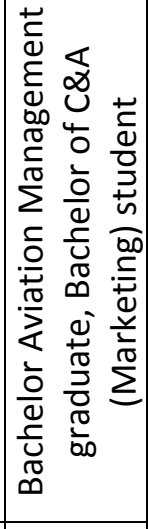 & 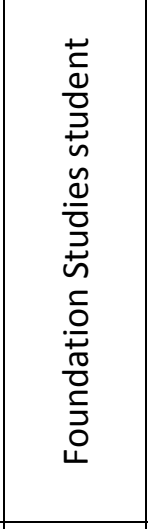 & 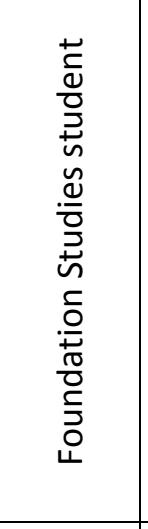 & 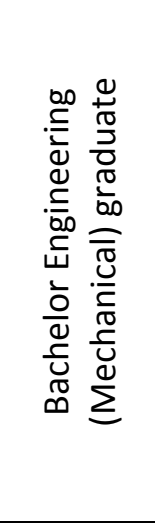 & 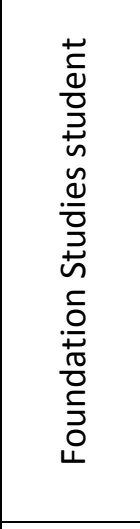 \\
\hline $\mid \frac{\bar{v}}{\frac{\bar{v}}{2}}$ & 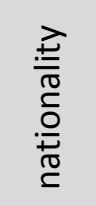 & 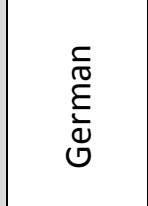 & 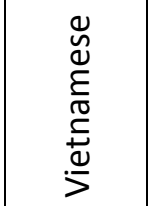 & 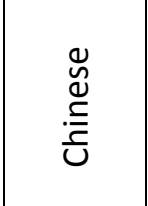 & 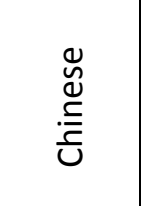 & $\begin{array}{l}\frac{\sqrt{0}}{\sqrt{n}} \\
\frac{\pi}{\frac{\pi}{\pi}} \\
\sum\end{array}$ & 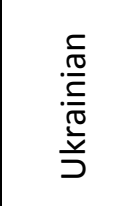 \\
\hline & 工 & 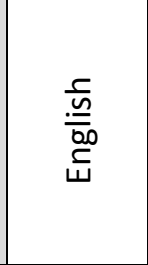 & $\begin{array}{l}\frac{5}{\frac{5}{-0}} \\
\frac{50}{\omega}\end{array}$ & $\begin{array}{l}\frac{c}{\frac{5}{\overline{0}}} \\
\frac{5}{\omega}\end{array}$ & 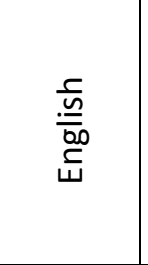 & 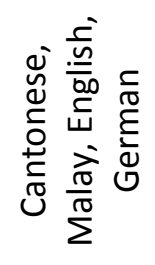 & 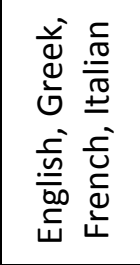 \\
\hline & $\exists$ & $\begin{array}{l}\frac{1}{\pi} \\
\frac{5}{8} \\
\stackrel{0}{0}\end{array}$ & 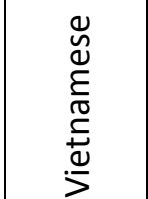 & 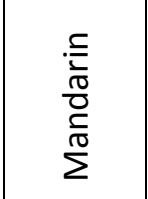 & $\begin{array}{l}\frac{\mathfrak{c}}{\frac{1}{\pi}} \\
\frac{\pi}{0} \\
\frac{1}{\sqrt{0}} \\
\sum\end{array}$ & 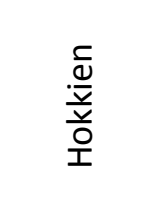 & 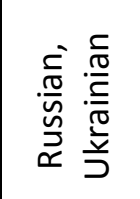 \\
\hline & 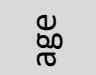 & ○े & $\stackrel{\sim}{\sim}$ & ஓ & $\stackrel{\sim}{ }$ & શ & $\stackrel{\sim}{ }$ \\
\hline & $\underset{\sim}{凶}$ & 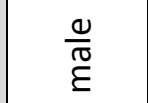 & 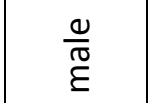 & 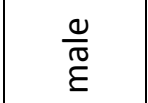 & $\frac{\frac{\varrho}{\sigma}}{\varepsilon}$ & $\frac{\frac{\mathscr{U}}{\widetilde{\widetilde{J}}}}{\underline{\xi}}$ & $\frac{\frac{\varrho}{\sigma}}{\varepsilon}$ \\
\hline & 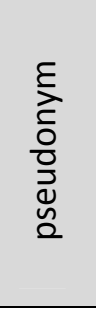 & 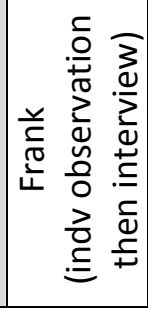 & 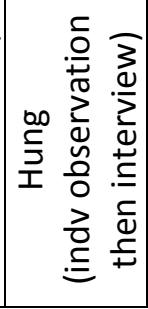 & 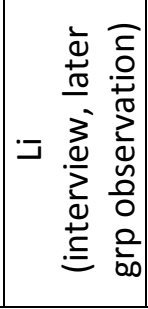 & 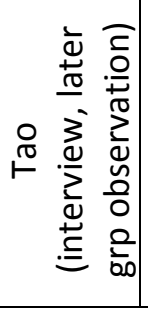 & 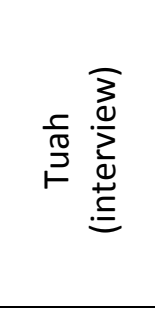 & 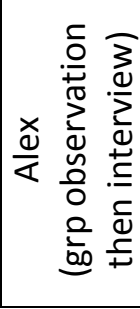 \\
\hline
\end{tabular}




\subsection{Ethics and preparation}

Before collecting any data, the Victoria University of Wellington Human Ethics Committee application (see appendix 7.2) was submitted and ethical approval was granted (see appendix 7.3) All participants read an information sheet (see appendix 7.4) and signed a consent form (see appendix 7.5) before participating. Participants remained anonymous. Data was only used for purposes originally specified, was accurate and securely stored, and will be destroyed on or before July 2015. Participants checked the accuracy of the data and initial results before publication, and were also emailed a summary or complete copy of the research report.

Initially data was planned to be collected in five subsequent steps: 1) a one-hour observation of one participant playing an MMORPG; 2) a one-hour interview with the participant who was observed; 3) a one-hour (or two one-hour) mini-focus group interview(s) with three to six participants depending on the number of respondents; 4) emailed questions; 5) and MMORPG texts. However, only one participant agreed to be interviewed as part of a group, and five participants initially only wanted to be observed, but subsequently agreed to be interviewed individually. Therefore, data collection methods were revised to suit what participants were comfortable with.

Before data collection, I ensured that MMORPGs by Blizzard and ArenaNet could be played from the computer in my office. Victoria University of Wellington allowed portals and servers which were normally blocked to be opened to allow access to MMORPG.

\subsection{Data collection}

Data was collected from observations of each participant playing an MMORPG of their choice, semi-structured individual interviews with each participant, elicited email texts from each participant and extant texts from the MMORPG World of Warcraft. Four of the observations and five of the interviews took place in my Victoria University of Wellington office. One observation and interview took place in a participant's home.

Five participants were observed playing an MMORPG for 30-60 minutes. Participants were asked to play their usual MMORPG in their usual way. Three of the participants all observed each other's gaming sessions. They all consented and stated that it was normal to watch each other play. Observations were digitally recorded with a video 
camera focused on the computer screen from over the player's shoulder. Four of the participants played World of Warcraft during the observations. One participant played Warhammer 4000: Dawn of War (Relic Entertainment, 2004).

Six participants were interviewed individually for 30-60 minutes. Three participants were interviewed immediately after playing a MMORPG for 30-60 minutes. Two were interviewed the day before they were observed. One participant was interviewed a second time for 10 minutes to comment on an issue that all other interviewees had commented on. Open interview questions (see appendix 7.6) were prepared, and semi-structured intensive interviews were conducted. In accordance with McDonough and McDonough's (1997) criteria, questions were open, simple, and positive. Also, in line with Charmaz's (2006) recommendations, participants were asked to express their personal opinions, explain their ideas further, give specific examples; participants were encouraged to break silences, be experts, share significant stories; the interviewer sometimes changed the topic, restated comments to check understanding, and expressed thanks. Also, participants were asked to write down words to clarify any unfamiliar pronunciation. Interviews were recorded digitally on an MP3 player with a voice-recording function. Recording the interviews allowed me to pay full attention to the participant and not be distracted by note-taking (Charmaz, 2006, p. 32). The MP3 player was unobtrusive: a small everyday item.

Elicited texts in the form of emails were collected. After analysis of data from observations and interviews, and further review of literature, participants were asked by email to answer two additional questions (see appendix 7.7) about how being alone or being part of a group of friends (or team) may change how they learn words in MMORPGs. Three participants sent email responses (see appendix 7.8)

Three types of extant texts were collected from within MMORPGs. These were limited to texts observed from World of Warcraft recorded during participants' observations: 6 quest descriptions (see appendix 7.9), 57 brief talent descriptions for rogue characters (see appendix 7.10), and a 5 minute chat log from Durotar (see appendix 7.11).

In this thesis, all quotes from interviews and information from observations and texts are recorded with the participants' pseudonym and data collection method (i.e. 
observation, interview, email, MMORPG text). In addition, data from observations includes the date, the recording $(A, B, C)$, and the time during the recording; data from interviews includes the date and the time during the recording; data from MMORPG texts includes the text name and location within World of Warcraft.

\subsection{Data analysis}

Transcribed data was coded with hundreds of overlapping initial-codes (see appendix 7.12) which remained extremely close to the ideas presented in the data and accurately preserved participants' words, actions and processes. These initial-codes were then sorted (see appendix 7.13) into lists and groups of similar items which produced 82 groups of codes. Referring back to the data and literature using constant comparative analysis, these codes were then synthesized and integrated into 45 more focused-codes. Patterns and relationships emerged through an on-going cyclic process of comparing data with data, and informal clustering, mind mapping (see appendices $\underline{7.14 \text { and } 7.15)}$, memo writing and reviewing the literature. After another review, 31 focused-codes emerged which were classified into vocabulary learning strategies and aspects of MMORPGs that affect vocabulary learning strategies. The aspects of MMORPGs that affect vocabulary learning strategies were further categorized into three groups: aspects that related to MMORPG play, MMORPG language, and MMORPG culture. Table 3-2 "Focused codes", on the next page, lists and shows the categories of the focused codes and also ranks the strategies in order of the number of times strategies and aspects were mentioned during interviews. Note that this ranking does not reveal which strategies participants used most frequently or considered most valuable. 


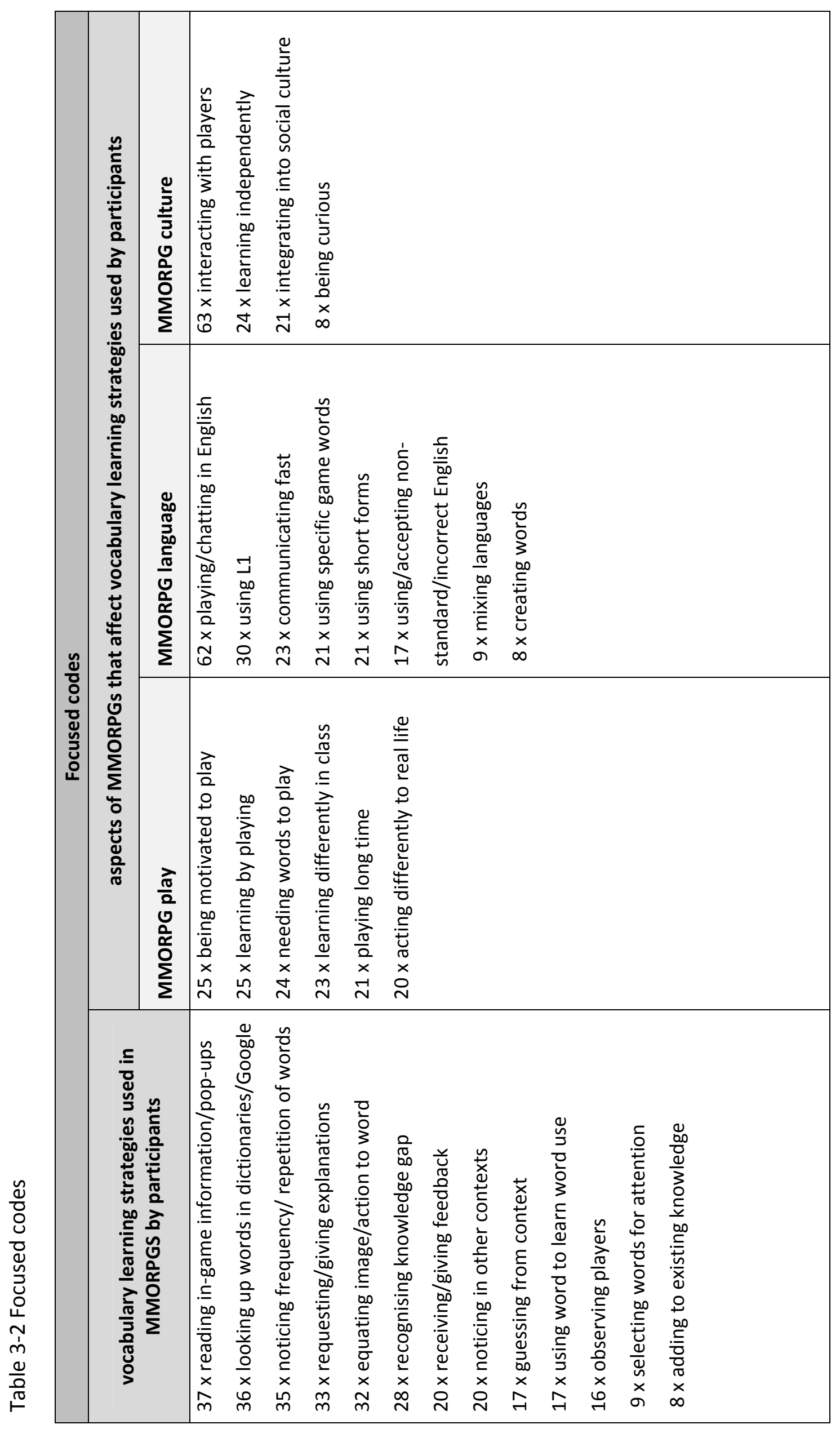




\subsection{Inter-rater and member checking}

To minimize personal bias during interpretation of the data, inter-rater and member checks were completed. Bernadette/Linda Forward, a Victoria University of Wellington MA (Applied Linguistics) student, checked coding for inter-rater reliability and confirmed by email and Skype conversation that the focused codes were clearly evident in the sample of data provided. All participants were emailed a brief summary of the data and results. Three participants replied: They all stated that they felt that the results were correct and that they agreed with all the points made in the supplied data and results.

\subsection{Conclusion}

An inductive case study is an effective way to explore an uncharted area. Six experienced gamers described and explained the vocabulary learning strategies they used in MMORPGS during interviews and in elicited email texts. Further information was collected from observations of participants gaming and extant World of Warcraft texts. Constant comparative analysis was used to allow themes and processes to emerge from the data. Inter-rater and member checking was completed.

The next chapter describes and discusses the results, including participants' vocabulary learning strategies, and aspects of MMORPG play, language, and culture that affected participants' vocabulary learning strategies. Gu's (2005) model of how learning contexts affect vocabulary learning strategies is used to discuss the results further. 


\section{RESULTS AND DISCUSSION}

\subsection{Introduction}

This chapter presents the results and discussion. Each section addresses a research question or questions and discusses patterns and processes that emerged from the data: participants' vocabulary learning strategies, and aspects of MMORPG play, language, and culture that affected participants' vocabulary learning strategies. The results of the study are compared to Gu's (2005) model of how learning context affects vocabulary learning strategies, and an adaptation of this model is presented.

\subsection{Reported vocabulary learning strategies}

This section answers this research question.

1. What vocabulary learning strategies do second language learners use in MMORPGs?

Vocabulary learning strategies are recognized as activities learners consciously choose to regulate language learning (Griffiths, 2008, p. 87). During semi-structured interviews, participants reported vocabulary learning activities they purposefully engaged in and were conscious of while playing MMORPGs. Data from observations, elicited and extant texts was compared with interview data so that similarities and differences between data collection methods emerged. A process of constant comparative analysis (Glaser \& Strauss, 1967) was used to identify the vocabulary learning strategies used by participants in MMORPGs.

Table 4-1 "Reported vocabulary learning strategies", on the next page, shows the 15 vocabulary learning strategies that were identified separated into two categories: 13 strategies that participants purposefully selected and used to learn vocabulary in MMORPGs, and 2 strategies that participants recommended other second language learners use to learn vocabulary in MMORPGs. The reported vocabulary learning strategies are ranked in order of the number of times participants mentioned the strategies during interviews. Note that this ranking does not reveal which strategies participants used most frequently or considered most valuable or effective. Participants' perception of frequency of strategy use and value and effectiveness of strategies were not explored in this small-scale case study. 
Table 4-1 Reported vocabulary learning strategies

\begin{tabular}{|c|c|}
\hline \multicolumn{2}{|c|}{ Reported vocabulary learning strategies } \\
\hline \multicolumn{1}{|c|}{ strategies used by participants } & \multicolumn{1}{c|}{$\begin{array}{c}\text { strategies recommended by } \\
\text { participants }\end{array}$} \\
\hline \multicolumn{1}{|c|}{ pop-ups } \\
36 x looking up words in \\
dictionaries/Google \\
$35 \times$ noticing frequency/repetition of \\
words \\
$\begin{array}{l}33 \times \text { requesting/giving explanations } \\
32 \times \text { equating image/action to word } \\
28 \times \text { recognising knowledge gap } \\
20 \times \text { receiving/giving feedback } \\
20 \times \text { noticing in other contexts } \\
17 \times \text { guessing from context } \\
17 \times \text { using word to learn word use } \\
16 \times \text { observing players } \\
9 \times \text { selecting words for attention } \\
8 \times \text { adding to existing knowledge }\end{array}$
\end{tabular}

\subsubsection{Playing/chatting in English}

All participants recommended other second language learners use the strategy playing in English to help learn vocabulary in MMORPGs. Tao recommends other second language learners play World of Warcraft in English, not Chinese to learn English vocabulary.

play the English one and do not ... use software to change all the things to Chinese | it's very easy so don't use that | so that's the first important thing | cause it's like if you use other one you have no opportunity to learn English | all the word change to Chinese $\quad$ (Tao, interview, 17 Aug 2010 00:11:34) 
All participants acknowledged that MMORPGs provide massive amounts of English language which could help other players learn English vocabulary.

However, MMORPGs can be played in many languages. Games can be purchased in different languages, different servers offer different languages, and add-ons and steam clients can also be used to translate game interfaces. Players are able to select their ingame language.

Participants recommend the strategy playing/chatting in English, but did not purposefully use this strategy. Participants did not start playing MMORPGs on an English interface or English server to purposefully learn vocabulary. Instead, playing in English is an inherent part of MMORPG gameplay with an English interface on an English server.

Several players reported that they changed their in-game language interface and started playing their MMORPG in English when they relocated to New Zealand. However, these participants started playing MMORPGs in English because the closer English server allowed faster gameplay or because they purchased locally available English versions. See following comments from Li and Frank.

I mostly play with Australians and New Zealanders now | my server is now Oceanic | it a just a for Australia and New Zealand | I can change [servers] (Li, interview, 17 Aug 2010 00:25:05) the first time I bought them here | and the first version was English and I download the German translation| because what easier for me than English (Frank, interview, 16 Aug 2010 00:25:24)

Participants stressed that MMORPGs with an English interface on an English server present a huge variety of English language that they consider meaningful and valuable for vocabulary learning. Observations of participants' gameplay also showed a massive variety and amount of English language on players' screens. Participants usually had multiple texts showing and were continually opening and closing tabs and pop-ups to access, show and hide further information and settings. Other digital game research (Frank, et al., 2006; Gee, 2007b; Piirainen-Marsha \& Tainiob, 2009; Rankin, 2008; Thorne, 2008; Turgut \& İrgin, 2009; Zheng, et al., 2009) confirms that MMORPGs 
provide rich language leaning contexts with many opportunities for meaning-focused input and output.

Use of the strategy playing/chatting in English was also observed. The following screenshot shows Tao playing World of Warcraft with an English interface. His screen is covered in language and he continually opened and closed tabs and pop-ups to show and hide further information. 


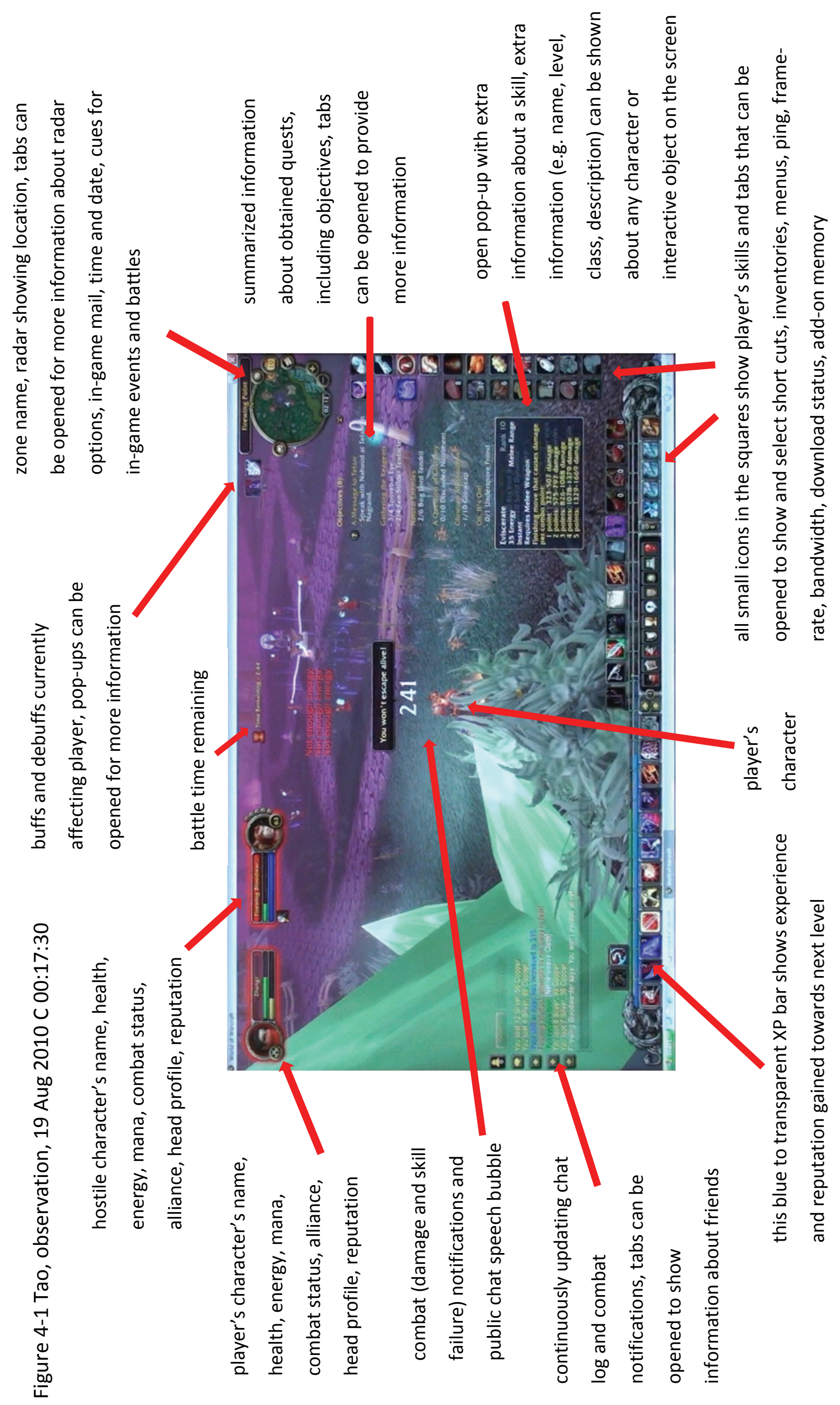


Participants reported that this strategy playing in English was essential for learning English vocabulary in MMORPGs, and other vocabulary learning strategies that they used required an English language game context. Also players implied that the use of the strategy playing in English facilitated the implicit learning of vocabulary. Nation (2001) agrees that vocabulary learning strategies can be used to help implicit vocabulary learning: i.e. activities that facilitate vocabulary learning while the learners are focused on meaningful and authentic communication.

Schmitt's (1997) taxonomy of vocabulary learning strategies also identified a less specific variation of this MMORPG vocabulary learning strategy playing in English. Schmitt identified the strategy as a metacognitive strategy and labeled it use Englishlanguage media (p. 208). Schmitt asserts that maximizing exposure to the target language will help learning (p. 216). Participants also recognize that an English context helps learning.

It is significant that participants recommended the strategy playing in English but did not purposefully use the strategy playing in English. Ultimately, all participants stressed that they did not play MMORPGs to learn English vocabulary: they played the games to enjoy the gameplay. Li reported that he learned English words within World of Warcraft even though his main aim is to play the game, not learn English words.

I learn English in classroom | I want to learn, but in game I want to play | but by the time passing I learn something

(Li, interview, 17 Aug 2010 00:05:21)

All participants acknowledged that, if they used an English interface and server, they needed to learn English words to enable them to play the game. Participants reported that they purposefully used vocabulary learning strategies to learn English words in MMORPGs. Players appeared to be motivated to use vocabulary learning strategies because they wanted to play the game but they needed words to play the game.

\subsubsection{Interacting with players}

All participants recommended other second language learners use the vocabulary learning strategy interacting with players to learn vocabulary in MMORPGs. 
For example, Tuah advises players to relax and join in the chat conversations to help learn words.

just like practise more | what it is | is they feel shy to type in the chat | to write more | so just type in and don't worry about the stuff | the more you more you use it you will much better | more relaxing

(Tuah, interview, 19 Aug 2010 00:29:58)

In addition, participants reported that they spoke with other players using VolP software, e.g. Ventrilo, Skype. See Hung's comment.

can communication with them with Ventrilo or um even Skype

(Hung, interview, 17 Aug 2010 00:23:48)

However, no participants used VolP software to communicate during the observed playing sessions.

This strategy interacting with players is also used to help implicit vocabulary learning. Participants recognized the value of experience, practice and repetition to learn words. However, again players do not use this strategy purposefully. Participants described interacting with players as an inherent part of playing MMORPGs: something they do to play the game, rather than to purposefully help learn words.

Schmitt (1997) identifies two social strategies similar to this MMORPG vocabulary learning strategy interacting with players: discover new meaning through group activity and interact with native speakers (p. 207). Rankin (2008) also claims that nonnative speakers learn English vocabulary in MMORPGs by interacting with native speakers. However, participants in this study never referred to native speakers and non-native speakers, but rather spoke about highly proficient (pro) and less proficient (beginner) English language users. MMORPGs are international and nation-less virtual environments, where English is sometimes used as a common language. Participants did not appear to bestow ownership of English on people from a real-world nation or culture. Participants did not report that they valued interaction with native-speakers to help learn vocabulary. 


\subsubsection{Observing players}

Four participants also reported using the strategy observing players to facilitate implicit vocabulary learning. These participants purposefully watched other players' typed chat conversations or listened to other players' spoken conversations to help word learning.

Several participants described how they used the strategy observing players to see appropriate context and use of words in typed chat conversations. In addition, Hung used this strategy to see other players' results from using requesting/giving explanations strategies.

sometime I just learn from people chatting together | I watch their chat like | this guy's a beginner this guy's the pros | and they chatting together and this guy ask them oh how does this word mean and how you do something bla bla bla | I just like an observer | and watch the chatting groups | I learn a lot from that

(Hung, interview, 17 Aug 2010 00:52:46)

In many language learning contexts, learners listen to conversations. MMORPGs provide opportunities to read typed chat conversations. This alternative mode of communication affects learners' vocabulary learning strategies. In MMORPGs, learners can re-read a written record of the conversation; whereas in spoken conversations, unless the conversation is recorded, the words exist in time and quickly pass, and learners have to remember what was said and how it was said.

Participants used the strategy observing players to purposefully create opportunities for meaning-focused input (Nation, 2001, 2007). Participants sometimes removed output opportunities from communication tasks to help vocabulary learning. One participant, Li, described disconnecting his microphone, pretending that it was broken, so that he did not have to speak and instead could just listen to his group's conversation.

I started without my microphone | and I can just a listen

(Li, interview, 17 Aug 2010 00:17:48) 
Participants in this study clearly differentiate between the strategies interacting with players and observing players. Participants included both meaning-focused input and meaning-focused output in their strategy interacting with players; whereas, participants removed meaning-focused output and included only meaning-focused input in the strategy observing players. Participants valued the use of both of these strategies to help them learn vocabulary in different ways.

Schmitt (1997) does not specifically identify a strategy similar to observing players. However, this strategy could be seen as part of Schmitt's strategies use Englishlanguage media and interact with native speakers (pp. 207-208).

The use of the strategy observing players also suggests that participants are using situated learning theory (Lave \& Wenger, 1991) to learn by observing the pros in action.

\subsubsection{Reading in-game information/pop-ups}

All participants reported using the strategy reading in-game information/pop-ups to learn words. This strategy was often used in combination with other strategies.

Li used the strategy reading in-game information/pop-ups in order to use the strategies recognizing knowledge gap and selecting words for attention.

I will read it quest and find some words I don't know

(Li, interview, 17 Aug 2010 00:22:28)

Whereas, Hung used the strategy reading in-game information/pop-ups to look up the meaning and use of words, which is a variation of the strategy looking up words in dictionaries/Google.

Everything has a hint inside | so you have to spend your time to read it

(Hung, interview, 17 Aug 2010 00:42:38)

The strategy reading in-game information/pop-ups was also observed through cursor movement. For example, Alex moved the glove-like cursor down through the text as he read the World of Warcraft quest description "The Edge of Winter". 
Figure 4-2 Alex, observation, 19 Aug 2010 00:05:13

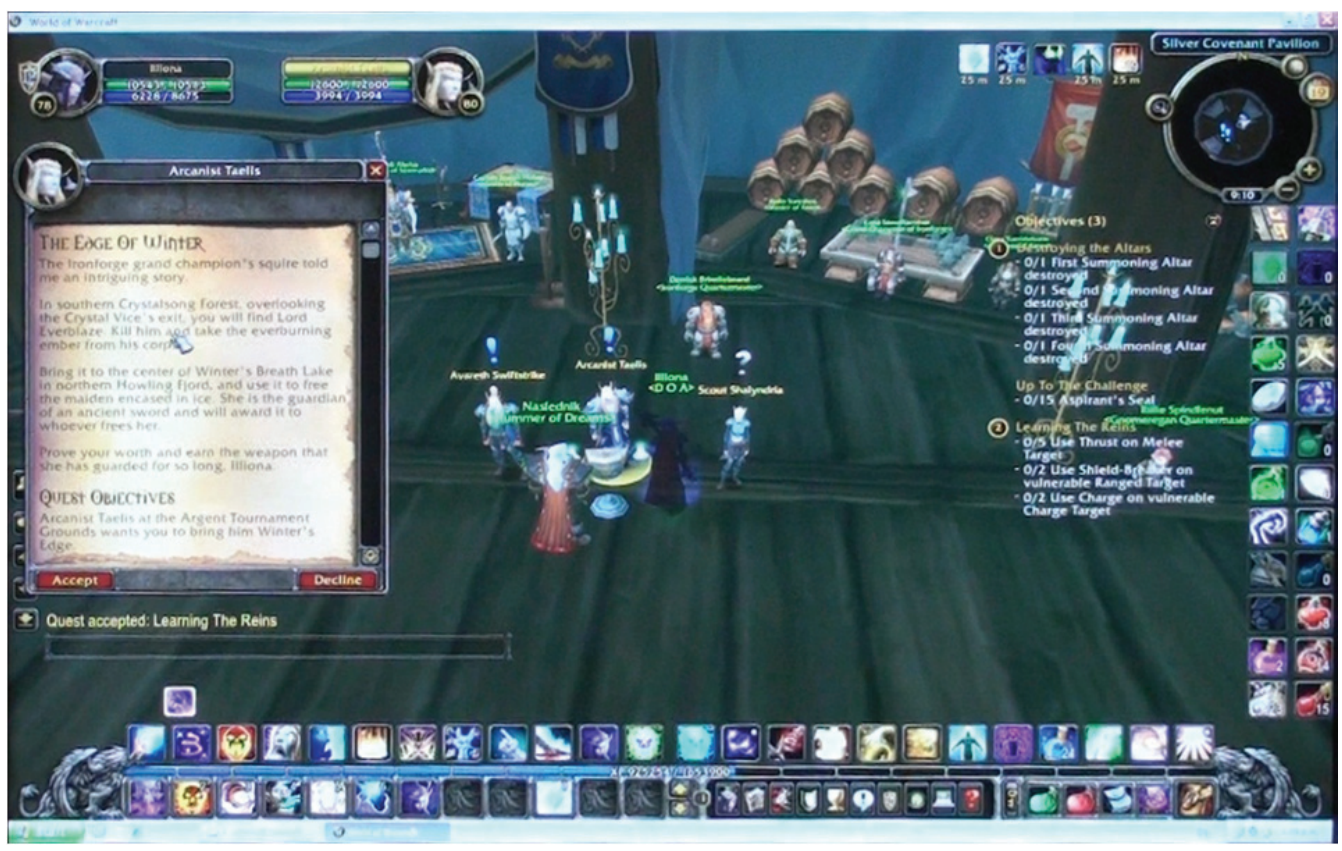

This strategy reading in-game information/pop-ups is another that fits within Schmitt's (1997) broad metacognitive strategy use English-language media (p. 207).

\subsubsection{Looking up words in dictionaries/Google}

All participants reported that they used the strategy looking up words in dictionaries/Google. However, many participants reported that they were reluctant to interrupt gameplay to look up words. If participants did look up words, they reported doing this after gameplay, not during gameplay. Tuah describes not knowing words, but continuing with gameplay and delaying looking up unknown words until later.

I did there are some words I didn't know | I couldn't remember but I didn't take the initiative to go and find out the meaning | I will say that it is just for the games and not | and just keep in the games | normally I will Google it and then look into it

(Tuah, interview, 19 Aug 2010 00:47:40)

All participants reported using the strategy looking up words in dictionaries/Google to learn the meaning of words. The participants did not report using the strategy looking up words in dictionaries/Google to find out any information other than a definition, e.g. spelling, pronunciation, examples of use, register, parts of speech or form were not looked up by participants. Participants are focused on using strategies that help 
them learn words and develop words skills that will help gameplay. Participants did not use vocabulary learning strategies for word knowledge or word skills that they judged as not necessary for gameplay.

Participants appeared to use the strategy looking up words in dictionaries/Google only after other vocabulary learning strategies did not help them understand a word's meaning and/or use. Again, participants' main aim was to play the game, and interruptions to gameplay were viewed negatively.

Participants did not specify whether they use bilingual or monolingual dictionaries; however, they referred only to online dictionaries and search engines, which are easy to access alongside computer game interfaces. This strategy looking up words in dictionaries/Google is similar to Schmitt's (1997) determination strategies bilingual dictionary and monolingual dictionary(p. 207) .

Note that participants may have mentioned the strategy looking up words in dictionaries/Google frequently because the interviewer may have been perceived as a language teacher. Looking up words in dictionaries/Google may have been interpreted as a correct response to "How do you learn words?"

\subsubsection{Noticing frequency/repetition of words}

All participants reported using the strategy noticing frequency/repetition of words. Several participants stressed that words are repeated a lot in MMORPGs. Li described the word repetition in MMORPGs.

learn by game | because this words appears a lot of times | I seen them again and again and again (Li, interview, 17 Aug 2010 00:07:55)

Game Studies' research (McGonigal, 2010; J. W. Rettberg, 2009; Steinkuehler, 2004).also maintains that repetition is a core part of gameplay.

This strategy noticing frequency/repetition of words would be affected by how many hours participants play MMORPGs. Tao describes how much he plays MMORPGs.

[during] holiday play longer | more than 4 hours a day| [normally] if possible | about couple of hours each day (Tao, interview, 17 Aug 2010 00:00:54) 
Gamers play on average 22 hours per week, but many play more than 30 hours (Seay \& Kraut, 2007; Williams, et al., 2008). Players could over a short period of time, perhaps a few days, be able to effectively use strategies such as noticing frequency/repetition of words because of the sheer volume of repetitive language they encounter.

Schmitt (1997) does not identify a strategy similar to the MMORPG vocabulary learning strategy noticing frequency/repetition of words.

\subsubsection{Recognizing knowledge gap and selecting words for attention}

Four participants reported that they use the strategies recognizing knowledge gap and selecting words for attention. Tuah reported that from initially recognizing knowledge gap, he waits until he has seen a word about five times before he uses the strategy selecting words for attention.

I never ever seen this word before | but from the game itself yeah I know it | I won't say once but like minimum five times | at least five times then you start to use the words again (Tuah, interview, 19 Aug 2010 00:16:06)

Participants frequently reported ignoring words they judged as not necessary to learn for gameplay. Participants judged words' usefulness from the use of the strategy noticing frequency/repetition of words.

For example, Tao explains his use of the vocabulary learning strategies noticing frequency/repetition of words and selecting words for attention clearly and succinctly.

and if it is not a common | I just ignore it

(Tao, interview, 17 Aug 2010 00:05:37)

Participants want to play the game and avoid interrupting gameplay. Again, participants used vocabulary learning strategies in MMORPGs to help learn words they perceive as useful for gameplay.

This strategy selecting words for attention is similar to Schmitt's (1997) metacognitive vocabulary learning strategy skip or pass new word, which is also identified as a strategy used to improve reading speed (p. $208 \& 217)$. Also, Gu's (2005) study 
revealed that selective attention was the most effective strategy of Chinese learners of English.

\subsubsection{Noticing in other contexts and adding to existing knowledge}

Three participants reported using the strategy noticing in other contexts and two participants reported adding to existing knowledge. Tao explains how he combines the strategies noticing frequency/repetition of words, recognizing knowledge gap, selecting words for attention, looking up words in dictionaries/Google, and noticing in other contexts, and adding to existing knowledge.

but in the game firstedly | first I feel ah yes it is a little bit familiar and then won't care | but later when I get to know it I check the meaning | oh I sees it's the one that I learned in the classroom | in class | ah

(Tao, interview, 17 Aug 2010 00:20:05)

In the context of the interview conversation, Tao's "ah" at the end of his statement implied that he had a eureka moment when he combined these vocabulary learning strategies. He appears to connect knowledge and reach a deeper level of understanding.

When Tao says, "later when I get to know it", I think he means when he became more familiar with the word and was noticing frequency/repetition of words. However, he may mean that he used the strategy guessing from context and now understood the word. It is not clear what Tao means and further clarification is required.

Participants appeared to combine vocabulary learning strategies. Although effectiveness of vocabulary learning strategies used by participants in MMORPGs is not included in this study, other research shows that successful learners use broad selections of strategies in flexible and versatile ways (Gu, 2005; Schmitt, 1997).

These strategies noticing in other contexts and adding to existing knowledge are similar to Schmitt's (1997) memory vocabulary learning strategy connect word to personal experience (p. 207). 


\subsubsection{Requesting/giving explanations}

Participants appeared to value both requesting and giving information to help them learn words, and identified themselves as requesters and givers of explanations. Hung describes requesting explanations to learn words.

first time I saw that | what the hell is that word | I haven't seen that before | I ask them | just random people | I say oh what's that mean | and people say oh that means ...

(Hung, interview, 17 Aug 2010 00:39:28)

In comparison, Tao appears to value giving explanation to learn words.

sometime the people asking me for help | and you can just have a look and you can also learn English $\quad$ (Tao, interview, 17 Aug 2010 00:21:15)

In this small-scale study, I defined this as a two-sided strategy: requesting/giving explanations.

Participants did not use traditional formal-education terms, e.g. teacher, student, pupil, or learner, to define people's roles when teaching or learning words or gameplay in MMORPGs. Participants appeared to value learning from other players and teaching other players.

In comparison, Schmitt's (1997) taxonomy of vocabulary learning strategies also identified requesting explanation strategies. However, Schmitt's research focused on classroom procedures and teacher instruction. Schmitt identified four strategies used to request information: ask a teacher for first language translation, ask a teacher for a paraphrase or synonym of new word, ask teacher for sentence including new word, and ask classmates for meaning. It is interesting that Schmitt's research revealed three methods to ask a teacher, but only one to ask another student, and none that involve the user of the strategy in an information giving role. Schmitt's strategies which were identified in a formal learning context appear to be less relevant within an informal learning context. Taxonomies that include vocabulary learning strategies used in informal learning contexts and digital contexts need to be developed. 


\subsubsection{Receiving/giving feedback}

Four participants described another two-sided strategy: receiving/giving feedback. Participants described other players recasting their words and requesting clarification of words with a simple "?" chat response.

Tao described positive feedback as no response.

I try to use the word | and this | and nothing happens | it means they understand the meaning (Tao, interview, 17 Aug 2010 00:10:28)

Participants also reported negative feedback. Other players sometimes laughed at them and made direct comments about their "terrible" English. See Hung's comment.

laughing at me | they say oh this guy he is not English or something like that | oh his English terrible or something like

(Hung, interview, 17 Aug 2010 00:35:53)

Participants did not feel protected from the humiliation of negative feedback from their peers by using an avatar. Participants stressed that their avatars reputations were their personal reputations, and that they considered their characters' reputations in MMORPGs as important and real. Game Studies' research (Chatfield, 2010b; Pearce \& Artemesia, 2009; Yee, 2003-2006; Yee, et al., 2009) supports this finding.

Also participants' virtual-lives and real-lives overlapped. Many participants played with existing friends. Several participants described forming new friendships in MMORPGs that were then transferred to real-life. See example from Hung.

I do meet someone I know from Singapore | I like that guy like a few years ago | we play together a lot | and when I get back to Vietnam I normally have to transit in Singapore ... so we really have some good time together | I already meet him a few times (Hung, interview, 17 Aug 2010 00:47:33)

\subsubsection{Equating image/action to word}

All participants reported using the strategy equating image/action to word. Tuah describes looking at pictures alongside written words to figure out what words mean. 
the word is like an identity for the thing or the creature | we see this pictures and it presents these words | like the elf | we see some night creatures coming up with the long ears | and oh | the elf word

(Tuah, interview, 19 Aug 2010 00:10:51)

This vocabulary learning strategy could also be used in passive media which included written words and pictures, such as newspaper and television with subtitles.

However, participants also used the vocabulary learning strategy equating image/action to word by clicking on items, which is a function that interactive media provides. Alex describes clicking on and using a game-ability to discover what a word means.

I didn't really understand | when I tried the ability | I saw what it did

(Alex, interview, 19 Aug 2010 00:52:56)

Participants use the vocabulary learning strategy equating image/action to word to learn the definition and use of the word that is meaningful for the MMORPG context. Tuah describes how he learned what 'stardust' means.

we learn from the function itself | what is it do | what is this word | and then you click it | stardust means everyone stand still and you can run away

(Tuah, interview, 19 Aug 2010 00:47:40)

Tuah does not seek or require a dictionary-like meaning, e.g. "stardust - a magic quality that some famous people with a great natural ability seem to have" (Oxford University Press, 2010). Instead, his deduction "stardust means everyone stand still and you can run away" directly helps gameplay.

Participants described MMORPGs as having stationary and moving digital images present alongside written language. Observations also showed a huge variety of language and images on the players' screens. This screen shot of Alex's gameplay shows the variety of language and images participants have on their screens, for descriptions of these images and language see Tao's observation in Figure 4-1 on page 36. 
Figure 4-3 Alex observation, 19 Aug 2010 A 00:21:37

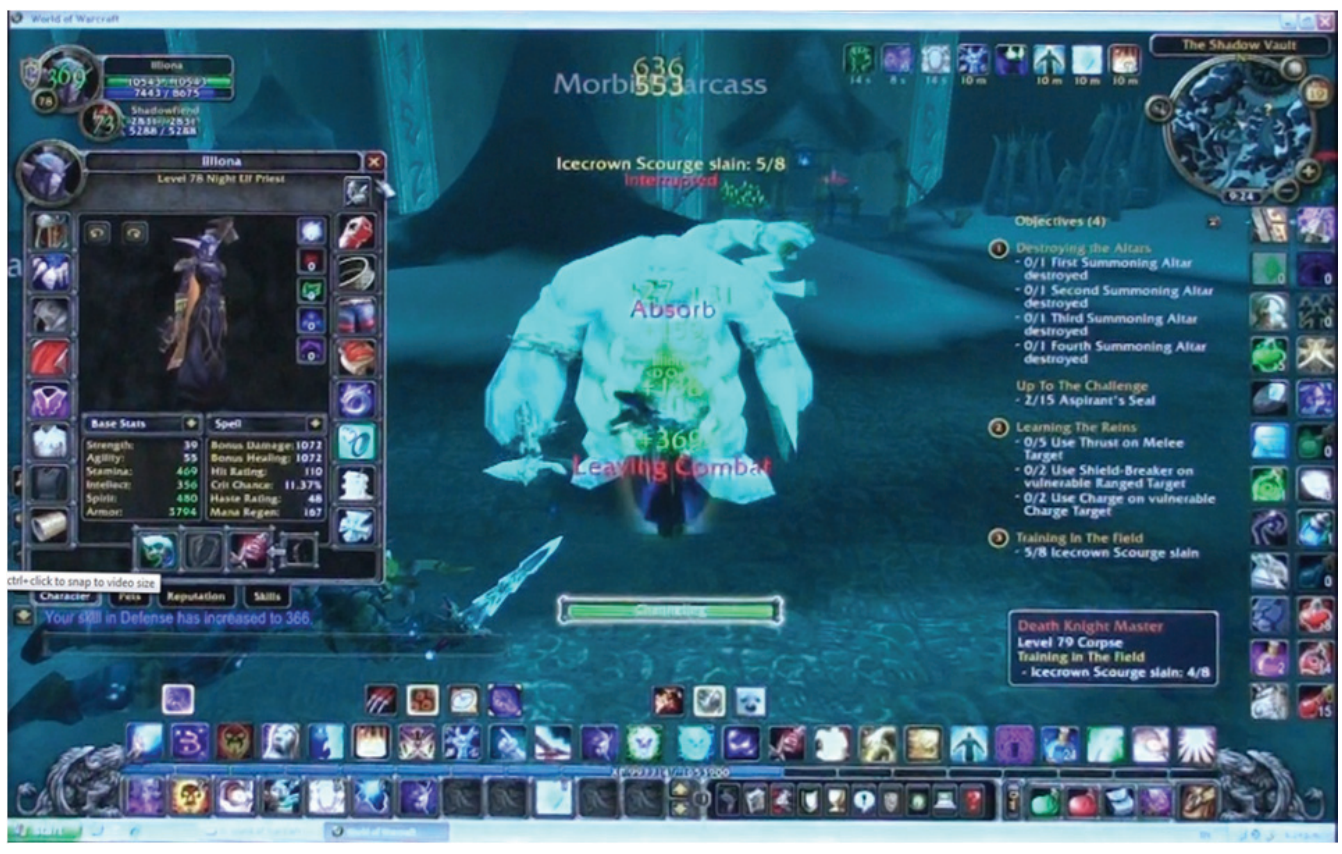

However, the actual strategy, equating image/action to word, described by participants during interviews was a thought process and was not observable. Many other vocabulary learning strategies were also not able to be observed.

Schmitt's (1997) taxonomy of vocabulary learning strategies also identified this strategy, which was identified as analyse any available pictures or gestures (p. 207).

\subsubsection{Guessing from context}

Participants also described the strategy guessing from context. Although similar, this strategy guessing from context was distinctly different from the strategy equating image/action to word. Frank and Hung describe how they guess words to fill in unknown gaps in a written text or spoken sentence.

you see the text and maybe some little words | and mostly there are some words in it you understand | and you can fill in the words | with your mind

(Frank, interview, 16 Aug 2010 00:19:22)

the word itself I don't understand | but when in a sentence | common sense something like that | I start guessing

(Hung, interview, 17 Aug 2010 00:37:41) 
Schmitt's (1997) taxonomy of vocabulary learning strategies identified a similar strategy, identified as guess from textual context used for the discovery of a new word's meaning. Schmitt states that this strategy is affected by the learner's proficiency level and background knowledge, and available clues about the target word that the context provides (p. 207).

\subsubsection{Using word to learn word use}

An interesting vocabulary learning strategy that emerged from this study's data was using word to learn word use. Hung and Li describe this strategy.

I don't basically like exactly know what is it means exactly | so I still use this word when playing this game (Hung, interview, 17 Aug 2010 00:49:14) I don't know the name | I don't know the meaning | I see them a lot and and see what happens and I try to use it (Li, interview, 17 Aug 2010 00:08:15)

Tao described this action by comparing it to using a mathematical formula.

this is like you use a mathematical formula but don't know how the mathematical formula was derived or discovered

(Tao, email text, 28 Jan 2011)

Participants appear to use a word before they know the meaning of the word and they are still unsure about the use of the word, a form of testing deductions (Smith, 2003). Tao expected feedback from other players to confirm or reject his use of the word.

I try to use the word | and this | and nothing happens | it means they understand the meaning |if it was wrong | they will maybe put question marks or what do you mean | or like this | lol (Tao, interview, 17 Aug 2010 00:10:28)

However, we need to avoid jumping to conclusions about why learners do this. Perhaps it is to purposefully test their understanding of the word meaning and appropriate use. But perhaps it is to show that they belong to the community and are a part of the gaming culture.

Schmitt (1997) does not identify any strategy similar to using word to learn word use. 


\subsubsection{Typology}

As Nyikos and Fan (2007) proclaimed, results from vocabulary learning strategy research are difficult to compare because researchers use different terminology and typologies. No clear categories for the 15 vocabulary learning strategies emerged from the data. Participants did sometimes mention the specific part of their vocabulary learning process in which they used a strategy: when they initially came across a word, later when a word became more familiar, and finally when word use became more automatic. Participants alluded to strategies being categorized as part of the vocabulary learning process, which is similar to Gu's (2005) initial handling, consolidation, and activation of words categories. Table 4-2 "Comparison with Gu's (2005) categories" compares Gu's categories with tentative categories that emerged from this study's data.

Table 4-2 Comparision with Gu's (2005) categories

\begin{tabular}{|l|l|}
\hline $\begin{array}{l}\text { Gu's categories } \\
\text { words }\end{array}$ & $\begin{array}{l}\text { strategies that emerged from the data } \\
\text { and participants' comment }\end{array}$ \\
\hline $\begin{array}{l}\text { initial handling of } \\
\text { when words were initially discovered } \\
\text { selecting word for attention } \\
\text { I found some words and ignored them } \\
\text { (Li, interview, 17 Aug 2010 00:05:56) }\end{array}$ & $\begin{array}{l}\text { later when words became more familiar } \\
\text { looking up words in dictionary/Google, adding to } \\
\text { existing knowledge } \\
\text { it is a little bit familiar and then [before] I won't care | } \\
\text { but later when I get to know it I check the meaning | } \\
\text { oh I sees it's the one that I learned in class } \\
\text { (Tao, interview, 17 Aug 2010 00:20:05) }\end{array}$ \\
\hline $\begin{array}{l}\text { activation of words } \\
\text { finally when words use became more automatic } \\
\text { then you start to use the words again when you play } \\
\text { the game I then you I I will use it, just flashes out, } \\
\text { just say it out } \\
\text { (Tuah, interview, 19 Aug 2010 00:16:36) }\end{array}$ \\
\hline
\end{tabular}

However, evidence was not frequent enough or clear enough for any categories of type or uses of vocabulary learning strategies to emerge from this data, and many of the strategies could be classified into several existing categories from other 
researchers (Ahmed, 1989; Gu, 2005; Gu \& Johnson, 1996; Hatch \& Brown, 1995; Kudo, 1999; Nation, 2001; Schmitt, 1997; Stoffer, 1997; Tao, 2006).

\subsection{How MMORPG context affects vocabulary learning strategies}

This section answers these research questions.

2. What aspects of MMORPGs affect second language learners' vocabulary learning strategies?

3. How do these aspects of MMORPGs affect second language learners' vocabulary learning strategies?

This section discusses aspects of MMORPG context that affect learners' vocabulary learning strategies: MMORPG language, MMORPG culture, and play.

\subsubsection{How MMORPG language affects vocabulary learning strategies}

Participants' vocabulary learning strategies are affected by use of language and attitudes toward language in MMORPGs. The main factors that emerged from the data that affect gamers' vocabulary learning strategies were that

- MMORPGs provide a huge variety of opportunities to use language in meaningful ways

- MMORPGs are plurilingual contexts where players swap and mix languages

- MMORPG players communicate fast, which results in creative non-standard language

- MMORPGs provide a wide range of language, from complex specialized technical terms to informal non-standard chat

\subsubsection{Variety of opportunities to use language in meaningful ways}

All participants reported that MMORPGs provided a valuable context for use of vocabulary learning strategies. Participants recognized that their language use in MMORPGs was meaningful and used vocabulary learning strategies to help them learn words in order to play the game. Observations of participants' gameplay also showed that MMORPGs provided a huge variety of language and opportunities for meaningfocused input and meaning-focused output. This screenshot of Li's gameplay in World 
of Warcraft is another example that shows how participants have language and images displayed on their screens.

Figure 4-4 Li, observation, 19 Aug 2010 C 00:17:30

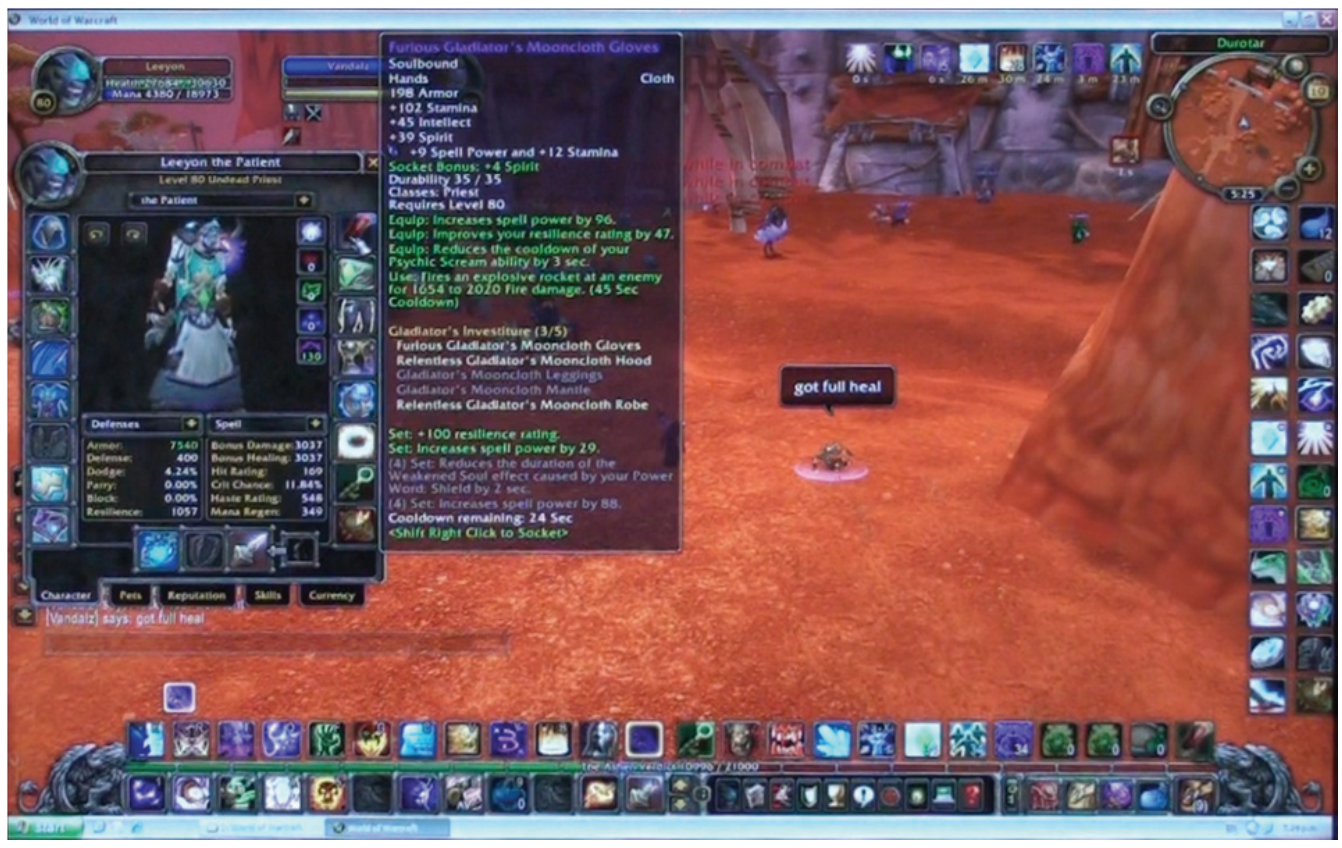

For descriptions of these images and language, see Tao's observation in Table 4-1 on page 36 .

MMORPGs are rich language learning environments that enable participants to use a wide variety of vocabulary learning strategies. Other researchers (Frank, et al., 2006; Gee, 2007b; Piirainen-Marsha \& Tainiob, 2009; Rankin, 2008; Thorne, 2008; Turgut \& İrgin, 2009; Zheng, et al., 2009) also assert that digital games provide rich language learning contexts. Kojic-Sabo and Lightbrown's (1999) results also support this claim. Kojic-Sabo and Lightbrown's study showed that the ease of access to opportunities to use language affected learners' vocabulary learning strategies.

\subsubsection{Mixing languages}

MMORPGs are plurilingual environments. Participants revealed that they use English, and their L1, and code mix and code switch within MMORPGs. Tuah describes mixing English and Cantonese. 
we will mix-up some local languages inside the English context | normally the person we play the game with | because of we are in the same team | we tend to use English as a priority | [also] we put in our own languages | inside some words we have created | normally Cantonese will be the second language that we use | so mix inside

(Tuah, interview, 19 Aug 2010 00:04:46)

Participants reported a variety of reasons for using English, their L1 or mix languages. However, interestingly, Hung reported that because swearing was an expected language norm in MMORPGs, some of his L1 friends preferred to use English in MMORPGs because they felt uncomfortable swearing in their L1.

some of them prefer to speak English cause when we chatting Vietnamese we will use bad word a lot and it feel uncomfortable for very of us | you know there are some rude words | and we keep saying in Vietnamese like we have to | so no Vietnamese words | when you say rude words just use English words | so it doesn't hurt as much as when you say it in our own language | it's much more like accepted | it's more acceptable I think

(Hung, interview, 17 Aug 2010 00:33:35)

Using English and the participant's L1 was also evident in the observations. Alex played the World of Warcraft within an English interface but chatted with Ukrainian guild members in Ukrainian. See chat log on left side of screen on next page. 
Figure 4-5 Alex, observation, 19 Aug 2010 A 00:33:02

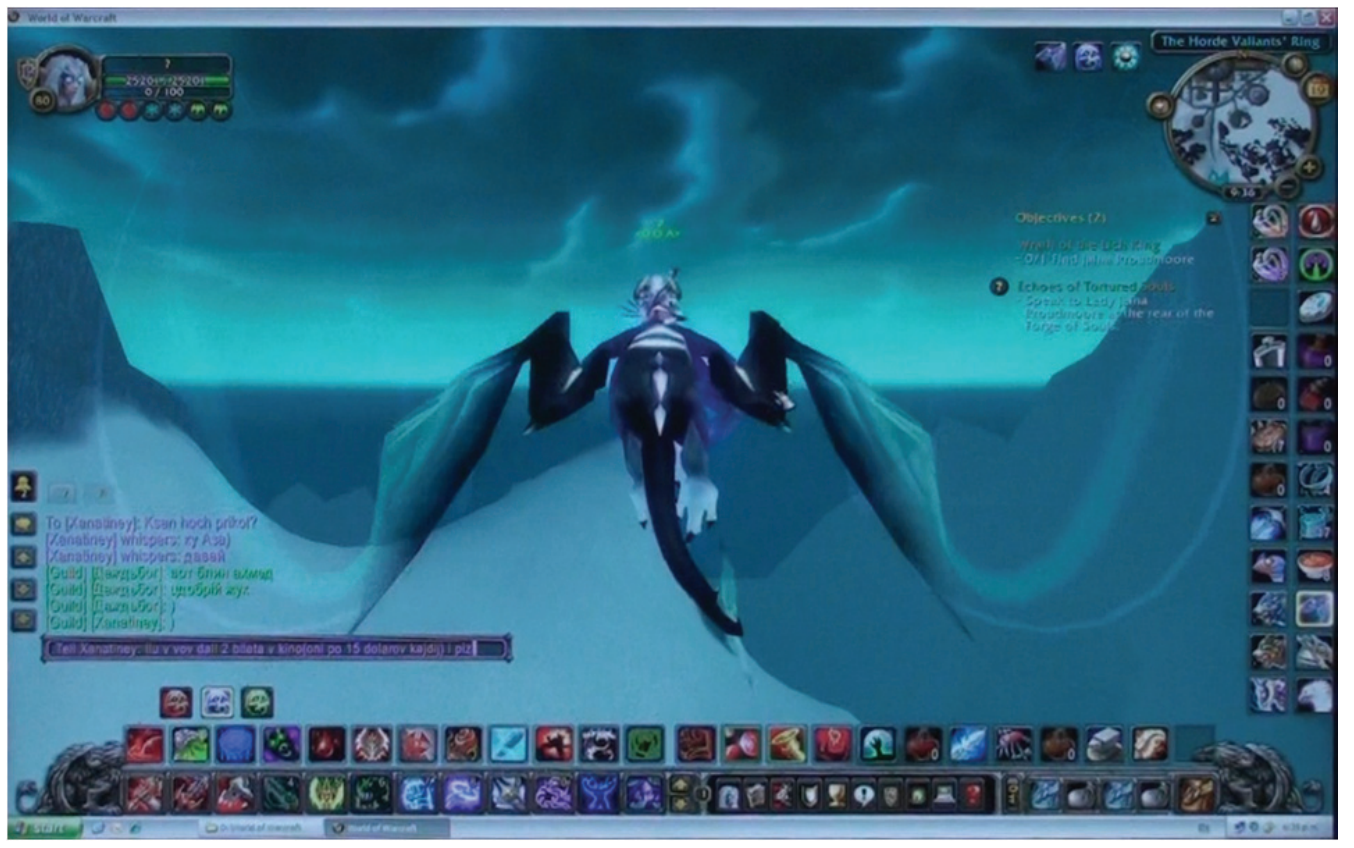

Players' vocabulary learning strategies are affected by the plurilingual environment. Standard English is not the participants' objective; instead, effective communication to enable gameplay is the participants' objective. The users of this plurilingual context appear to accept code switching and code mixing to enable effective communication. Participants overwhelmingly expressed an easy-going, casual attitude towards language use in MMORPGs. Participants can use all their available language knowledge and skills when using MMORPG vocabulary learning strategies, such as requesting/giving explanation, giving/receiving feedback, observing players, and interacting with players. Participants can use vocabulary learning strategies in languages other than English. Participants can compensate for any restriction created by their level of proficiency in English by swapping to another language.

\subsubsection{Communicating fast, using short forms, creating words, using non-standard English}

Participants communicated fast and hurriedly when playing MMORPGs. During observations, gameplay was fast and required participants to swap quickly between tasks. Participants used the keyboard and mouse to control camera angle, character movement, select and use various skills and weapons, access inventories and other pop-up tabs and chat. 
During interviews, all participants stressed how important fast communication was in MMORPGs, and how this need for speed resulted in accepting non-standard English, using in-game short forms, and valuing creating new words. Hung describes accepting non-standard language.

I know that people will understand it | cause they make a mistake when typing as well | cause it is really fast | the game is going really fast

(Hung, interview, 17 Aug 2010 00:37:20)

Tuah describes the importance of speed and short forms and word creation.

in the online games the most critical parts is the speed | you have to keep everything short simple | and you know | easy to communicate | with short forms and you create your own words out of nowhere | your own type of spelling forms like later for example later we put L8R

(Tuah, interview, 19 Aug 2010 00:33:11)

Other research (Anis, 2007; MacCallum-Stewart \& Parsler, 2009; North, 2007; Yee, 2006a) also identified that MMORPG language is fast, and uses non-standard forms, short forms, and creative language.

The use of short forms was also evident in the observations. When an unknown player lost a player versus player (PvP) duel with Li, the unknown player typed in chat "luck fear won taht". Li read it aloud as "lucky, fair, won that". The three participants observing the gameplay appeared to accept this non-standard language as appropriate: no one commented, no one laughed or even gwaffed. The black chat speech bubble show this comment in the screenshot of Li's gameplay in World of Warcraft. 
Figure 4-6Li, observation, 19 Aug 2010 C 00:17:29

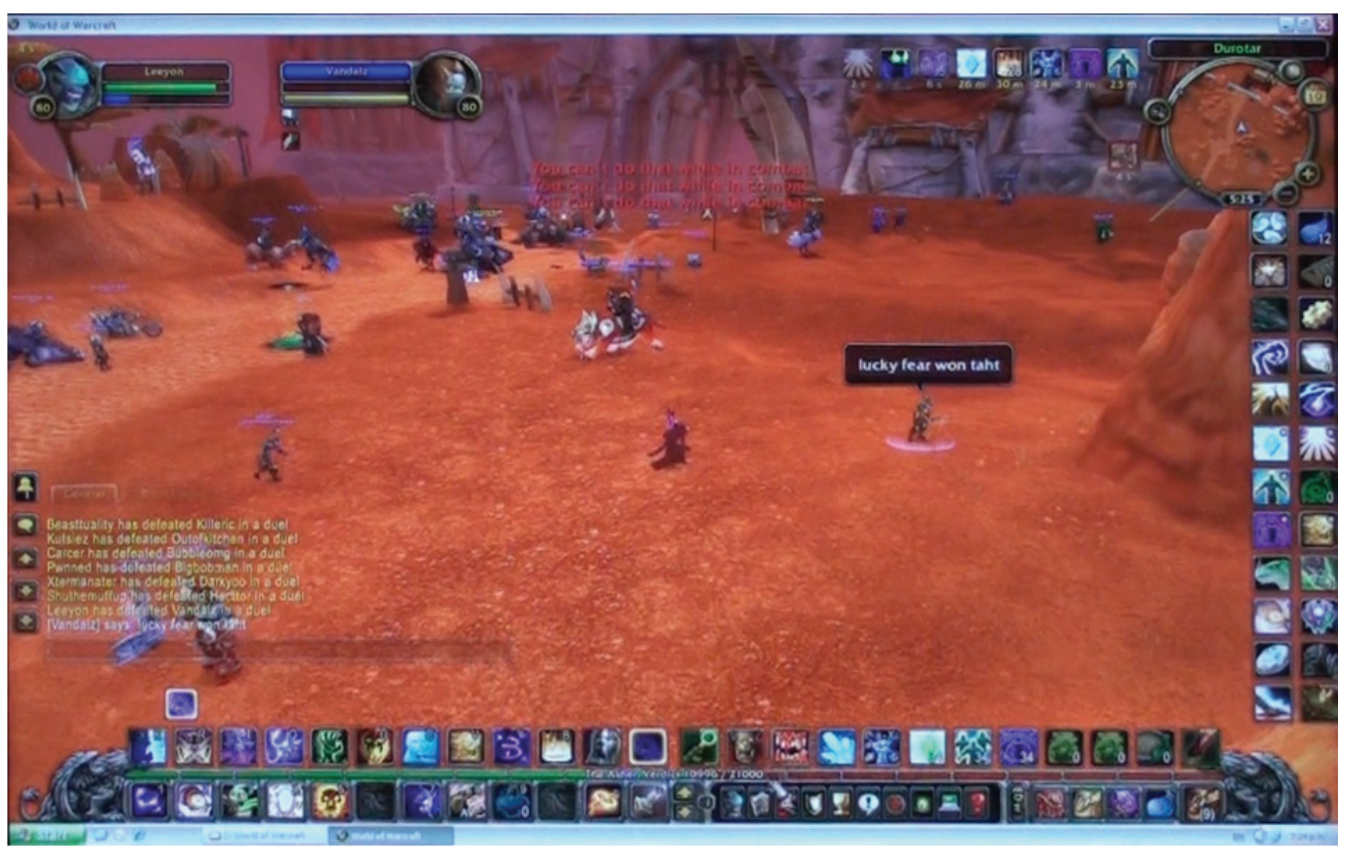

An extant MMORPG text, a five minute chat log from Durotar, World of Warcraft, also included many examples of non-standard language and short forms. Table 4-3 "Examples of chat language from chat log, Durotar, World of Warcraft" show a selection of non-standard language and short forms used during this chat conversation.

Table 4-3 Examples of chat language from chat log, Durotar, World of Warcraft

\begin{tabular}{|l|l|l|l|}
\hline \%^\&*ing stupid !@\#\$ $^{\wedge}$ & I have both \$\$ now & Oi & yes noob?, \\
\hline and u cant show ur face & supa zak & unna & >.> \\
\hline u don't if ur playing wow & ur so good? & haaiirr & nah man \\
\hline wow this still going? & u don't have a gf & lol & Dw \\
\hline Takin it to far man & Dukass & $:)$ & Dks are bad \\
\hline is trying to diss me over wow & Scarm & lol & shows how fall u $r$ \\
\hline
\end{tabular}

Note, Dw means don't worry, Dks means Death Knights, show how fall u $r$ means shows how fail you are, and fail means loser. Although many of these forms are not understood by laypeople, participants explained that short forms and typing errors were language norms within MMORPGs and understood by gamers. See comments by Frank and Hung. 
normally I use the short cuts yes | everyone understand those | I think that's normal (Frank, interview, 16 Aug 2010 01:13:24)

I know that people will understand it | cause they make a mistake when

typing as well | cause it is really fast | the game is going really fast

(Hung, interview, 17 Aug 2010 00:37:20)

This creative approach to language affects gamers' use of language, the development of an MMORPG variety of English, and has established a playful, experimental, and accepting attitude towards language. This playful attitude affects participants' selection and use of vocabulary learning strategies. Participants are able to freely use non-standard (or incorrect) language, take risks and use the strategy using word to learn word use. These relaxed language norms may lower learning anxiety.

The speed of communication can also affect participants' use of vocabulary learning strategies. Participants may use the strategy guessing from context and equating image/action to word frequently because of this need to communicate fast and not interrupt gameplay.

\subsubsection{Using specific game words}

Extant texts showed that MMORPGs also included advanced specialized terms text. For example Table 4-4 shows examples of terms from Rogue Talent descriptions that are beyond the General Service List (West, 1953) and Academic Word List (Coxhead, 1998).

Table 4-4 Examples of advanced terms from Rogue Talents, World of Warcraft

\begin{tabular}{|l|l|l|l|}
\hline activated & empower & linger & regenerate \\
\hline afflicting & eviscerate & melee & sinister \\
\hline assassination & garrotte & momentum & stealth \\
\hline bypass & haemorrhage & opponents & subtlety \\
\hline concealments & impairing & recuperate & unerring \\
\hline
\end{tabular}

Research from Game Studies (Klastrup, 2003, pp. 105-106; Mäyrä, 2008, pp. 25-27) also recognizes that MMORPG contexts include advanced specialized terms. 
MMORPGs include different types of language: advanced specialized terms and rushed informal chat. This range of language could affect participants' vocabulary learning strategies. Participants would need to develop a broad range of strategies or use strategies in a variety of ways to help learn different kinds of words for different purposes in different contexts within MMORPGs. Also, research shows that successful learners use a broad selection of strategies in flexible and versatile ways (Gu, 2005; Schmitt, 1997).

\subsubsection{How MMORPG culture affects vocabulary learning strategies}

Participants' vocabulary learning strategies are affected by the MMORPG in-game culture. The main factors that emerged from the data that affect gamers' vocabulary learning strategies were that

- Participants desire to belong to the in-game culture

- MMORPG cultures include hierarchical structures

- MMORPG cultures value independent learning

- MMORPG cultures value curiosity

- MMORPG cultures are cooperative and interactive

\subsubsection{Integrating into social culture}

Participants were aware of in-game cultural norms and expectations and appeared to want to belong. Here Tao talks about wanting to be the same as other players.

but you can learn ... how to talk to them / and how to yeah how to be same to them | and not act like maybe foreigners

(Tao, interview, 17 Aug 2010 00:16:39)

Participants' reports suggested that participants were becoming enculturated in MMORPGS and were participating in and belonging to a gaming community of practice (Wenger, 1998). Participants' vocabulary learning strategies were affected by their motivation to belong and fit in to the MMORPG culture. 
Nyikos and Fan (2007) identified that learning environments affect the vocabulary learning strategies of people of the same cultural background. However, in MMORPGs players of different real-world cultures appear to quickly assimilate into an inclusive ingame culture (Gee, 2007a, p. 74).

\subsubsection{Conforming to hierarchical structures}

All participants were acutely aware of in-game hierarchical structures, and appeared to conform to this cultural norm. Tuah and Alex describe how the hierarchical structures affect their use of the vocabulary learning strategy requesting/giving explanations.

and I have achieved quite a high level I I would not ask somebody who is level lower than mel it is pride (Tuah, interview, 19 Aug 2010, 21:15) you can ask the guild for help to like explain something | but if you are a higher level that would be weird (Alex, interview, 19 Aug 2010 00:12:00)

Participants did not request explanations for words from higher level characters. This restricted their use of the strategy requesting/giving explanations. This conformance to in-game hierarchies could also restrict the use of the strategy receiving/giving feedback. Also, players' levels are publically shown in World of Warcraft, so participants could easily target, what they call, the pros when using the strategy observing players. Note that in-game hierarchies are similar to real-life, and as Yee et al. (2006) state social interaction in virtual-worlds and the real-world adhere to the same social norms.

\subsubsection{Learning independently}

An aspect of MMORPG culture that could affect vocabulary learning strategies is the in-game expectation that people need to learn autonomously and independently. Alex explains that players need to learn independently through experience and not rely on other players to help them too much.

people who play first time should mostly level up by themselves| or they won't know how to play their class| if someone else helps you | you just don't use your abilities and just don't know how they work

(Alex, interview, 19 Aug 2010 01:05:41) 
Although Alex is specifically talking about progressing through gameplay, many participants talked about learning gameplay and learning language and words as interdependent factors. Participants want to play but need words to play. This cultural norm of expecting autonomous learning affects participants' vocabulary learning strategies. Participants cannot rely solely on strategies such as requesting/giving explanations, and receiving/giving feedback. Participants need to also use independent strategies, such as reading in-game information/pop-ups, guessing from context, and using word to learn word use.

\subsubsection{Being curious}

Another aspect of MMORPG culture that could affect gamers' vocabulary learning strategies is being curious. Tuah reports being curious.

I was curious ... | I'll just search for it (Tuah, interview, 19 Aug 2010 00:27:40)

MMORPGs inherently encourage exploration and curiosity. MMORPG extant texts, quest instructions, Icecrown, World of Warcraft, confirmed this. These quests frequently requested that players travel to new places and search for people or items and then figure out something and do something and report to another new place; which in turn, allowed players to access new areas which could be explored to discover new quests and missions.

This cultural norm of curiosity can affect participants' vocabulary learning strategies. Participants could increase their use of the strategies interacting with players, reading in-game information/pop-ups and looking up words in dictionaries/Google because of a sense of curiosity.

\subsubsection{Interacting with players}

Participants all reported that cooperative gameplay and interaction between players is a normal and inherent part of playing MMORPGs. Alex describes the different people he interacts with in World of Warcraft.

I communicate with other players who are in the game | I might not know them ... | and with the people from my guild some of whom I met in reality | and my girlfriend is also in the guild | or my friend | two friends

(Alex, interview, 19 Aug 2010 00:51:09) 
A variety of Game Studies research (Chatfield, 2010b; Cole \& Griffiths, 2007; Delwiche, 2006; Goodwin-Jones, 2005; Mortensen, 2009; Nardi \& Harris, 2006; Shen \& Williams, 2010b; Steinkuehler \& Williams, 2006; Thorsen, 2009; Williams, et al., 2007; Williams, et al., 2008; Yee, 2003-2006, 2006b, 2006c) also confirms that cooperation and interaction are built-in to MMORPGs.

The MMORPG cooperative and interactive culture affects participants' use of the vocabulary learning strategy interacting with players. This strategy can easily be frequently used by participants because of the in-game cultural norm of cooperative play.

In elicited email texts, participants further explained how playing as part of a group affected their use of vocabulary learning strategies. Tao wrote that playing in a group increased his motivation to learn words faster.

when I'm in a group or a team, to learn or understand a new word become compulsory task ... I learn faster when I'm a part of the team than when I'm alone, because you don't have too much time to learn

(Tao, email text, 28 Jan 2011)

He would, therefore, be more likely to select and use strategies that he perceived would help him learn words fast and provide shortcuts to learning.

\subsubsection{How play affects vocabulary learning strategies}

Ultimately MMORPG learning contexts exist within the greater context of play. Play has some inherent qualities that affect participants' vocabulary learning strategies. The main factors that emerged from the data that affect gamers' vocabulary learning strategies were that

- Learning in MMORPGs was different from learning in classrooms

- Participants learned through play and needed words to play

- MMORPGs are highly motivating contexts which affect how often and long participants play 


\subsubsection{Learning differently in class}

Participants reported that learning in MMORPGs was different from learning in classrooms. Here Hung describes being more active, less shy and more responsible in MMORPGs.

you much more active in the game than in a classroom | you not as shy | so you can easily ask whatever say whatever| say whatever you like| so you just take responsible (Hung, interview, 17 Aug 2010 00:51:32)

These differences could affect the vocabulary learning strategies participants use in MMORPGs compared to those they use in classrooms. Participants may take responsibility for their learning and use strategies to manage this responsibility, such as recognizing knowledge gap and selecting words for attention.

Participants appear to have low learning anxiety in MMORPGs. However, it is important not to jump to conclusions and attribute this relaxed attitude to the use of avatars. Indeed in this study, participants stressed that the reputation of their characters was as important and valuable as their real-world reputations. This lowering of learning anxiety could be from the playful and creative attitude to language in MMORPGs. Further research would be required to investigate this effect.

\subsubsection{Learning by playing, needing words to play}

Ultimately, all participants stressed that they did not play the games in order to learn English: they played the games to enjoy the gameplay. Li clearly describes this difference.

I learn English in classroom, I want to learn, but in game I want to play | but by the time passing I learn something (Li, interview, 17 Aug 2010 00:05:21)

No participants reported using vocabulary learning strategies to increase enjoyment of words learning as defined by Cohen (2007) and Oxford (1990). Instead, participants stressed that gameplay was enjoyable and word learning was required for effective gameplay. 
All participants reported learning English vocabulary in order to play the game and the game providing a valuable context to learn English vocabulary, in a sort of meaningful interdependent context. Although, learning through play is stressed as valuable in early childhood education (Bruce, 1994; Duncan \& Lockwood, 2008; Gordon \& EsbjornHargens, 2007; Moyles, 1994; Opie \& Opie, 1984), and is well-known as incorporating essential principles of learning (S. Brown, 2010; Duncan \& Lockwood, 2008; Montessori, 2003; Piaget, 1962; Sutton-Smith, 1997; Vygotsky, 1978), adult learning through play is not a common research area. Adult second language learning research and practice appears to focus on learning in classrooms and work environments (H. D. Brown, 2007; Gass \& Selinker, 1994; Harmer, 2007; Mitchell \& Myles, 2004; Ortega, 2009), but research should look at what adult second language learners are playing at too.

The play context affects the vocabulary learning strategies that participants use. Perhaps because participants are playing the game, they also are free to play with language. Therefore, participants could use playful and experimental vocabulary learning strategies, such as using word to learn word.

\subsubsection{Being motivated to play, playing a long time}

All participants talked at length about how motivating MMORPG environments were, and one participant stressed how addictive he found MMORPGs. High levels of motivation affected how long participants played the games. Here Tao describes how many hours he usually plays MMORPGs.

[during] holiday play longer| more than 4 hours a day| [normally] if possible | about couple of hours each day (Tao, interview, 17 Aug 2010 00:00:54)

The average gamer plays 22 hours per week, but many gamers play more than 30 hours (Seay \& Kraut, 2007; Williams, et al., 2008). Many hours spent playing MMORPGs will affect players' vocabulary learning strategies. Players can effectively use strategies such as noticing frequency/repetition of words, selecting words for attention, and noticing in other contexts because of the sheer volume of language they are encountering and processing. 
Researchers (Chatfield, 2010b; Gee, 2007a, 2007b, 2008; McGonigal, 2010; Oxford, 2009; Sykes, et al., 2008) agree that MMORPGs are highly motivating environments. Participants explained that because MMORPGs are so motivating, MMORPGs affect how they learn and use learning strategies, especially when compared to traditional classroom learning environments. Tuah describes how relevant the learning is in MMORPGs, how motivated he feels in MMORPGs, and the intense level of concentration he achieves in MMORPGs. He alludes to achieving a state of flow (Csikszentmihalyi, 1992) while playing MMORPGs.

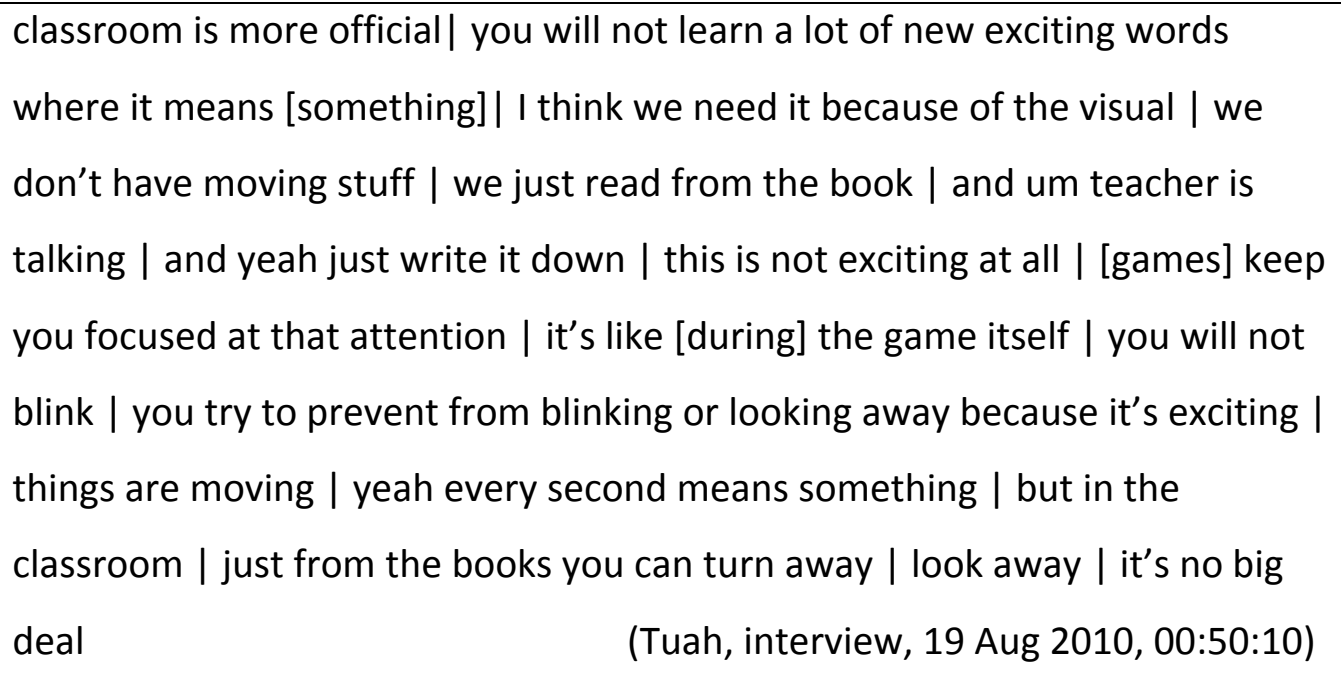

Motivation is attributed as a key factor for the success or failure of learning (Deci, 1975; R. Gardner, 1985; Maslow, 1970; Weiner, 1986) and second language acquisition (Dörnyei, 2001b; Dörnyei \& Ushioda, 2009). However, it appears that in MMORPGs the learner does not need to use strategies to manage their motivation. Instead, the gaming environment provides motivation for learning English words, and removes responsibly from individual learners to manage their motivation.

\subsection{Comparison with Gu's (2005) model}

Gu (2005) presents a model to show factors that affect learners' vocabulary learning strategies, which can be adapted to illustrate the findings of this study.

Gu maintains that only after analyzing the learning task and context, and available resources, do learners select, plan, use, monitor, and evaluate strategies to improve language learning. Gu asserts that vocabulary learning is affected by first the learning context and then the strategies that learners' use for specific tasks. 
Figure 4-7 Gu (2005) model

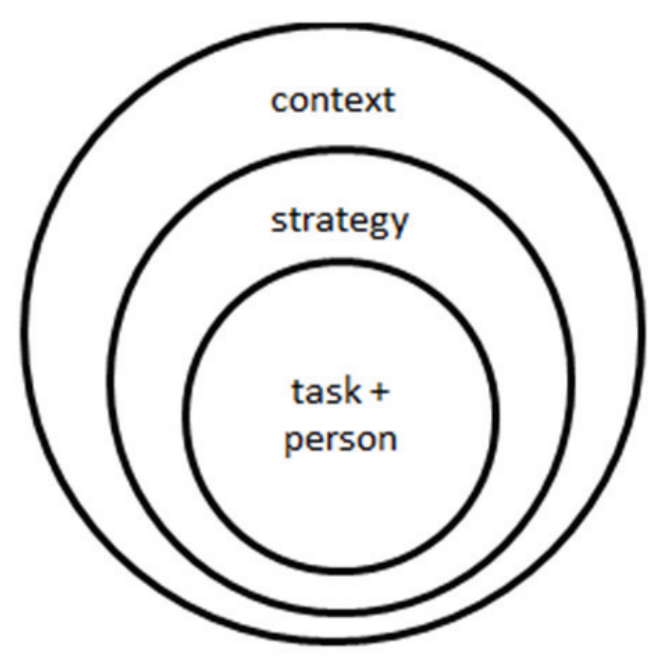

Gu (2005) defines context as the learning environment and culture, and opportunities for language input and output; explains that learners are affected by their prior knowledge, attitudes, and motivation; and states that tasks vary in type, complexity, difficulty, and generalability.

In general, I agree with Gu's (2005) model; however, I have adapted Gu's (2005) model to show specifically how MMORPGs affect learners' vocabulary learning strategies. These are the main differences between Gu's original model and my adaptation of his model.

- In MMORPGs learners do not take responsibility for or manage their motivation with any learning strategy. Therefore, instead of learners affecting their motivation, the MMORPG context affects learners' motivation removing the need for a motivational learning strategy.

- In MMORPGs an in-game cultural norm facilitates playful and creative language use. Therefore instead of learners affecting their attitude to language use, the MMORPG culture affects their language use, which in turn affects the strategies learners use.

Figure 4-8 "Adaptation of Gu's (2005) model for MMORPG context" shows an integration of Gu's (2005) model with the findings that emerged from this study. 
Figure 4-8 Adaptation of Gu's (2005) model for MMORPG context

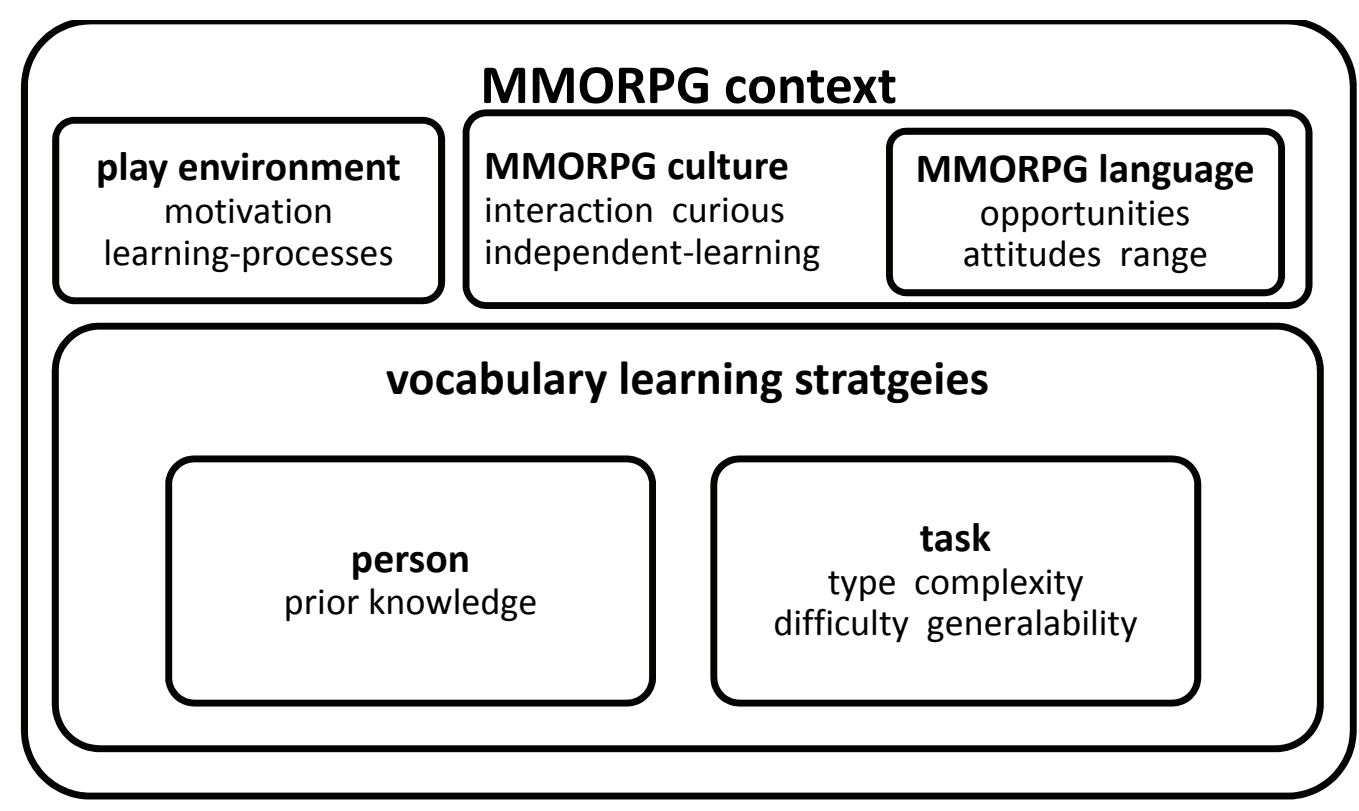

MMORPGs as second language learning contexts must take into account the play environment, MMORPG culture and MMORPG language use. These aspects of MMORPGs affect the vocabulary learning strategies that learners use in MMORPGs.

The play environment affects learners' motivation and learning processes. The MMORPG culture affects learners' interaction opportunities, levels of curiosity, and desire to learn independently. MMORPG language affects learners' opportunities to use language, the range of language learners' encounter, and learners' attitude to language.

Learners use a broad range and combinations of vocabulary learning strategies in MMORPGs. However, the question remains whether learners can transfer the use of vocabulary learning strategies to other contexts in real-life. Steinkuehler (2007a) and Delwiche (2006) conclude that learners can and do transfer learning from virtual-life to real-life. However, no participants in this study reported that they use MMORPG vocabulary learning strategies in other contexts and only two participants reported that they use words learned in MMORPG in the real-world. 
it is a word I learned and then I can use it in | I do yeah | it's like what we do | in real life (Tuah, interview, 19 Aug 2010 00:43:42) and you feel some word is quite interesting | use it in your real life (Tao, interview, 17 Aug 2010 00:12:05)

These reports of transfer of learning from a virtual-world to the real-world is not enough evidence to make any claims, but is enough show that it warrants further investigation.

\subsection{Conclusion}

Participants reported 15 strategies that they use or recommend others use in MMORPGs. Participants used vocabulary learning strategies in a variety of ways and combinations.

The MMORPG context affects participants' use of these vocabulary learning strategies. The aspects of the context that affect participants' vocabulary learning strategies are the MMORPG language and culture, and play.

Participants played MMORPGs to play, not to learn language. However, the participants need vocabulary to play MMORPGs, and MMORPGs provide rich vocabulary learning contexts. All participants were aware of vocabulary learning strategies that they used, and developed and used vocabulary learning strategies that suit the MMORPG context.

MMORPGs surrounded the participants with a wide variety of language (from advanced technical terms to non-standard chat) and opportunities for meaning focused communication. The accepted use of non-standard, creative and playful, language allowed the participants to develop and use vocabulary learning strategies that suit these relaxed language norms.

MMORPGs have an in-game culture. Gaming norms include cooperative interaction and also encourage autonomous learning. The participants developed, selected and used vocabulary learning strategies that use both the interactive qualities and autonomous learning qualities of MMORPG contexts. 
MMORPGs are incredibly motivating. The participants did not manage their motivation. The urgency to learn vocabulary is high and the participants developed and used vocabulary learning strategies to learn vocabulary as fast as possible.

This chapter presented the results and discussion. The next chapter is the conclusion and describes limitations, and suggests learning implications and further research. 


\section{CONCLUSION}

\subsection{Introduction}

This chapter describes the limitations of this study. It also presents implications for use, learning and transfer of vocabulary strategies and suggestions for further research

\subsection{Limitations}

This small scale study includes limitations. Collecting data from only a few participants limits generalizability. A broader range of participants that included females and people over 30 would have improved this study. Also, further data collection from criterion samples to allow further patterns and processes to emerge from constant comparative analysis would have provided more evidence to support the claims suggested from these results and could have led to the development of a theory, rather than merely revealing areas requiring further study.

During observations, participants' normal gaming behaviour may have been affected by the presence of observers, being filmed, and the unfamiliar computer and room. Many vocabulary learning strategies cannot be observed. Participants' reflection and recall of vocabulary learning strategies in MMORPGs may have been improved if they could all have played their usual MMORPG immediately before being interviewed. The addition of further criterion samples who participated in a think-aloud protocol would allow further triangulation of the data, improving the reliability and validity of the results.

Learners may be unreliable reporters of their own strategy use and may have forgotten strategies that have become more automatic and less conscious processes. Participants' responses during interviews may have been affected by the interviewer unconsciously imposing their own ideas. A team of interviewers working together and discussing their findings and interpretations could have improved the results. Student participants may have given 'correct' responses, rather than honest responses to please the researcher, who may have been identified by students as a teacher. Using trained interviewers who were a similar age to the student participants may have improved this. Also completing the interviews in the participants' first languages, instead of English, could have improved the quality of their responses and ability to 
explain complex ideas; however, translation services were beyond the financial resources of this project.

Also, coding could be biased by personal preconceptions of the researcher; however, inter-rater checking and member checking were utilized to minimize this effect.

This study used processes that were inherent to Grounded Theory but was not a Grounded Theory study. A Grounded Theory study continues a process of data collection and constant comparative analysis until a point of saturation is reached, but this small-scale study limited participant numbers, and the duration of data collection and analysis.

\subsection{Implications}

This study shows gamers develop, select and use a range of vocabulary learning strategies in a variety of combinations for a broad range of purposes in MMORPGs. Participants of this study appear to be using vocabulary learning strategies effectively within MMORPGs to manage their learning autonomously, without researchers or teachers intruding or instructing them how to learn. Perhaps it would do us good to remember Rubin's (1975) advice, and focus on discovering what good language learners do, and use their successful practices to shape our teaching practices and formal learning contexts. Teachers should encourage gamers to share their experiences of vocabulary learning within MMORPGs with other learners to raise learners' awareness of the variety of vocabulary learning strategies and encourage learners to critically examine of the effectiveness of these strategies in a variety of contexts.

The effects of digital games are often portrayed negatively by the media (Chatfield, 2010b; Gee, 2007b; Mäyrä, 2008; McGonigal, 2010; Prensky, 2006; Rankin, 2008; Williams, 2006b; Yee, 2003-2006). However, teachers need to dispel these negative myths and inform learners about how vocabulary learning strategies can be used in MMORPGs to help the learning of English words. Teachers already encourage the use of passive media such as reading newspapers and watching TV for vocabulary learning, and this encouragement needs to be extended to interactive media such as MMORPGs. As people decrease their use of passive media and increase their use of interactive media, teachers need to ensure learning experiences remain relevant and 
meaningful to learners by including examples of interactive media in learning experiences. For many learners, information about how MMORPGs can be used to help vocabulary learning may be valuable and empowering.

Teachers should also raise gamers' awareness of the vocabulary learning strategies they use in MMORPGs. Gamers should be helped to transfer vocabulary learning strategies they develop and use within MMORPGs to other vocabulary learning contexts. Also teachers could have gamers teach the vocabulary learning strategies they use in MMORPGs to other non-gaming learners for use in other vocabulary learning contexts.

MMORPGs could be used in formal learning contexts. However, DeKoven (1992) and Squire (2005) warn that educators need to be careful that using games in schools does not destroy the qualities of play that make them so engaging (DeKoven, 1992; Squire, 2005). Teachers need to be aware that inherent aspects of the play context (e.g. voluntary, purposeless) may be lost when used in formal learning contexts. Loss of inherent aspects of play could affect learners' use of vocabulary learning strategies in MMORPG contexts.

\subsection{Suggestions for further research}

This study skims the surface of many aspects of MMORPGs as contexts for vocabulary learning strategies. Many ideas for further research to explore the effects of aspects of MMORPG contexts on language learning, vocabulary learning, and learning strategies and vocabulary learning strategies are yet to be explored.

Context has been identified as affecting vocabulary learning strategies. However, previous research has compared English as second language environments with English as foreign language environments. Perhaps formal and informal environments could be compared, or work and play environments, or learning from passive (e.g. TV) and interactive media (e.g. game), or from environments that use slow or fast communication.

Research could investigate the impact digital communication is having on vocabulary learning strategies. How do moving and stationary images and texts affect vocabulary learning strategies? How does chat interaction affect vocabulary learning strategies? 
How does code mixing and switching in MMORPGs affect vocabulary learning strategies?

Ways in which MMORPG culture affects vocabulary learning strategies could be explored. How do hierarchical structures between gamers affect vocabulary learning strategies? How does playing alone or playing collaboratively affect vocabulary learning strategies? How does the use of and attitude towards MMORPG language affect vocabulary learning strategies? Why do gamers use words before understanding them? What factors lower learners' learning anxiety in MMORPGs? How do MMORPG cultural beliefs about learning affect vocabulary learning strategies? Why is motivation attributed to individual learners, instead could it be an inherent part of the learning context? MMORPG language as a variety of English could be explored. How does use of this variety affect users learning and use of Standard English and vocabulary learning strategies in other environments, e.g. academic context?

Researchers could work towards developing a taxonomy of vocabulary learning strategies that includes strategies used in formal and informal learning environments. They could explore how learners or gamers actually classify their own vocabulary learning strategies.

Vocabulary learning strategies in MMORPGs could be examined to find out which are used most frequently and which are most effective.

Are gamers learning language and words from playing MMORPGs? What words are gamers learning? How many words are gamers learning? Is learning transferred from MMORPGs to other contexts. Are vocabulary learning strategies used in MMORPGs transferred to real-life? How are vocabulary learning strategies used in virtual-life transferred to real-life?

\subsection{Conclusion}

Limitations that may have affected data collection and analysis have been identified. Teachers need to be aware that MMORPGs are valuable vocabulary learning strategy contexts, which can be used in similar ways to the reading of newspapers and the watching of TV. This study was an exploration into an uncharted area and has revealed many areas for further research. 


\section{REFERENCES}

1UP. (2004, March 12). Review: World of Warcraft: massive, both in size and quality.

Retrieved September 18, 2010, from

http://www.1up.com/do/reviewPage?cld=3137027

Ahmed, M. O. (1989). Vocabulary learning strategies. In P. Meara (Ed.), Beyond words

(pp. 3-14). London: British Association for Applied Linguistics.

Aitchison, J. (1996). Taming the wilderness: Words in the mental lexicon. In G.

Anderman \& M. Rogers (Eds.), Words, words, words: The translator and the language learner (pp. 15-26). Clevedon: Multilingual Matters.

Anis, J. (2007). Neography. In B. Danet \& S. C. Herring (Eds.), The multilingual internet:

Lnguage, culture and communication online (pp. 87-115). Oxford: Oxford University Press.

Beetham, H., \& Sharpe, R. (2007). An introduction to rethinking pedagogy for a digital age. In H. S. Beetham, R (Ed.), Rethinking pedagogy for a digital age (pp. 1-10). Abingdon, Oxon: Routledge.

Bennerstedt, U., \& Linderoth, J. (2009). The spellbound ones: Illuminating everyday collaborative gaming practices in a MMORPG. Paper presented at the Computer supported collaborative learning practices, University of the Aegean, Rhodes, Greece.

Bialystok, E. (1978). A theoretical model of second language learning. Language Learning, 28(1), 68-83.

Biklen, S. K., \& Casell, R. (2007). A practical guide to the qualitative dissertation. New York: Teachers College Press.

Blizzard Entertainment. (2004-2010). World of Warcraft: game guide Retrieved September 10, 2010, from http://www.worldofwarcraft.com/info/

Blizzard Entertainment (Producer). (2009). World of Warcraft.

Blizzard Entertainment. (2010, October 7). Press releases: World of Warcraft subscribers base reaches 12 million worldwide Retrieved October 31, 2010, from http://eu.blizzard.com/en-gb/company/press/pressreleases.html?101007

Bonk, C. (2009). The world is open: How web technology is revolutionizing education. San Francisco: Jossey-Bass. 
Brown, H. D. (2007). Principles of language learning and teaching. White Plains, NY: Pearson Education.

Brown, J. S. (2005). New learning environments for the 21st century. Forum for the Future of Higher Education. Retrieved from http://www.johnseelybrown.com/newlearning.pdf

Brown, S. (2010). Play: How it shapes the brain, opens the imagination, and invigorates the soul. New York: Penguin Group.

Bruce, T. (1994). Play, the universe and everything! In J. Moyles (Ed.), The excellence of play (pp. 255-267). Maidenhead: Open University Press.

Caillois, R. (2001). Man, play and games. Urbana, IL: University of Illinois Press.

Charmaz, K. (2006). Constructing grounded theory: A practical guide through qualitative analysis. London: Sage Publications.

Chatfield, T. (2010a). 7 ways games reward the brain. TED: Ideas worth spreading. Retrieved January 18, 2011, from http://www.ted.com/talks/tom chatfield 7 ways games reward the brain.h $\underline{\mathrm{tml}}$

Chatfield, T. (2010b). Fun Inc.: Why games are the 21st century's most serious business. London: Virgin Books.

Cohen, A. (1998). Strategies in learning and using a second language. London: Longman.

Cohen, A. (2007). Coming to terms with language learner strategies: Surveying the experts. In A. Cohen \& E. Macaro (Eds.), Language learner strategies: Thirty years of research practice (pp. 29-45). Oxford: Oxford University Press.

Cohen, A., \& Macaro, E. (Eds.). (2007). Language learner strategies: Thirty years of research and practice. Oxford: Oxford University Press.

Cohen, L., Manion, L., \& Morrison, K. (2007). Research methods in education (6th ed.). Abingdon, Oxon: Routledge.

Cole, H., \& Griffiths, M. D. (2007). Social interactions in massively multiplayer online role-playing gamers. CyberPsychology \& behavior, 10(4), 575-583.

Collins, A., \& Halverson, R. (2009). Rethinking education in the age of technology: The digital revolution and schooling in America. New York: Teachers College Press.

Corneliussen, H. G., \& Rettberg, J. W. (2008). Introduction: "Orc Professor LFG,"or researching an Azeroth. In H. G. Corneliussen \& J. W. Rettberg (Eds.), Digital 
culture, play, and identity: A World of Warcraft ${ }^{\circledR}$ reader (pp. 1-15). Cambridge, MA: MIT Press.

Coxhead, A. (1998). An Academic Word List. ELI Occasional Publications \#18.

Wellington: School of Linguistics and Applied Language Studies, Victoria University of Wellington.

Coxhead, A. (2006). Essentials of teaching academic vocabulary. Boston, MA: Thomson Heinle.

Coxhead, A. (2009, March 1). [Personal communication: Student reports during the study "How big is your vocabulary?" at Victoria University of Wellington ].

Craik, F., \& Lockhart, R. (1972). Levels of processing: A framework for memory research. Journal of verbal learning and verbal behaviour, 11, 671-684.

Crystal, D. (2006). Language and the internet. Cambridge: Cambridge University Press.

Csikszentmihalyi, M. (1992). Flow: The classical work on how to achieve happiness. London: Rider Books.

Csikszentmihalyi, M. (1997). Finding flow: the psychology of engagement with everyday life. New York: Basic Books: Perseus Books Group.

Darhower, M. (2002). Interactional features of synchronous computer-mediated communcation in the intermediate L2 class: A sociocultural case study. CALICO Journal, 19(2), 249-277.

Deci, E. (1975). Intrinsic motivation. New York: Plenum Press.

deHaan, J. (2005). Learning language through video Games: A theoretical framework, an evaluation of game genres and questions for future research. In S. Schaffer \& M. Price (Eds.), Interactive convergence: Critical issues in multimedia (Vol. 10, pp. 229-239). Retrieved from http://www.inter-disciplinary.net/publishingfiles/idp/eBooks/Interactive\%20Convergence\%201.6.pdf.

DeKoven, B. (1992). Of fun and flow Retrieved November 30, 2010, from http://www.deepfun.com/funflow.htm

Delwiche, A. (2006). Massively multiplayer online games (MMOGs) in the new media classroom. Education Technology \& Society, 9(3), 160-172.

Denscombe, M. (2007). The good research guide for small-scale social research projects (3rd ed.). Maidenhead, Berkshire: Open University Press.

Denscombe, M. (2010). Ground rules for social research: Guidelines for good practice (2nd ed.). Maidenhead, Berkshire: Open University Press. 
Dörnyei, Z. (2001a). Motivational strategies in the language classroom. Cambridge: Cambridge University Press.

Dörnyei, Z. (2001b). Teaching and researching motivation. Harlow, Essex: Pearson Education.

Dörnyei, Z. (2007). Research methods in applied linguistics. Oxford: Oxford University Press.

Dörnyei, Z., \& Ushioda, E. (Eds.). (2009). Motivation, language identity and the LS self. Bristol: Multilingual Matters.

Duncan, J., \& Lockwood, M. (2008). Learning through play: A work-based approach for the Early Years professional. London: Continuum.

Ellis, N. (1994). Consciousness in second language learning: Psychological perspectives on the role of consciousness in vocabulary acquisition. AILA Review, 11, 37-56.

Ellis, R. (1994). The study of second language acquisition. Oxford: Oxford University Press.

Fan, M. Y. (2003). Frequency of use, perceived usefulness, and actual usefulness of second language vocabulary strategies: A study of Hong Kong learners. The Modern Language journal, 87(2), 222-241.

Forman, J. (2003). Next-generation: Education technology verusu the lecture. Educational Review, July/August, 12-22.

Frank, I., Sanbou, N., \& Terashima, K. (2006, June 14-16). Some positive effects of online gaming. Paper presented at the ACE, Hollywood. CA.

Gamespot. (2010). Blizzard Entertainment announces Russian-language version of World of Warcraft Retrieved January 15, 2011, from http://www.gamespot.com/news/6183897.html

Gardner, H. (2000). Intelligence reframed: Multiple intelligences for the 21st century. New York: Basic Books.

Gardner, R. (1985). Social psychology and second language learning: The role of attitudes and motivation. London: Edward Arnold.

Gass, S. M. (1977). Input, interaction and the second language learner. Mahwah, NJ: Lawrence Erlbaum Associates.

Gass, S. M., \& Selinker, L. (1994). Second language acquisition. Hillsdale, NJ: Lawrence Erlbaum Associates. 
Gee, J. P. (2007a). Good video games + good learning: Collected essays on video games, learning and literacy (Vol. 27). New York: Peter Lang.

Gee, J. P. (2007b). What video games have to teach us about learning and literacy. New York: Palgrave Macmillan.

Gee, J. P. (2008). Good videogames, the human mind, and good learning. In T. Willoughby \& E. Wood (Eds.), Children's learning in a digital world (pp. 40-61). Oxford: Blackwell Publishing.

Gibson, D., Aldrich, C., \& Prensky, M. (2007). Games and simulations in online learning: Research development frameworks. Hershey, PA: Information Science Publishing.

Glaser, B. (1978). Theoretical sensitivity. Mill Vallley, CA: The Sociology Press.

Glaser, B., \& Strauss, A. (1967). The discovery of Grounded Theory. Chicago: Aldine. Godwin-Jones, R. (2005). Emerging technologies: Messaging, gaming, peer-to-peer sharing: Language learning strategies and tools for the Millennial Generation. Language Learning \& Technology, 9(1), 17-22.

Goodwin-Jones, R. (2005). Emerging technologies: Messaging, gaming, peer-to-peer sharing, language learning strategies and tools for the millennial generation. Language, learning \& technology, 9(1), 17-22.

Gordon, G., \& Esbjorn-Hargens, S. (2007). Are we having fun yet? An exploration of the transformative power of play. Journal of Humanistic Psychology, 47(2), 198222.

Graham, S. (1997). Effective language learning: Positive strategies for advanced level language learning. Clevedon: Multilingual Matters.

Griffiths, C. (Ed.). (2008). Lessons from good language learners. Cambridge: Cambridge University Press.

Gu, P. Y. (2003a). Fine brush and freehand: The vocabulary-learning art of two successful Chinese EFL learners TESOL Quarterly, 37(1), 73-104.

Gu, P. Y. (2003b). Vocabulary learning in a second language: Person, task, context and strategies. TESL-EJ, 7(2), A-4.

Gu, P. Y. (2005). Vocabulary learning strategies in the Chinese EFL context. Singapore: Marshall Cavendish Academic.

Gu, P. Y., \& Johnson, K. R. (1996). Vocabulary learning strategies and language learning outcomes. Language Learning, 46(4), 643-679. 
Harmer, J. (2007). The practice of English language teaching (4th ed.). Harlow, Essex: Pearson Education.

Hatch, E., \& Brown, C. (1995). Vocabulary, semantics, and language education. Cambridge: Cambridge University Press.

Hirsh, D. (2010). Researching vocabulary. In B. Paltridge \& A. Phakiti (Eds.), Continuum companion to research methods in applied linguistics (pp. 222-239). London: Continuum.

Huizinga, J. (1950). Homo ludens: A study of the play element in culture. New York: Roy Publishers.

Joinson, A., McKenna, K., Postmes, T., \& Reips, U. (2007). The Oxford Handbook of Internet Psychology. Oxford: Oxford University Press.

Jurković, V. (2006). Vocabulary learning strategis in an ESP context. Journal of Slovene Association of LSP Teachers, 2(1), 1-9.

Kasavin, G. (2004, November 29). Gamespot: World of Warcraft review Retrieved September 18, 2010, from

\section{http://www.gamespot.com/pc/rpg/worldofwarcraft/review.html}

Klastrup, L. (2003). A poetics of virtual worlds. Paper presented at the Digital Arts and Culture, Melbourne. http://hypertext.rmit.edu.au/dac/papers/Klastrup.pdf

Kojic-Sabo, I., \& Lightbrown, M. (1999). Students' approaches to vocabulary learning and their relationship to success. Modern Language Journal, 83, 176-192.

Kolb, D. (1984). Experiential learning. Englewood Cliffs, NJ: Prentice Hall.

Koster, R. (2005). A theory of fun for game design. Scottsdale, AZ: Paraglyph Press.

Kudo, Y. (1999). L2 vocabulary learning strategies. University of Hawai'i, Honolulu. Retrieved from http://faculty.ksu.edu.sa/Magda/My\%20Research\%20Library/ESL/article\%5D.p $\underline{\mathrm{df}}$

Laufer, B. (1997). What's in a word that makes it hard or easy: Some intralextical factors that affect the learning of words. In N. Schmitt \& M. McCarthy (Eds.), Vocabulary: Description, acquisition and pedagogy (pp. 140-155). Cambridge: Cambridge University Press.

Laufer, B., \& Hulstijn, J. (2001). Incidental vocabulary acquistion in a second language: The construct of task-induced involment. Applied Linguistics, 22(1), 1-26. 
Lave, J., \& Wenger, E. (1991). Stiuated learning: Legitimate peripheral participation (Learning in doing: Social cognitive and computational prespectives. Cambridge: Cambridge University Press.

Lawson, M. J., \& Hogben, D. (1996). The vocabulary-learning strategies of foreignlanguage students. Language Learning, 46(1), 101-135.

Leeke, P., \& Shaw, P. (2000). Learners' independent records of vocabulary. System, 28, 271-289.

Lemay, P. (2007). Developing a pattern language for flow experiences in video games. Paper presented at the Situated play: DiGRA 2007 Conference, Tokyo.

Lessard-Clouston, M. (1996). ESL vocabulary learning in a TOEFL preparation class: A case study. Modern Language Review, 53, 97-119.

Linden Lab (Producer). (1999-2009). Second Life.

Locastro , A. (1994). Learning strategies and learning environments TESOL Quarterly, 28(2), 409-414.

MacCallum-Stewart, E., \& Parsler, J. (2009). Role-play vs. gameplay: The difficulties of playing a role on Workld of Warctaft. In H. G. Corneliussen \& J. W. Rettberg (Eds.), Digital culture, play, and identity: A World of Warcraft ${ }^{\circledR}$ reader (pp. 226246). Cambridge, MA: MIT Press.

Mackey, A., \& Gass, S. M. (2005). Second language research: Methodology and design. Mahwah, NJ: Lawrence Erlbaum Associates, Inc.

Maslow, A. (1970). Motivation and personality (2nd ed.). New York: Harper \& Row.

Mason, R., \& Rennie, F. (2008). E-learning and social network handbook: Resources for higher education. New York: Routledge.

Mäyrä, F. (2008). An introduction to game studies: Games in culture. Los Angeles, CA: Sage Publications.

McCarthy, M. (1984). A new look at vocabulary in EFL. Applied Linguistics, 5, 12-22.

McDonough, J., \& McDonough, S. (1997). Research methods for English language teachers. London: Hodder Arnold.

McGonigal, J. (2010, February). Gaming can make a better world Paper presented at the Ted Conferences, Longbeach, CA.

McGonigal, J. (2011). Reality is broken: Why games make us better and how they can change the world. London: Jonathan Cape. 
McNamara, T. (2004, December 10). World of Warcraft review: Blizzard does it again Retrieved November 22, 2010, from http://uk.pc.ign.com/articles/572/572070p1.html

Meara, P. (1980). Vocabulary acquisition: A neglected aspect of language learning. Language teaching and linguistics abstracts, 13, 221-246.

Meara, P. (1996). The classical research in L2 vocabulary acquistion. In G. Anderman \& M. Rogers (Eds.), Words, words, words: The translator and the language learner (pp. 27-40). Clevedon: Multilingual Matters.

Mitchell, R., \& Myles, F. (2004). Second language learning theories (2nd ed.). London: Hodder Arnold.

Montessori, M. (2003). The Montessori method. New York: Barnes \& Noble Publishing. Mortensen, T. E. (2009). Humans playing World of Warcraft: Or deviant strategies? In H. G. Corneliussen \& J. W. Rettberg (Eds.), Digital culture, play, and identity: A World of Warcraft ${ }^{\circledR}$ reader (pp. 205-223). Cambridge, MA: MIT Press.

Moyles, J. (1994). Introduction. In J. Moyles (Ed.), The excellence of play (pp. 1-12). Maidenhead: Open University Press.

Nardi, B., \& Harris, J. (2006). Stranger and friends: Collaborative play in World of Warcraft. Paper presented at the 20th anniversary conference on Computer supported cooperative work, Banff, Alberta, Canada.

Nation, P. (1990). Teaching and learning vocabulary. Boston, MA: Heinle \& Heinle Publishers.

Nation, P. (2001). Learning vocabulary in another language. Cambridge: Cambridge University Press.

Nation, P. (2007). The four strands. Innovation in language learning and teaching, 1(1), $1-12$.

Nation, P. (2008). Teaching vocabulary: Strategies and techniques. Boston: Heinle Cengage Learning.

Nation, P., \& Gu, P. Y. (2007). Focus on vocabulary. Sydney: National Centre for English Language Teaching and Research, Macquarie University.

North, S. (2007). 'The voices, the voices': Creativity in online conversation. Applied linguistics, 28(4), 538-555.

Nyikos, M., \& Fan, M. (2007). A review of vocabulary learning strategies: Focus on language proficiency and learner voice. In A. Cohen \& E. Macaro (Eds.), 
Language learner strategies: Thirty years of research practice. Oxford: Oxford University Press.

O'Malley, J. M., \& Chamot, A. U. (1990). Learning strategies in second language acquisition. Cambridge: Cambridge University Press.

Opie, I., \& Opie, P. (1984). Children's games in street and playground. Oxford: Oxford Paperback.

Ortega, L. (2009). Understanding second language acquisition. London: Hodder Education.

Oxford, R. (1990). Language learning strategies: What ever teacher should know. Boston: Newbury House.

Oxford, R. (1993). Language learning strategies in a nutshell: Update and ESL suggestions. TESOL Journal, 2(2).

Oxford, R. (1996). Language learning strategies around the world: Cross-cultural perspectives. Honolulu: University of Hawai'i Press.

Oxford, R. (2009). Navigating White Water: The digital age and sensory learning styles. Paper presented at the DigitalStream conference on emerging technologies in teaching languages and culture, Monterey Bay, CA.

Oxford, R., \& Lee, K. R. (2007). L2 grammar strategies: the Second Cinderella and beyond. In A. Cohen \& E. Macaro (Eds.), Language learner strategies (pp. 117140). Oxford: Oxford University Press.

Oxford University Press. (2010). Oxford Advanced Learner's Dictionary. Retrieved from http://www.oxfordadvancedlearnersdictionary.com/

Pearce, C. (2006). Players, games \& culture. Paper presented at the Medi@terra Festival and Symposium,, Athens.

\section{http://www.ludica.org.uk/PearceMediaterra06.pdf}

Pearce, C., \& Artemesia. (2009). Communities of play: Emergent cultures in multiplayer games and virtual worlds. Cambridge, MA: The MIT Press.

Piaget, J. (1962). Play, dreams, and imitation in childhood. New York: Norton.

Piirainen-Marsha, A., \& Tainiob, L. (2009). Collaborative game-play as a site for participation and situated learning of a second language. Scandinavian Journal of Educational Research, 53(2), 167-183.

Prensky, M. (2006). "Don't bother me mom-I'm learning!". St Paul, MN: Paragon House. 
Purushotma, R. (2005). Commentary: You're not studying, you're just... Language, learning \& technology, 9(1), 80-96.

Rankin, Y. A. (2008). Design and evaluation of Massive Multiplayer Online Role Playing Games that facilitate second language acquisition Ph.D. Ph.D. dissertation, Northwestern University, Illinois. Retrieved from

http://proquest.umi.com/pqdweb?did=1642934221\&Fmt $=2 \&$ clientld $=7511 \& R$ $\underline{Q T=309 \& V \text { Name }=P Q D}$ ProQuest database.

Rankin, Y. A., Gold, R., \& Gooch, B. (2006). Evaluating interactive gaming as a language learning tool. Paper presented at the SIGGRAPH, Boston, MA.

Rankin, Y. A., McNeal, M., Shute, M. W., \& Gooch, B. (2008). User centered game design: Evaluating Massive Multiplayer Online Role Playing Games for second language acquisition. Paper presented at the ACM SIGGRAPH '08 Sandbox, Los Angeles, CA.

Rankin, Y. A., Morrison, D., McNeal, M., Gooch, B., \& Shute, M. W. (2009, April 26-30, 2009). Time will tell: In-game social interactions that facilitate second language acquisition. Paper presented at the 4th International Conference on Foundations of Digital Games, Port Canaveral, FL.

Relic Entertainment (Producer). (2004). Warhammer 4000: Dwan of War.

Rettberg, J. W. (2009). Quests in World of Warcraft: Defferral and repetition. In H. G. Corneliussen \& J. W. Rettberg (Eds.), Digital culture, play, and identity: A World of Warcraft ${ }^{\circledR}$ reader (pp. 168-184). Cambridge, MA: MIT Press.

Rettberg, S. (2009). Corporate identity on World of Warcraft. In H. G. Corneliussen \& J. W. Rettberg (Eds.), Digital culture, play, and identity: A World of Warcraft ${ }^{\circledR}$ reader (pp. 20-38). Cambridge, MA: MIT Press.

Robinson, P. J. (1989). A rich view of lexical competence. ELT Journal, 43, 274-282.

Rubin, J. (1975). What the "good language learner" can teach us. TESOL Quarterly, 9(1), 41-51.

Rubin, J. (1981). Study of cognitive processes in second language learning. Applied linguistics, 2(2), 117-131.

Sanaoui, R. (1995). Adult learners' approach to learning vocabulary in second languages. Modern Language Journal, 79(1), 15-28. 
Schmitt, N. (1997). Vocabulary learning strategies. In N. Schmitt \& M. McCarthy (Eds.), Vocabulary: Description, acquisition and pedagogy (pp. 199-227). Cambridge: Cambridge University Press.

Schmitt, N. (2000). Vocabulary in language teaching. Cambridge: Cambridge University Press.

Schmitt, N. (2010). Researching vocabulary: A vocabulary research manual. New York: Palgrave Macmillan.

Schmitt, N., \& Mcarthy, M. (1997). Vocabulary description, acquisition and pedagogy. Cambridge: Cambridge University Press.

Seay, A. F., \& Kraut, R. E. (2007, April 28-May 3). Project massive: Self-regulation and problematic use of online gaming. Paper presented at the Human Factors in Computer Systems - The Computer-Human Interaction (CHI) Conference, San Jose, $\mathrm{CA}$.

Shen, C., \& Williams, D. (2010a). Unpacking time online: connecting internet and MMO use with psychosocial well-being. Retrieved from

\section{http://dmitriwilliams.com/Unpacking.pdf}

Shen, C., \& Williams, D. (2010b). Unpacking time online: Connecting internet and MMO use with psychosocial well-being. Communication Research. Retrieved from http://dmitriwilliams.com/Unpacking.pdf

Smith, B. (2003). Computer-mediated negotiated interaction: An expanded model. Modern Language Journal, 81, 38-57.

Squire, K. (2005). Changing the game: What happens when video games enter the classroom? Innovate, 1(6). Retrieved from http://innovateonline.info/pdf/vol1 issue6/Changing the GameWhat Happens When Video Games Enter the Classroom .pdf

Squire, K. (2006). From content to context: Video games as designed experiences. Educational Researcher, 35(8), 19-29.

Steinkuehler, C. (2004). Learning in massively multiplayer online games. Paper presented at the Sixth International Conference of the Learning Sciences, Mahwah, NJ.

Steinkuehler, C. (2007a). Massively multiplayer online games and education: An outline of research. Paper presented at the 8th international conference on computer supported collaborative learning, New Brunswick, NJ. 
Steinkuehler, C. (2007b). Massively multiplayer online gaming as a constellation of literacy practices. eLearning, 4(3), 297-318. Retrieved from http://website.education.wisc.edu/steinkuehler/papers/Steinkuehler edtech.p df

Steinkuehler, C., \& Squire, K. (2009). Virtual worlds and learning. On The Horizon, 17(1), 8-11.

Steinkuehler, C., \& Williams, D. (2006). Where everybody knows your (screen) name: Online games as "Third Places". Journal of Computer-Mediated Communication, 11(4). Retrieved from http://jcmc.indiana.edu/vol11/issue4/steinkuehler.html

Stern, H. H. (1975). What can we learn from the good language learner. Canadian Modern Language Review, 31, 301-318.

Stern, H. H. (1986). Fundamental concepts of language teaching. Oxford: Oxford University Press.

Stoffer, I. (1997). University foreign language students' choice of vocabulary learning strategies as related to individual difference variables. Unpublished doctoral dissertation. University of Alabama.

Sutton-Smith, B. (1997). The ambiguity of play. Cambridge, MA: Harvard University Press.

Sykes, J., Oskoz, A., \& Thorne, S. (2008). Web 2.0, synthetic immersive environments and mobile resources for language education. CALICO Journal, 25(3), 528-546.

Sykes, J., Reinhardt, J., \& Sauro, S. (Producer). (2010, 22 March). Episode 4: Massively multiplayer online games (MMOGs) and language learning. the CALLspot. [Interview] Retrieved from http://callspot.libsyn.com/

Takač, V. P. (2008). Vocabulary learning strategies and foreign language acquisition. Toronto: Multilingual Matters.

Tao, T. (2006). An investigation into vocabulary learning strategies used by non-English majors. CELEA Journal, 29(2), 27-33.

Tarone, E. (1981). Some thoughts on the notion of communication strategy. TESOL Quarterly, 15(3), 285-295.

Thorne, S. (2006). New technologies and additional language learning. (CALPER Working Paper Series, No. 7). Pennsylvania State University: Centre for Advanced Language Proficiency Education and Research. 
Thorne, S. (2008). Transcultural communication in open Internet environments and massively multiplayer online games. In S. Magnan (Ed.), Mediating discourse online (pp. 305-327). Amsterdam: John Benjamins Publishing.

Thorne, S., \& Payne, J. (2005). Evolutionary trajectories, internet-mediated expression, and language education. CALICO Journal, 22, 371-397.

Thorsen, T. (2009, July 31). Gamespot: US game population: 170 million - NPD Retrieved November 30, 2010, from http://www.gamespot.com/news/6214598.html

Tseng, W.-T., Dörnyei, Z., \& Schmitt, N. (2006). A new approach to assessing strategic learning: The case of self-regulation in vocabulary acquistion. Applied Linguistics, 27(1), 78-102.

Turgut, Y., \& İrgin, P. (2009). Young learners' language learning via computer games. Procedia Social and Behavioral Sciences, 1, 760-764.

University of Twente students (2010, January 7). [Personal communication: Student reports during research project into Language Learner Strategies used for academic writing for Victoria University of Wellington MA course Learner Autonomy and Learner Strategies].

Vygotsky, L. S. (1978). Mind in society: The development of higher psychological processes. Cambridge, MA: Harvard University Press.

Weiner, B. (1986). An attribution theory of motivation and emtion. New York: Springer.

Wenger, E. (1998). Communities of practice: Learning, meaning, and identity. Cambridge: Cambridge University Press.

West, M. (1953). A general service list of English words. London: Longman.

Williams, D. (2006a). A brief social history of game play. In P. Vorderer \& J. Bryant (Eds.), Playing computer games: Motives, responses, and consquences. Mahwah, NJ: Lawrence Erlbaum.

Williams, D. (2006b). Why Game Studies now? Games and culture, 1(1), 1-4. Retrieved from http://dmitriwilliams.com/WhyGameStudies.pdf

Williams, D., Caplan, S. E., \& Xiong, L. (2007). Can you hear me now? The impact of voice in an online gaming community. Human Communication Research, 33, 427-449. Retrieved from http://dmitriwilliams.com/HCRVoice.pdf 
Williams, D., Yee, N., \& Caplan, S. E. (2008). Who plays, how much, and why? Debunking the stereotypical gamer profile. Journal of Computer-Mediated Communication, 13, 999-1018.

Yee, N. (1999-2004). The Daedalus Gateway: The psychology of MMORPGs Retrieved October 17, 2009, from

http://www.nickyee.com/daedalus/gateway intro.html

Yee, N. (2003-2006). The Daedalus project: The psychology of MMORPGs Retrieved March-November, 2010, from http://www.nickyee.com/daedalus/

Yee, N. (2006a). The demographics, motivations and derived experiences of users of massively-multiuser online graphical environments. PRESENCE: Teleoperators and Virtual Environments, 15, 309-329.

Yee, N. (2006b). The labour of fun: How video games blur the boundaries of work and play. Games and culture, 1(1), 68-71.

Yee, N. (2006c). The psychology of massively multi-user online role-playing games: motivations, emotional investment, relationships and problematic usage. In $\mathrm{R}$. Schroeder \& A.-S. Axelsson (Eds.), Avatars at work and play: Collaboration and interaction in shared virtual environments (pp. 185-208). Dordrecht, The Netherlands: Springer.

Yee, N., Bailenson, J. N., \& Duchenaut, N. (2009). The Proteus Effect: The effect of transformed self-representation on online and offline behavior. Communication Research, 36(2), 285-312. Retrieved from http://www.stanford.edu/ bailenso/papers/Proteus\%20lmplications.pdf

Yee, N., Bailenson, J. N., Urbanek, M., Chang, F., \& Merget, C. (2006). The unbearable likeness of being digital: The persistence of nonverbal social norms in online virtual environments. Retrieved from http://www.nickyee.com/pubs/Yee,\%20Bailenson,\%20Urbanek,\%20Chang\%20 \&\%20Merget\%20-\%20SL\%20NonVerbal.pdf

Yu, T. W. (2009). Learning in the virtual world: The pedagogical potentials of the massively multiplayer online role playing games. International Education Studies, 2(1), 32-38.

Zheng, D., Young, M. F., Wagner, M. M., \& Brewer, R. A. (2009). Negotiation for action: English language learning in Game-Based virtual worlds. The Modern Language Journal, 93(4), 489-511. 


\subsection{Recruitment poster}

Figure

\section{Free Movie Tickets}

I need experienced

MMORPG players

(WoW, GW, FFXIV, LotRO, Aion ... )

who are

\section{non-native}

English speakers

to participate in a

research project

for one hour

contact julie.bytheway@vuw.ac.nz
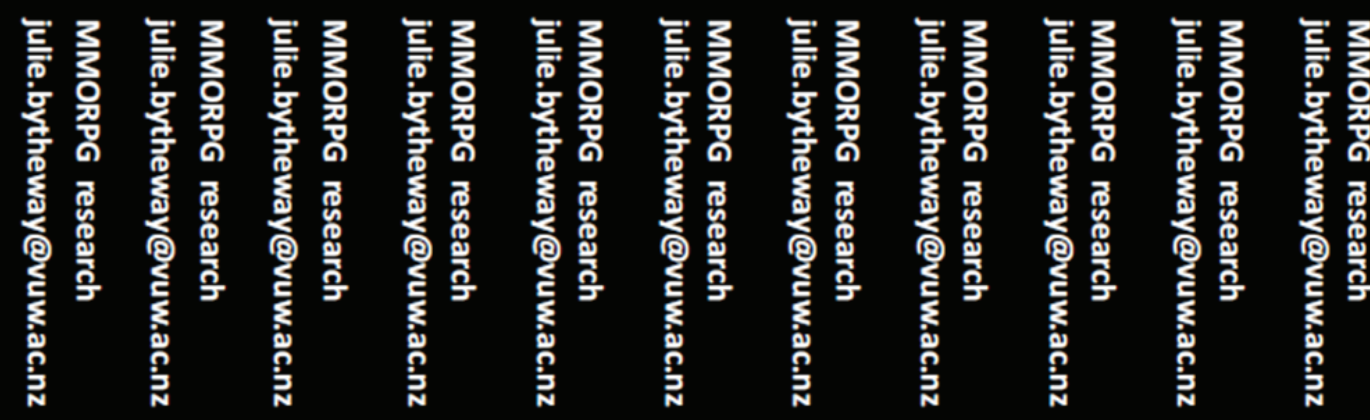


\subsection{Ethics application}

\section{VICTORIA UNIVERSITY OF WELLINGTON \\ Te Whare Wananga o te Upoko o te lka a Maui

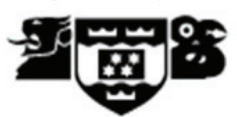

HUMAN ETHICS COMMITTEE

Application for Approval of Research Projects

Please write legibly or type if possible. Applications must be signed by supervisor (for student projects) and Head of School

Note: The Human Ethics Committee attempts to have all applications approved within three weeks but a longer period may be necessary if applications require substantial revision.

\section{NATURE OF PROPOSED RESEARCH:}

(a) Staff Research

(b) If Student Research

Student Research $\square \quad$ (tick one)

(c) Project Title: Vocabulary Learning Strategies in Massively Multiplayer Online Games (MMOGs)

\section{INVESTIGATORS:}

(a) Principal Investigator

Name

Julie Bytheway

e-mail address

julie.bytheway@vuw.ac.nz

School/Dept/Group

LALS

(b) Other Researchers

Name

Position

(c) Supervisor (in the case of student research projects)

Dr Averil Coxhead

Senior lecturer

3 DURATION OF RESEARCH

(a) Proposed starting date for data collection 19 July 2010

(Note: that NO part of the research requiring ethical approval may commence prior to approval being given)

(b) Proposed date of completion of project as a whole 1 February 2011 

CONSIDERATIONS

(a) Sources of funding for the project

Please indicate any ethical issues or conflicts of interest that may arise because of sources of funding

e.g. restrictions on publication of results

I will apply for a small grant of less than $\$ 130$ from the VUW FHSS Faculty Research Committee for five to eight (\$16) Reading Cinema vouchers to reimburse participants for their time.

This will cover:

1 participant $x 1$ hour observation

1 participant $x 1$ hour individual interview

3-6 participants $x 1$ hour focus group interview

i.e. maximum of 8 hours participation at $\$ 16$ per hour $=\$ 128$

(b) Is any professional code of ethics to be followed

$Y \square N \bigotimes$

If yes, name

(c) Is ethical approval required from any other body $\quad \mathrm{Y} \square \mathrm{N} \bigotimes$

If yes, name and indicate when/if approval will be given

5

DETAILS OF PROJECT

Briefly Outline:

(a) The objectives of the project

This small-scale case study will identify and explain learners' Vocabulary Learning Strategies in Massively Multiplayer Online Games (MMOGs).

MMOGs are computer games where more than 1000 players simultaneously in real-time interact in an online virtual world. Players create personal characters/avatars and control these characters/avatars with a computer keyboard and mouse or hand-held gaming-console controller. Players explore virtual worlds, complete collaborative tasks, trade items and interact for social and in-game business purposes.

b) Method of data collection

Data will be collected and stored in five ways:

1) a digital film recording of a one-hour observation of one participant playing an MMOG. Note any other characters/avatars visible on the computer screen are identified only by anonymous character/avatar names. The characters/avatars are not able to be traced back to actual players;

2) a digital audio recording of a one-hour interview with the participant who was observed;

3) a digital audio recording of a one-hour (or two one-hour) mini-focus group interview(s) with three to six participants depending on the number of respondents;

4) digital screen-shots of texts within MMOGs. According to the VUW copyright consultant, Brian McKeon, these types of texts can be used for examination (thesis) purposes without infringement 
of the Copyright Act (B. McKeon, personal communication, May 28, 2010);

5) digital text files of one or two brief emails from one to six participants to answer questions that arise during analysis of the data.

(c) The benefits and scientific value of the project

Insights gained from this study will enable teachers and learners to purposefully use popular MMOGs in practical ways to develop English vocabulary. MMOGs appear to be rich, positive learning environments for English vocabulary; however, practical ways teachers and learners can take advantage of their popularity and use them for language learning has not yet been identified or explained.

\section{(d) Characteristics of the participants}

A maximum of six participants will take part in this study. The participants will be VUW BEd (TESOL) teacher trainees who are non-native speakers of English and have played MMOGs for more than 1000 hours.

The BEd (TESOL) programme is for teacher trainees from Malaysia. These tertiary students are proficient users of English with at least the equivalent of an IELTS overall band score of 6 .

The participants need to have played MMOGs for at least 1000 hours to be familiar with all features of MMOG environments.

This cohort was chosen because BEd (TESOL) students reported vocabulary gains from playing MMOGs during Dr Averil Coxhead's 2009 study "How big is your vocabulary?" (A. Coxhead, person communication, March 1, 2010). Also, because they are TESOL teacher trainees, it is expected that they have an increased awareness of vocabulary learning strategies. .

(e) Method of recruitment

An announcement will be made on the BEd (TESOL) Blackboard site to recruit participants. This announcement will state that participants need to be non-native speakers of English and experienced MMOG players. It will also describe the study's procedures, ethical considerations, and participants' reimbursement. The study's aim will be described as identifying how languages are used in MMOGs, rather than identifying Vocabulary Learning Strategies in MMOGs, so that the observation remains as natural as possible and the participant's behaviour is not affected by knowing the specific aim of the study. At the beginning of all interviews, the participants will be informed of the study's specific focus on Vocabulary Leaming Strategies.

(f) Payments that are to be made/expenses to be reimbursed to participants

The participants will be given a Reading Cinema voucher worth $\$ 16$ in return for each hour of participation.

(g) Other assistance (e.g. meals, transport) that is to be given to participants 
(h) Any special hazards and/or inconvenience (including deception) that participants will encounter

(i) State whether consent is for:

\begin{tabular}{|ll|ll|}
\hline (i) & the collection of data & $\mathrm{Y}$ & $\mathrm{N}$ \\
\hline (ii) & attribution of opinions or information & $\mathrm{Y}$ & $\mathrm{N}$ \\
\hline (iii) & release of data to others & $\mathrm{Y} \square$ & $\mathrm{N}$ \\
\hline (iv) & use for a conference report or a publication & $\mathrm{Y}$ & $\mathrm{N}$ \\
\hline (v) $\quad$ use for some particular purpose (specify) & $\mathrm{Y} \bigotimes$ & $\mathrm{N}$ \\
\hline
\end{tabular}

The study and subsequent thesis will be submitted as part of a MA (TESOL).

Attach a copy of any questionnaire or interview schedule to the application

(j) How is informed consent to be obtained (see sections 4.1, 4.5(d) and 4.8(g) of the Human Ethics Policy)

(i) the research is strictly anonymous, an information sheet is supplied and informed consent is implied by voluntary participation in filling out a questionnaire for example (include a copy of the information sheet) $\quad \mathrm{Y} \square \mathrm{N} \bigotimes$

(ii) the research is not anonymous but is confidential and informed consent will be obtained through a signed consent form (include a copy of the consent form and information sheet) $\mathrm{Y} \bigotimes \mathrm{N} \square$

(iii) the research is neither anonymous or confidential and informed consent will be obtained through a signed consent form (include a copy of the consent form and information sheet) $\quad \mathrm{Y} \square \mathrm{N}$ \

(iv) informed consent will be obtained by some other method (please specify and provide details)

$\mathrm{Y} \square \mathrm{N}$ \

With the exception of anonymous research as in (i), if it is proposed that written consent will not be obtained, please explain why 
(k) If the research will not be conducted on a strictly anonymous basis state how issues of confidentiality of participants are to be ensured if this is intended. (See section 4..1(e) of the Human Ethics Policy). (e.g. who will listen to tapes, see questionnaires or have access to data). Please ensure that you distinguish clearly between anonymity and confidentiality. Indicate which of these are applicable.

(i) access to the research data will be restricted to the investigator

$\mathrm{Y} \square \mathrm{N}$ Q

(ii) access to the research data will be restricted to the investigator and their supervisor (student research)

$\mathrm{Y} \otimes \mathrm{N}$

(iii) all opinions and data will be reported in aggregated form in such a way that individual persons or organisations are not identifiable

Y $\triangle N$

(iv) Other (please specify)

(I) Procedure for the storage of, access to and disposal of data, both during and at the conclusion of the research. (see section 4.12 of the Human Ethics Policy). Indicate which are applicable:

(i) all written material (questionnaires, interview notes, etc) will be kept in a locked file and access is restricted to the investigator

$\mathrm{Y} \otimes \mathrm{N}$

(ii) all electronic information will be kept in a password-protected file and access will be restricted to the investigator

$\mathrm{Y} \bigotimes \mathrm{N}$

(iii) all questionnaires, interview notes and similar materials will be destroyed:
(a) at the conclusion of the research
$\mathrm{Y} \square \mathrm{N} \square$
or (b) 5 years after the conclusion of the research $\mathrm{Y} \otimes \mathrm{N}$

(iv) any audio or video recordings will be returned to participants and/or electronically wiped

$\mathrm{Y} \otimes \mathrm{N}$

(v) other procedures (please specify):

If data and material are not to be destroyed please indicate why and the procedures envisaged for ongoing storage and security 
(m) Feedback procedures (See section 7 of Appendix 1 of the Human Ethics Policy). You should indicate whether feedback will be provided to participants and in what form. If feedback will not be given, indicate the reasons why.

Participants will be able to check the accuracy of the data and initial results before publication. Also, participants will be emailed a summary or complete copy of the research report.

(n) Reporting and publication of results. Please indicate which of the following are appropriate. The proposed form of publications should be indicated on the information sheet and/or consent form.
(i) publication in academic or professional journals
$\mathrm{Y} \bigotimes \mathrm{N}$
(ii) dissemination at academic or professional conferences
$\mathrm{Y} \otimes \mathrm{N}$
(iii) deposit of the research paper or thesis in the University Library (student research)
(iv) other (please specify)

\author{
$\mathrm{Y} \otimes \mathrm{N}$
}

Because this study is a small-scale 90-point research project, according to VUW LALS regulations, it will be deposited in the VUW LALS resource room instead of the VUW Library. 
Signature of investigators as listed on page 1 (including supervisors) and Head of School.

NB: All investigators and the Head of School must sign before an application is submitted for approval

\begin{tabular}{|l|l|}
\hline & Date \\
\hline & Date \\
\hline Date \\
\hline
\end{tabular}

Head of School:

Date 


\subsection{Ethics approval}

te Whare Wananga o te opoko o te ika a máu

MEMORANDUM

Phone 0-4-4635670

Fax $\quad 0-4-4635209$

Email Allison kirkmanavuw.ac.ne

\begin{tabular}{l|l}
\hline TO & Julie Bytheway \\
\hline COPY TO & Averil Coxhead \\
\hline FROM & Dr Allison Kirkman, Convener, Human Ethics Committee \\
\hline
\end{tabular}

\begin{tabular}{l|l}
\hline DATE & 11 July 2010 \\
\hline PAGES & 1 \\
\hline
\end{tabular}

SUBJECT

Ethics Approval: No 17798 Vocabulary Learning Strategies in Massively Multiplayer Online Games

Thank you for your applications for ethical approval, which have now been considered by the Standing Committee of the Human Ethics Committee.

Your applications have been approved from the above date and this approval continues until 01 February 2011. If your data collection is not completed by this date you should apply to the Human Ethics Committee for an extension to this approval.

Best wishes with the research.

Allison Kirkman

Convener 


\subsection{Information sheet}

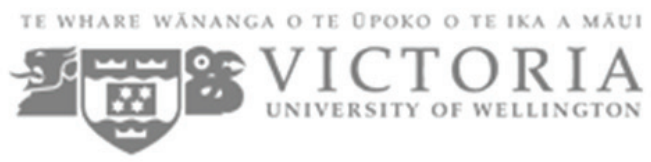

Information Sheet: How languages are used in MMOGs

Dear fellow VUW student.

My name is Julie Bytheway and I am studying how languages are used in Massively Multiplayer Online Games as part of my MA (TESOL) at Victoria University of Wellington.

This research project, which includes observations and interviews, has been approved by the VUW Human Ethics Committee. Please read this information sheet carefully.

If you participate in this research project, I will observe you for one hour while you play an MMOG and later I will interview you for one hour about how languages are used in MMOGs. I will film the observation and record the interview. Later I may email you one or two brief questions that arise during analysis of the data: please answer these if you can. I will save your replies and include them in the data.

Only Dr Averil Coxhead (my supervisor) and I will watch and listen to the recordings and we have formally agreed to keep your identity confidential. I will store the recordings as encrypted digital files with a password that only I know, and I will lock any printed data in a filing cabinet. I will destroy all the data on or before 1 July 2015. When I transcribe the data and report the findings, I will remove your name and any information that may identify you and replace it with terms that cannot identify you.

I appreciate you giving your time and sharing your ideas. For every hour you are observed or interviewed, you will get a Reading Cinema voucher for free entry into a movie.

In August 2010, I will email you the data and initial results. You may check this information to make sure it is accurate and email me your feedback. In February 2010, I will email you a summary or complete copy of the research report. This research project will be reported in my MA (TESOL) thesis. I may also publish the results in journals or present it at conferences. The data will not be used for any other purposes or by any other people.

You do not have to participate in this research: it is not a part of your studies at VUW. If you participate, you can refuse to answer any questions or stop the observation or interview at any time. Also, any time before 1 February 2011, you can have the information from the observation and/or interview destroyed and then it will not be used in any way.

If you have any questions about this research project, just ask me anytime; julie.bytheway@vuw.ac.nz ,phone 044635233 ext 7531, office MY804.

You can also contact my supervisor, Dr Averil Coxhead:

averil.coxhead@vuw.ac.nz, phone: 04463 5625, office VZ 403.

Thank you en

Julie Bytheway 


\subsection{Consent form}

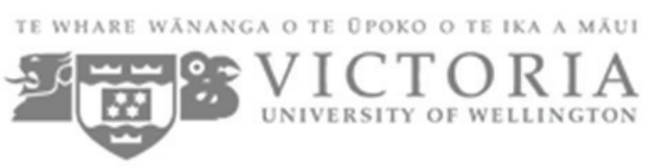

Consent Form:

How languages are used in Massively Multiplayer Online Games

If you have any questions, just ask Julie Bytheway.

Tick the boxes to show you agree with the statements.

$\square$ I have had the research project explained to me and have been able to ask questions.

I I understand the aim of research project and how data will be collected and stored.

- I understand that the results will be published as a VUW MA (TESOL) thesis and may also be published in journals and presented at conferences.

I understand that I can stop the interview or observation at any time, and that I can have data collected from me destroyed any time before 1 February 2011.

$\square$ I understand that the data collected will only be used for this research project and will not be used for any other purposes or by any other people.

$\square$ I understand that data will be destroyed on or before 1 July 2015.

Tick one of the boxes to show which you prefer

Email me a summary of the results

$\square$ Email me the complete report

Full name

Email address

Signature

Date 


\subsection{Interview questions}

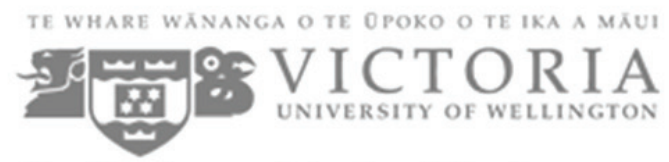

Proposed Interview Questions for a semi-structured interview

name, sex, age, $1^{s:}$ language(s), $2^{\text {s }}$ language(s), nationalities, previous education

(where/level), English level (IELTS/TOEFLscores), MMOGs played, time played,

email address

Which MMOGs do you play? How often do you play?

Who do you play/communicate with?

What features of MMOGs do you use to communicate?

Which languages do you use in MMOGs?

How do you use those languages in MMOGs? And English?

What do you do when you read/hear unknown words?

Have you ever learned words while playing MMOGs?

Describe a memorable incident.

Did you have help learning words? From whom orw what?

Describe howyou learnwords?

Describe how you remember words?

Do you have any tricks for learning words in MMOGs?

Describe how you use new words?

What kinds of problems do you have learning words in MMOGS?

How did you solve these problems?

Have you ever helped someone else learn words?

How would you recommend new players use MMOGs to learn English words?

Describe example?

Can you explain that further? Tell me more about...? What happens when...? Is there anything else you would like to say? 
From: Julie Bytheway

Sent:

To:

Subject: MMORPG research

$\mathrm{Hi}$,

Thanks again for being a part of my study into how people learn words in MMORPGs. It was great to talk to you back in August 2010. I've nearly finished the study and will email you the results soon. But I have just two more questions. Please email me a quick reply. Just write like you are talking to me. I don't need formal English for this. Just tell me your first reaction and first thoughts. Of course, any answer is helpful, because it is your opinion that I want to find out.

Thinking about how you learn words in online games and MMORPGs:

- Do you learn words differently when you are alone compared to when you are a part of a group of friends (or team or guild)?

- How does being alone or part of a group of friends (or team or guild) change how you learn words?

I'd really like to read your ideas, but just like the face-to-face interviews, you do not have to answer my questions.

Thanks again. I look forward to hearing from you soon, Julie 


\subsection{Example of email reply}

From: Tao

I do feel that I learn words differently when I in those two kind of situations.

As I use the U.S. server to play WOW, I always can find new words when I'm doing quests or just watching the public chatting. However when I'm alone, some times I do ignore the words which I don't know, and some times I learn or try to remember some new words without understand the meaning(this is like you use a mathematical formula but don't know how the mathematical formula was derived or discovered). And sometimes you may only see some new words once in your life time.

But when I'm in a group or a team, to learn or understand a new word become compulsory task. Because, when people talking in the group or in the team, you should realize are they talking to you or talking to everybody. If they talking to you or you know the information which they need, you may have to give opportunely response. Therefore if there any word which I don't know I will check the word's meaning and remember it before I write back. Moreover, learn word in this kind situation, I feel I can remember the word longer and more clear about the meaning. And the word may also more useful.

In addition, if I want learn a new word in both situations, I learn faster when I'm a part of the team than when I'm alone, because you don't have too much time to learn. 


\subsection{Example of quest instruction text}

Figure 7-2 Quest instructions, Destroying the Altars, Icecrown, World of Warcraft

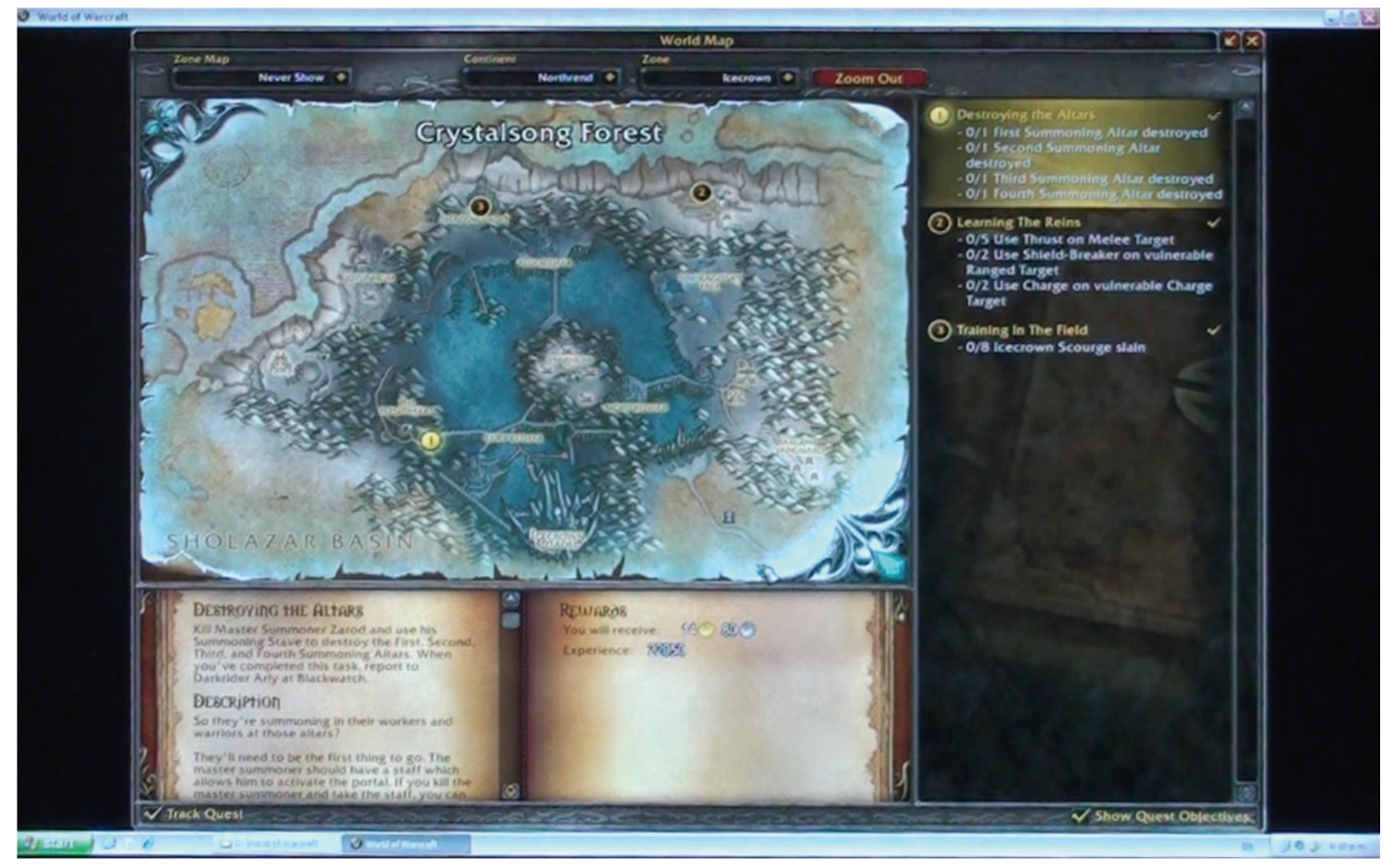

Kill Master Summoner Zarod and use his Summoning Stave to destroy the First, Second, Third, and Fourth Summoning Altars. When you've completed this task, report to Darkrider Arly at Blackwatch.

Objectives: 1x First Summoning Altar destroyed, $1 x$ Second Summoning Altar destroyed, 1x Third Summoning Altar destroyed, 1x Fourth Summoning Altar destroyed.

So they're summoning in their workers and warriors at those altars? They'll need to be the first thing to go. The master summoner should have a staff which allows him to activate the portal. If you kill the master summoner and take the staff, you can use it to overload the summoning portal and destroy its altar. Do this at all four of the altars and return to me once they've been destroyed. 


\subsection{Example of talents text}

Figure 7-3 Talent description, Cheat Death, Aldore Rise, World of Warcraft

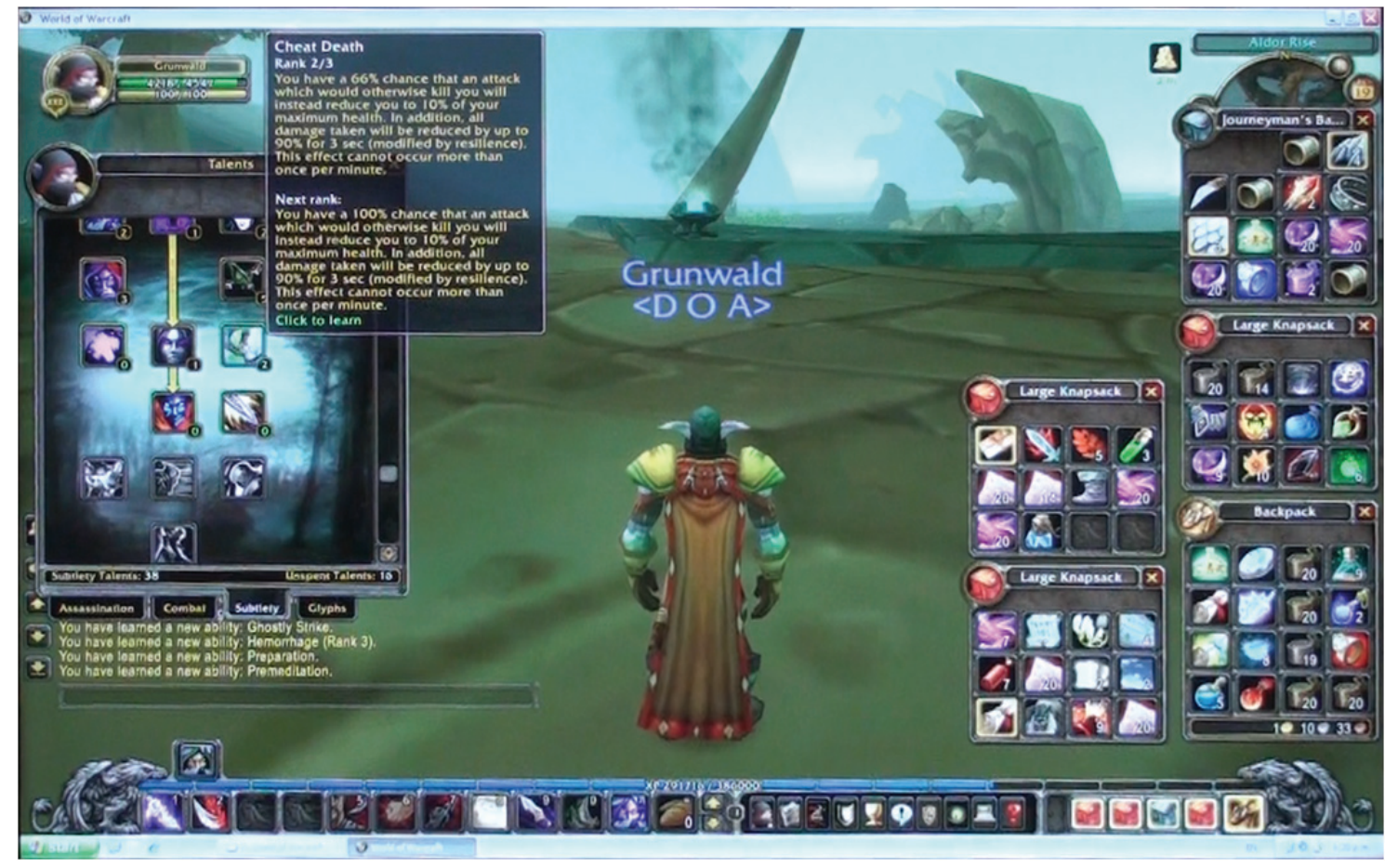

\section{Cheat Death talent description}

Rank 2/3

You have a $66 \%$ chance that an attack which would otherwise kill you will instead reduce you to $10 \%$ of your maximum health. In addition, all damage taken will be reduced by up to $90 \%$ for $3 \mathrm{sec}$ (modified by resilience). The effect cannot occur more than once per minute.

Next rank: You have a 100\% chance that an attack which would otherwise kill you will instead reduce you to $10 \%$ of your maximum health. In addition, all damage taken will be reduced by up to $90 \%$ for $3 \mathrm{sec}$ (modified by resilience). This effect cannot occur more than once per minute.Click to learn. 


\subsection{Example of chat log text}

Figure 7-4 Chat log, Durotar, World of Warcraft. Li, observation, 19 Aug 2010 C $00: 17: 30-00: 22: 30$

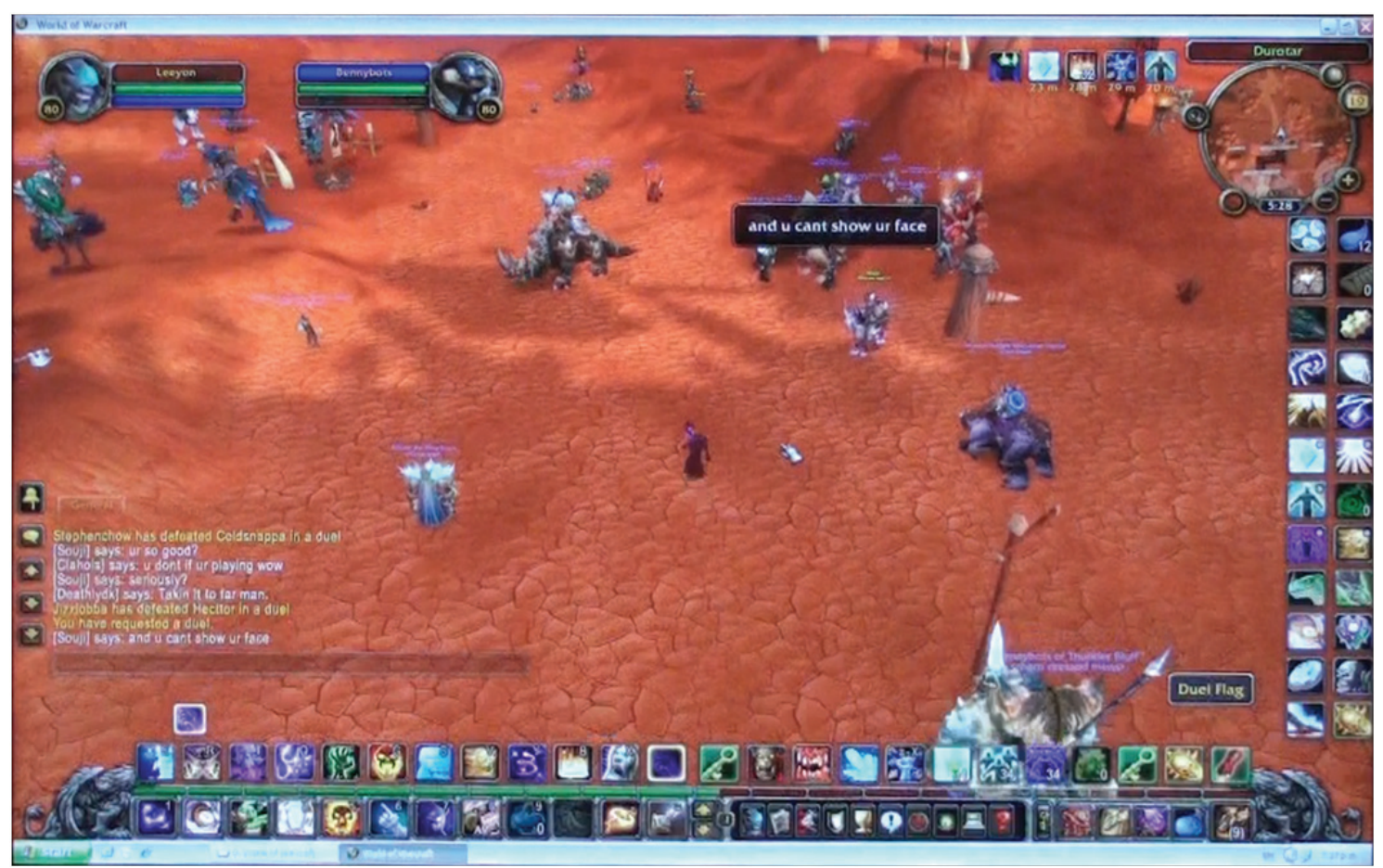

\section{Chat log from Durotar}

Leeyon has defeated Vandalz in a duel

Vandalz says: luck fear won that

Vandalz says: got full heal

Stephenchow has defeated Coldsnappa

in a duel

Beasttuality has fled from Arigōld in a

duel

Orgrimmar Grunt says: my family was

wiped out by the Scourge! MONSTER

Deathiydk says: You should be

Soul says: I have both $\$$ now

Deathiydk says: \%^\&*ing stupid!@\#\$

Soul says: forum post?
Hinton has defeated Trisful in a duel

Deathiydk says: Oi Yano

Carcer has defeated Pwnned in a duel

Soul says: yes noob?

Deathiydk says: I need some tips on

styling my hair.

Deathiydk says: Wait

Soul says: I'm a post

Deathiydk says: Dw

Soul says: ur lies

Soul says: wait

Soul says: SORRY 


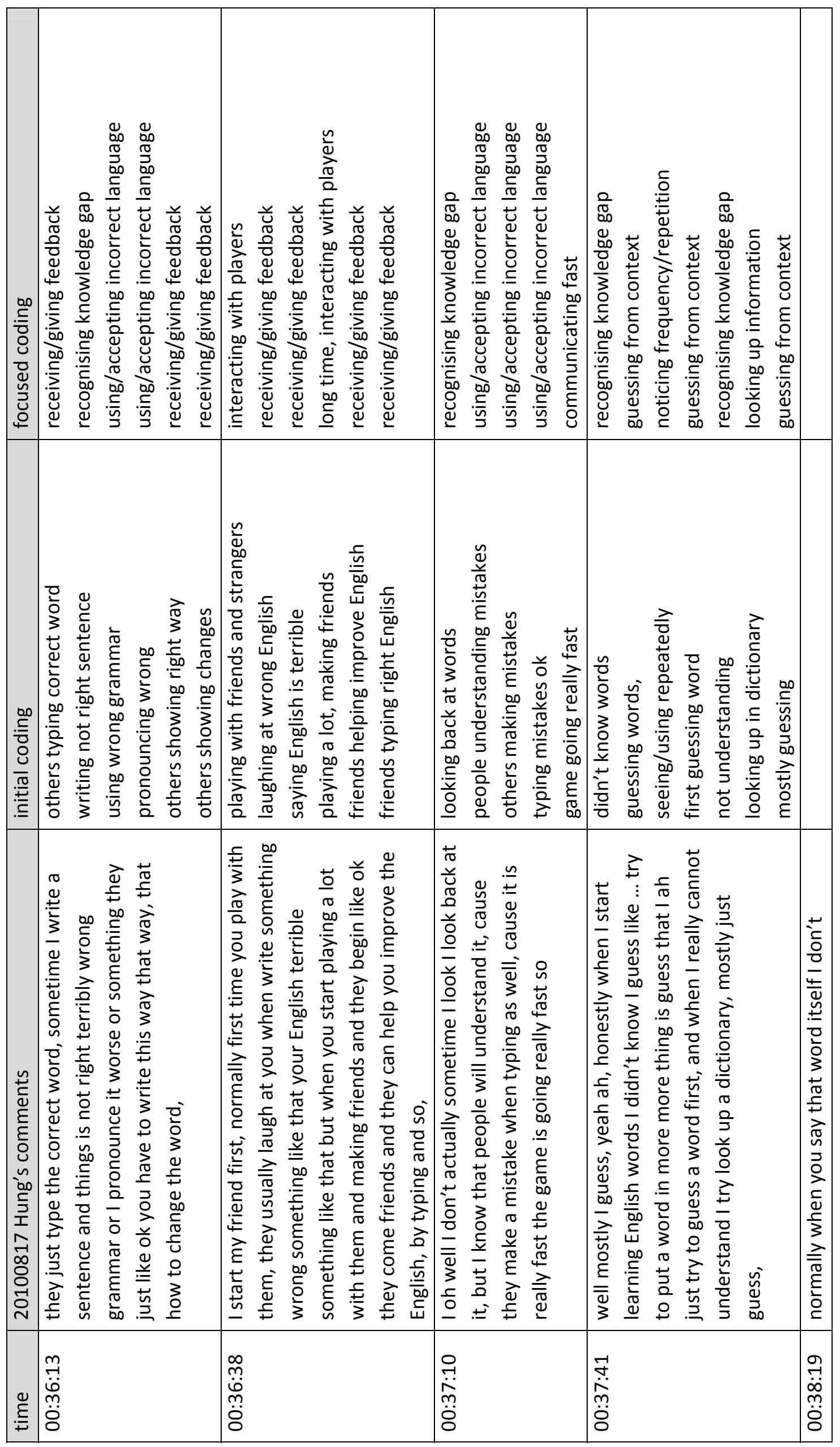




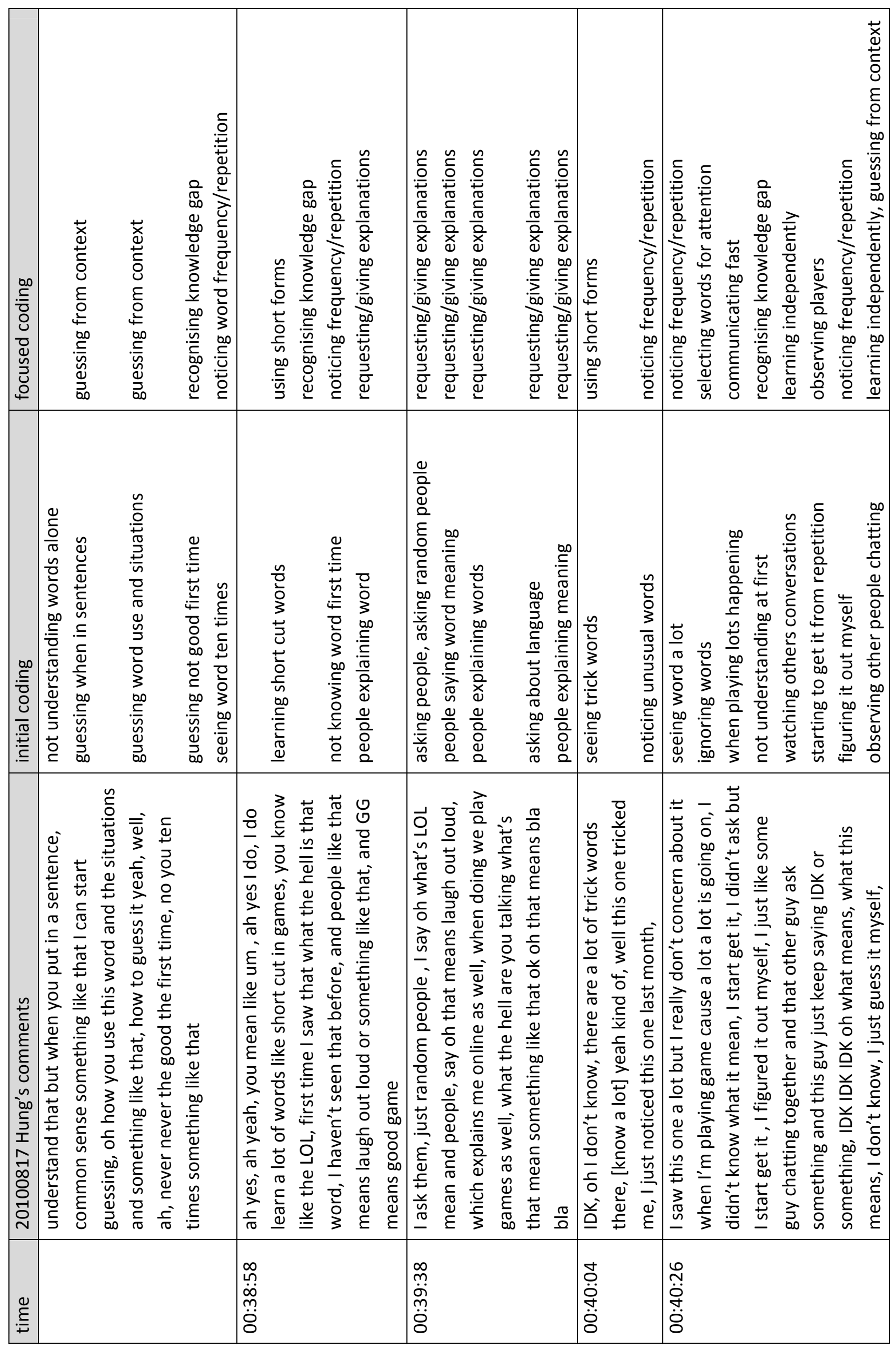




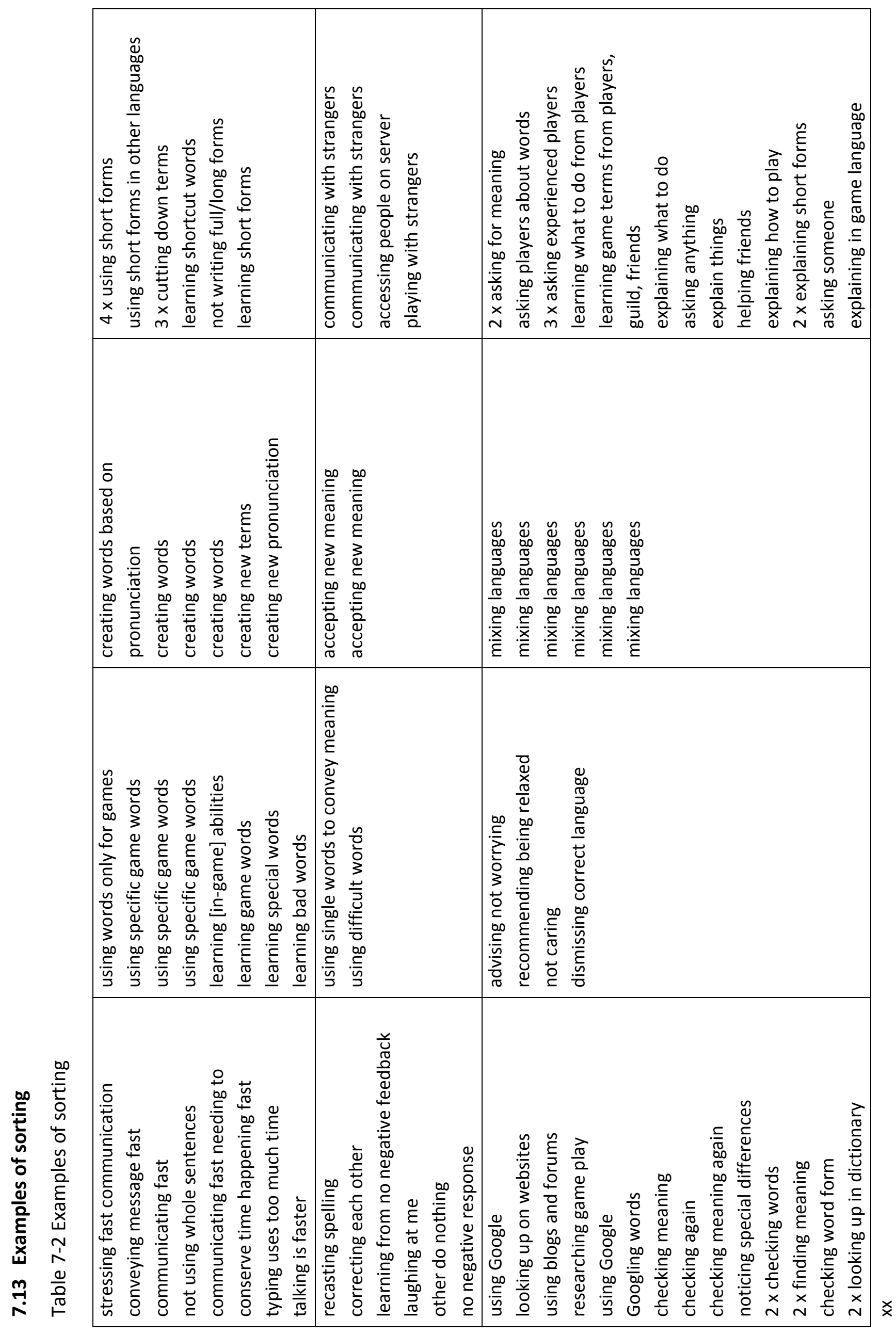




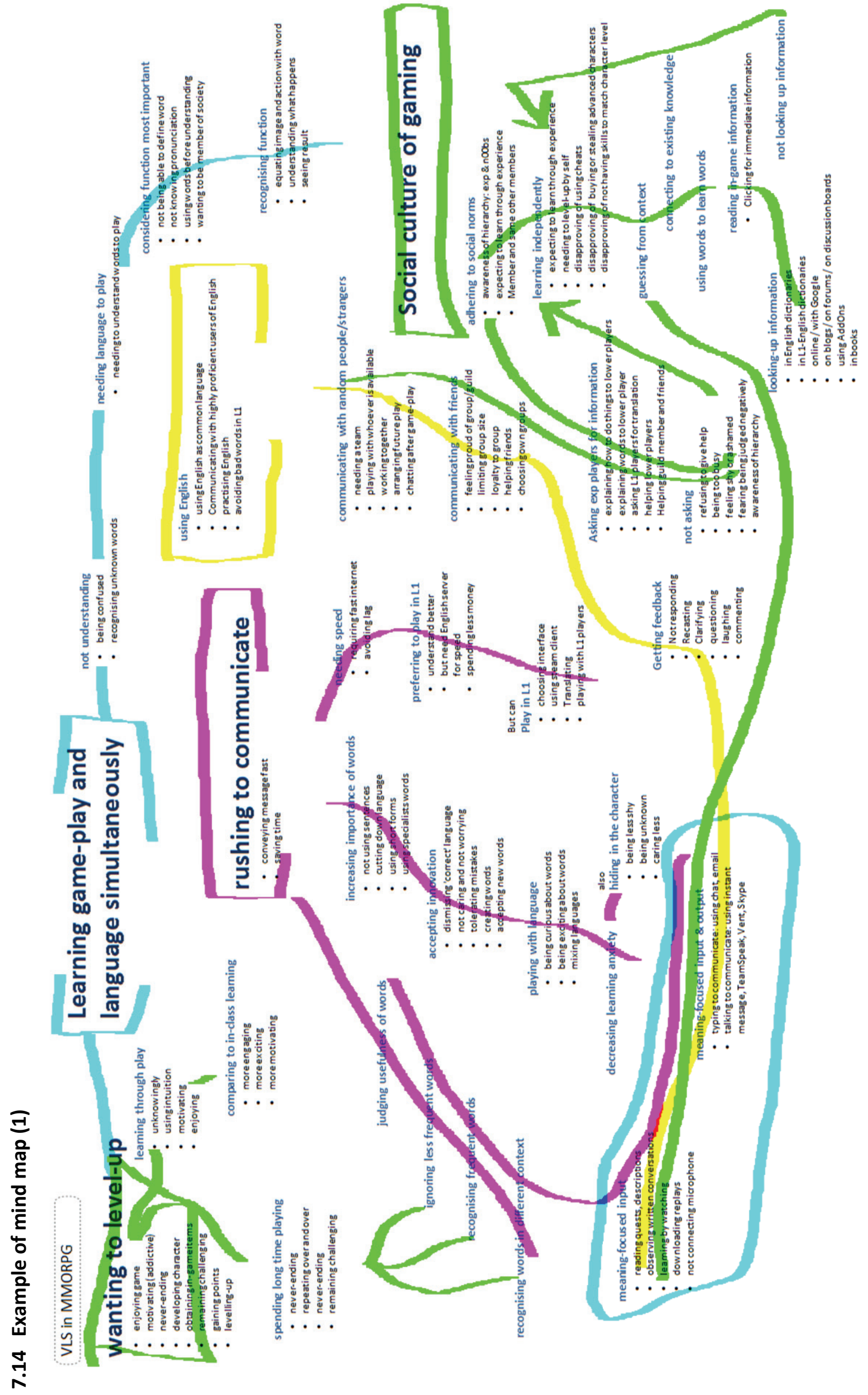




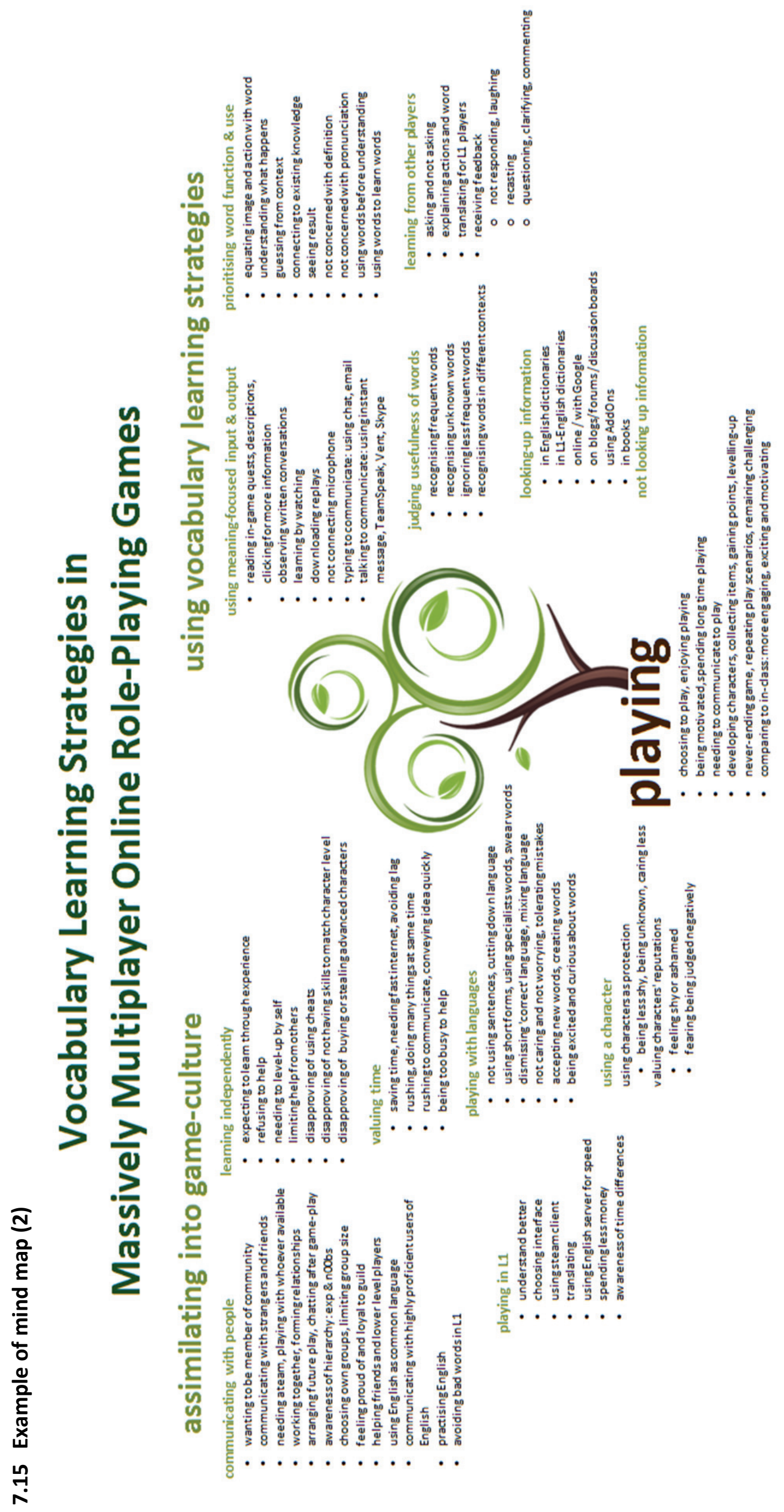

